\title{
Primary prophylaxis for venous thromboembolism in patients undergoing cardiac or thoracic surgery (Review)
}

Di Nisio M, Peinemann F, Porreca E, Rutjes AWS
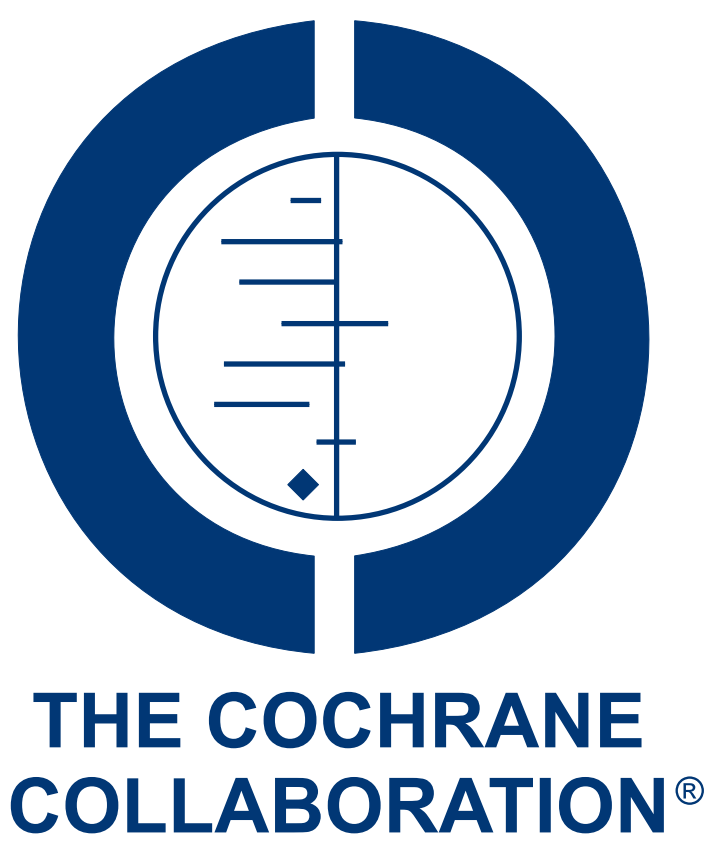

This is a reprint of a Cochrane review, prepared and maintained by The Cochrane Collaboration and published in The Cochrane Library 2015, Issue 6

http://www.thecochranelibrary.com

\section{WILEY}

Primary prophylaxis for venous thromboembolism in patients undergoing cardiac or thoracic surgery (Review)

Copyright $\odot 2015$ The Cochrane Collaboration. Published by John Wiley \& Sons, Ltd. 
TABLE OF CONTENTS

HEADER . . . . . . . . . . . . . . . . . . . . . . . . . . . . . . . . . . . . . . . . . . . . . . . . . . . . .

ABSTRACT . . . . . . . . . . . . . . . . . . . . . . . . . . . . . . . . . . . . . . . . . . . . . . . . . . . .

PLAIN LANGUAGE SUMMARY . . . . . . . . . . . . . . . . . . . . . . . . . . . . . . . . . . . . . . . . . . . .

BACKGROUND . . . . . . . . . . . . . . . . . . . . . . . . . . . . . . . . . . . . . 3

OBJECTIVES . . . . . . . . . . . . . . . . . . . . . . . . . . . . . . . . . . . . . . . . . . . . . . . . . . . .

METHODS . . . . . . . . . . . . . . . . . . . . . . . . . . . . . . . . . . . . . . 4

RESUlTS . . . . . . . . . . . . . . . . . . . . . . . . . . . . . . . . . . . . . . . .

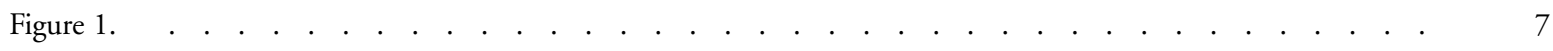

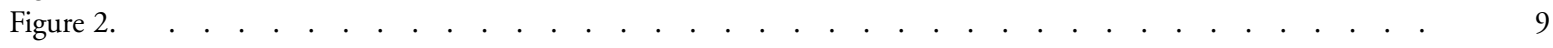

Figure 3. . . . . . . . . . . . . . . . . . . . . . . . . . . . . . . . . . . . . . 10

DISCUSSION . . . . . . . . . . . . . . . . . . . . . . . . . . . . . . . . . . . . . . . . . . .

AUTHORS' CONCLUSIONS . . . . . . . . . . . . . . . . . . . . . . . . . . . . . . . . . . . . . . . . . . .

ACKNOWLEDGEMENTS . . . . . . . . . . . . . . . . . . . . . . . . . . . . . . . . . . . . . . . . . . . . . . . . .

REFERENCES . . . . . . . . . . . . . . . . . . . . . . . . . . . . . . . . . . . . . . . . . . . . . 15

CHARACTERISTICS OF STUDIES . . . . . . . . . . . . . . . . . . . . . . . . . . . . . . . . . 22

DATA AND ANALYSES . . . . . . . . . . . . . . . . . . . . . . . . . . . . . . . . . . . . . . . . . . . . . . . . . . . . .

Analysis 1.1. Comparison 1 Cardiac surgery: symptomatic VTE, Outcome 1 UFH versus LMWH. . . . . . . . . $\quad 49$

Analysis 1.2. Comparison 1 Cardiac surgery: symptomatic VTE, Outcome 2 Intermittent pneumatic compression plus graded elastic compression stockings versus graded elastic compression stockings. . . . . . . . . . . . . . . 50

Analysis 1.3. Comparison 1 Cardiac surgery: symptomatic VTE, Outcome 3 UFH plus IPC versus UFH. . . . . 50

Analysis 1.4. Comparison 1 Cardiac surgery: symptomatic VTE, Outcome 4 UFH plus aspirin versus UFH. . . . $\quad 51$

Analysis 2.1. Comparison 2 Thoracic surgery: symptomatic VTE, Outcome 1 Heparin versus inactive control. $\quad$. . 51

Analysis 2.2. Comparison 2 Thoracic surgery: symptomatic VTE, Outcome 2 UFH versus defibrotide. . . . . . . 52

Analysis 2.3. Comparison 2 Thoracic surgery: symptomatic VTE, Outcome 3 UFH versus LMWH. . . . . . . . $\quad 53$

Analysis 2.4. Comparison 2 Thoracic surgery: symptomatic VTE, Outcome 4 Fixed-dose LMWH versus weight-adjusted dose LMWH. . . . . . . . . . . . . . . . . . . . . . . . . . . . . . . . . . . . . . . . . . 53

Analysis 3.1. Comparison 3 Cardiac surgery: major bleeding, Outcome 1 VKAs versus platelet inhibitor. $\quad$. . . . . 54

Analysis 3.2. Comparison 3 Cardiac surgery: major bleeding, Outcome 2 3-month VKAs versus 3-month platelet inhibitor.

Analysis 4.1. Comparison 4 Thoracic surgery: major bleeding, Outcome 1 UFH versus LMWH. $\quad . \quad . \quad . \quad . \quad . \quad . \quad$.
Analysis 4.2. Comparison 4 Thoracic surgery: major bleeding, Outcome 2 Fixed-dose LMWH versus weight-adjusted dose LMWH.

Analysis 5.1. Comparison 5 Cardiac surgery: overall VTE, Outcome 1 UFH versus LMWH. . . . . . . . . . . . . 56

Analysis 5.2. Comparison 5 Cardiac surgery: overall VTE, Outcome 2 Intermittent pneumatic compression plus graded elastic compression stockings versus graded elastic compression stockings. . . . . . . . . . . . . . . . . . . . 56

Analysis 5.3. Comparison 5 Cardiac surgery: overall VTE, Outcome 3 VKAs versus platelet inhibitor. $\quad . \quad$. . . . 57

Analysis 5.4. Comparison 5 Cardiac surgery: overall VTE, Outcome 4 3-month VKAs versus 3-month platelet inhibitor. 57

Analysis 5.5. Comparison 5 Cardiac surgery: overall VTE, Outcome 5 UFH plus aspirin versus UFH. . . . . . $\quad 58$

Analysis 6.1. Comparison 6 Thoracic surgery: overall VTE, Outcome 1 UFH versus inactive control. . . . . . . . 58

Analysis 6.2. Comparison 6 Thoracic surgery: overall VTE, Outcome 2 UFH versus LMWH. . . . . . . . . . $\quad$. 59

Analysis 6.3. Comparison 6 Thoracic surgery: overall VTE, Outcome 3 Fixed-dose LMWH versus weight-adjusted dose LMWH.

Analysis 6.4. Comparison 6 Thoracic surgery: overall VTE, Outcome 4 UFH versus VKAs. . . . . . . . . . . . . . 60

Analysis 7.1. Comparison 7 Cardiac surgery: overall mortality, Outcome 1 VKAs versus platelet inhibitor. $\quad . \quad$. . . $\quad 60$

Analysis 7.2. Comparison 7 Cardiac surgery: overall mortality, Outcome 2 3-month VKAs versus 3-month platelet inhibitor.

Analysis 8.1. Comparison 8 Cardiac surgery: minor bleeding, Outcome 1 UFH versus LMWH. . . . . . . . . . 61

Analysis 8.2. Comparison 8 Cardiac surgery: minor bleeding, Outcome 2 VKAs versus platelet inhibitor. $\quad$. . . . . . $\quad 62$

Analysis 8.3. Comparison 8 Cardiac surgery: minor bleeding, Outcome 3 3-month VKAs versus 3-month platelet inhibitor. . . . . . . . . . . . . . . . . . . . . . . . . . . . . . . . . . . . . . . 62

Analysis 8.4. Comparison 8 Cardiac surgery: minor bleeding, Outcome 4 UFH plus aspirin versus UFH. $\quad$. . . . . 63

Primary prophylaxis for venous thromboembolism in patients undergoing cardiac or thoracic surgery (Review)

Copyright $\odot 2015$ The Cochrane Collaboration. Published by John Wiley \& Sons, Ltd. 
Analysis 9.1. Comparison 9 Thoracic surgery: minor bleeding, Outcome 1 UFH versus LMWH. . . . . . . . Analysis 9.2. Comparison 9 Thoracic surgery: minor bleeding, Outcome 2 Fixed-dose LMWH versus weight-adjusted dose LMWH.

Analysis 10.1. Comparison 10 Thoracic surgery: serious adverse events, Outcome 1 Fixed-dose LMWH versus weightadjusted dose LMWH.

Analysis 11.1. Comparison 11 Cardiac surgery: adverse events, Outcome 1 VKAs versus platelet inhibitor.

Analysis 11.2. Comparison 11 Cardiac surgery: adverse events, Outcome 2 3-month VKAs versus 3-month platelet inhibitor.

Analysis 12.1. Comparison 12 Thoracic surgery: adverse events, Outcome 1 Fixed-dose LMWH versus weight-adjusted LMWH.

APPENDICES

CONTRIBUTIONS OF AUTHORS . . . . . . . . . . . . . . . . . . . . . . . . . . . . . . . . . . . . . . . .

DECLARATIONS OF INTEREST . . . . . . . . . . . . . . . . . . . . . . . . . . . . . . . . . . .

SOURCES OF SUPPORT . . . . . . . . . . . . . . . . . . . . . . . . . . . . . . . . . . . . . . . . . . . . . . . 


\title{
[Intervention Review]
}

\section{Primary prophylaxis for venous thromboembolism in patients undergoing cardiac or thoracic surgery}

\author{
Marcello Di Nisio ${ }^{1,2}$, Frank Peinemann ${ }^{3}$, Ettore Porreca ${ }^{4}$, Anne WS Rutjes ${ }^{1,5,6}$ \\ ${ }^{1}$ Department of Medical, Oral and Biotechnological Sciences, University “G. D’Annunzio” of Chieti-Pescara, Chieti, Italy. ${ }^{2}$ Department \\ of Vascular Medicine, Academic Medical Center, Amsterdam, Netherlands. ${ }^{3}$ Pediatric Oncology and Hematology, Children’s Hospital, \\ University of Cologne, Cologne, Germany. ${ }^{4}$ Department of Medicine and Aging; Centre for Aging Sciences (Ce.S.I.), Internal Medicine \\ Unit, "University G. D’Annunzio" Foundation, Chieti, Italy. ${ }^{5}$ Centre for Systematic Reviews, Fondazione “Università G. D’Annunzio”, \\ Chieti, Italy. ${ }^{6}$ Institute of Social and Preventive Medicine (ISPM), University of Bern, Bern, Switzerland \\ Contact address: Marcello Di Nisio, Department of Medical, Oral and Biotechnological Sciences, University “G. D’Annunzio” of \\ Chieti-Pescara, via dei Vestini 31, Chieti, 66013, Italy. mdinisio@unich.it.
}

Editorial group: Cochrane Vascular Group.

Publication status and date: New, published in Issue 6, 2015.

Review content assessed as up-to-date: 30 May 2014.

Citation: Di Nisio M, Peinemann F, Porreca E, Rutjes AWS. Primary prophylaxis for venous thromboembolism in patients undergoing cardiac or thoracic surgery. Cochrane Database of Systematic Reviews 2015, Issue 6. Art. No.: CD009658. DOI: 10.1002/14651858.CD009658.pub2.

Copyright (C) 2015 The Cochrane Collaboration. Published by John Wiley \& Sons, Ltd.

\section{A B S T R A C T}

\section{Background}

Cardiac and thoracic surgery are associated with an increased risk of venous thromboembolism (VTE). The safety and efficacy of primary thromboprophylaxis in patients undergoing these types of surgery is uncertain.

\section{Objectives}

To assess the effects of primary thromboprophylaxis on the incidence of symptomatic VTE and major bleeding in patients undergoing cardiac or thoracic surgery.

\section{Search methods}

The Cochrane Peripheral Vascular Diseases Group Trials Search Co-ordinator searched the Specialised Register (last searched May 2014) and CENTRAL (2014, Issue 4). The authors searched the reference lists of relevant studies, conference proceedings, and clinical trial registries.

\section{Selection criteria}

Randomised controlled trials (RCTs) and quasi-RCTs comparing any oral or parenteral anticoagulant or mechanical intervention to no intervention or placebo, or comparing two different anticoagulants.

\section{Data collection and analysis}

We extracted data on methodological quality, participant characteristics, interventions, and outcomes including symptomatic VTE and major bleeding as the primary effectiveness and safety outcomes, respectively.

Primary prophylaxis for venous thromboembolism in patients undergoing cardiac or thoracic surgery (Review)

Copyright $\odot 2015$ The Cochrane Collaboration. Published by John Wiley \& Sons, Ltd. 


\section{Main results}

We identified 12 RCTs and one quasi-RCT (6923 participants), six for cardiac surgery (3359 participants) and seven for thoracic surgery (3564 participants). No study evaluated fondaparinux, the new oral direct thrombin, direct factor Xa inhibitors, or caval filters. All studies had major study design flaws and most lacked a placebo or no treatment control group. We typically graded the quality of the overall body of evidence for the various outcomes and comparisons as low, due to imprecise estimates of effect and risk of bias. We could not pool data because of the different comparisons and the lack of data. In cardiac surgery, 71 symptomatic VTEs occurred in 3040 participants from four studies. In a study of 2551 participants, representing $85 \%$ of the review population in cardiac surgery, the combination of unfractionated heparin with pneumatic compression stockings was associated with a $61 \%$ reduction of symptomatic VTE compared to unfractionated heparin alone (1.5\% versus 4.0\%; risk ratio (RR) 0.39; $95 \%$ confidence interval (CI) 0.23 to 0.64 ). Major bleeding was only reported in one study, which found a higher incidence with vitamin $\mathrm{K}$ antagonists compared to platelet inhibitors (11.3\% versus $1.6 \%$, RR 7.06 ; $95 \%$ CI 1.64 to 30.40). In thoracic surgery, 15 symptomatic VTEs occurred in 2890 participants from six studies. In the largest study evaluating unfractionated heparin versus an inactive control the rates of symptomatic VTE were $0.7 \%$ versus $0 \%$, respectively, giving a RR of 6.71 (95\% CI 0.40 to 112.65$)$. There was insufficient evidence to determine if there was a difference in the risk of major bleeding from two studies evaluating fixed-dose versus weight-adjusted low molecular weight heparin $(2.7 \%$ versus $8.1 \%$, RR 0.33 ; $95 \%$ CI 0.07 to 1.60$)$ and unfractionated heparin versus low molecular weight heparin $(6 \%$ and $4 \%$, RR $1.50 ; 95 \%$ CI 0.26 to 8.60 ).

\section{Authors' conclusions}

The evidence regarding the efficacy and safety of thromboprophylaxis in cardiac and thoracic surgery is limited. Data for important outcomes such as pulmonary embolism or major bleeding were often lacking. Given the uncertainties around the benefit-to-risk balance, no conclusions can be drawn and a case-by-case risk evaluation of VTE and bleeding remains preferable.

\section{PLAIN LANGUAGE SUMMARY}

Prevention of blood clots in patients undergoing cardiac or thoracic surgery

\section{Background}

Patients undergoing surgery have an increased probability of developing blood clots in their veins (venous thromboembolism). These clots may be in the deep veins (deep vein thrombosis) or travel to the lungs (pulmonary embolism). As in other types of surgery, effective prevention of blood clots (thromboprophylaxis) after cardiac or thoracic surgery may reduce the risk of postoperative vein clots. These potential benefits, however, have to be balanced against the associated risks of bleeding. This systematic review looked at the effectiveness and safety of anticoagulants (medicines that reduce the ability of the blood to clot), mechanical interventions (such as pneumatic pumps on the legs to promote blood flow), and caval filters (a type of vascular filter, implanted into the main abdominal vein to prevent movement of clots from the legs to the lungs) in patients undergoing cardiac or thoracic surgery.

\section{Study characteristics and key results}

We identified 13 randomised controlled trials (6923 participants), six for cardiac surgery (3359 participants) and seven for thoracic surgery (3564 participants). The evidence is current to May 2014. No study evaluated fondaparinux, the new oral direct thrombin or direct factor Xa inhibitors, or caval filters. Data could not be combined because of the different comparisons and the lack of data. Data for clinically relevant outcomes such as pulmonary embolism (blockage of one or more arteries of the lung) or major bleeding were often lacking. In cardiac surgery, symptomatic venous thromboembolism occurred in 71 out of 3040 participants from three studies. In a study of 2551 participants, representing $85 \%$ of the review population in cardiac surgery, the combination of unfractionated heparin with intermittent pneumatic compression was associated with an important reduction of symptomatic venous thromboembolism compared to unfractionated heparin alone. Major (important) bleeding was reported in one study only, and the best estimate was that bleedings occurred seven times more often in participants on vitamin $\mathrm{K}$ antagonists compared to participants on platelet inhibitors, but the true estimate may lay between one and a half to 30. In thoracic surgery, symptomatic venous thromboembolism occurred in 15 out of 2890 participants from six studies. Combined analysis could not be performed, but the largest study evaluating unfractionated heparin versus an inactive control did not show a benefit in terms of reduced occurrence of symptomatic venous thromboembolism. Major bleeding was reported in two studies that did not find significantly different rates between fixed-dose and weight-adjusted low molecular weight heparin $(2.7 \%$ versus $8.1 \%)$ and between unfractionated heparin and low molecular weight heparin $(6 \%$ and $4 \%)$.

Quality of the evidence

Primary prophylaxis for venous thromboembolism in patients undergoing cardiac or thoracic surgery (Review)

Copyright $\odot 2015$ The Cochrane Collaboration. Published by John Wiley \& Sons, Ltd. 
Overall, the evidence on the use of thromboprophylaxis in cardiac and thoracic surgery appeared to be scarce, so we are very uncertain about the benefit-to-risk balance. All studies had major study design flaws and most lacked a placebo or no treatment control group. We typically graded the quality of the overall body of evidence for the various outcomes and comparisons as low, due to imprecise estimates of effect and risk of bias. Our data suggest that thromboprophylaxis cannot be suggested for all patients undergoing these types of surgery, but should rather be considered case-by-case based on the individual risk of venous thromboembolism and bleeding.

\section{B A C K G R O U N D}

\section{Description of the condition}

Venous thromboembolism (VTE), that is deep vein thrombosis (DVT) and pulmonary embolism (PE), represents a common complication in patients undergoing surgery, with an incidence of objectively confirmed postoperative VTE of $10 \%$ up to $60 \%$ in the absence of any perioperative thromboprophylaxis (Geerts 2008). Postoperative VTE requires long-term (three to six months or longer) anticoagulant treatment, which decreases the quality of life and exposes the patient to the risk of bleeding (Gangireddy 2007; Geerts 2008). In addition, postoperative VTE may prolong the length of hospital stay, with consequent additional costs. The increase in morbidity and mortality associated with postoperative VTE is particularly challenging among patients with cancer, who have twice the risk of postoperative VTE and more than three times the risk of fatal PE than non-cancer patients for similar procedures (Gangireddy 2007; Geerts 2008; Kakkar 2009; White 2003).

The exact incidence of postoperative VTE after thoracic surgery remains unclear, with the observed estimates ranging from $0.4 \%$ to $51 \%$ for DVT and from less than $1 \%$ to $5 \%$ for PE, about $2 \%$ of the PE cases being fatal (Agnelli 2006; Gangireddy 2007; Jackman 1978; Kalweit 1994; Ljungstrom 1985; Mason 2006; Nagahiro 2004; Sugarbaker 2004; White 2003). The large variation in the reported incidences likely depends on the type of underlying (comorbid) conditions and the diagnostic test used, as well as on the use and type of thromboprophylaxis in the postoperative period. The rate of VTE following cardiac surgery is even more controversial since most of the data come from retrospective series with several methodological limitations (Geerts 2008). Furthermore, the use of systemic heparin anticoagulation in most cardiac operations and the administration of antiplatelet drugs or oral anticoagulation after surgery hamper a precise estimation of postoperative VTE in this setting. Three prospective studies in patients undergoing coronary artery bypass grafting reported postoperative asymptomatic DVT in $16 \%$ to $48 \%$ of cases and the involvement of the proximal veins in 3\% of the cases (Ambrosetti 2004; Goldhaber 1995; Reis 1991). Symptomatic VTE after cardiac surgery seems to occur less often, with rates between $0.5 \%$ and $3 \%$ (Ambrosetti
2004; DeLaria 1991; Gillinov 1992; Goldhaber 1995; Hannan 2003; Josa 1993).

\section{Description of the intervention}

Currently available drugs for the prevention of postoperative VTE are unfractionated heparin (UFH), low molecular weight heparin (LMWH), and fondaparinux, with the new orally available direct thrombin and factor $\mathrm{Xa}$ inhibitors being under extensive evaluation in phase III clinical studies. In patients with an estimated high risk of bleeding, a valid option for the prophylaxis of postoperative VTE is represented by mechanical interventions, which comprise intermittent pneumatic compression (IPC) devices and graded elastic compression stockings (Geerts 2008).

\section{Why it is important to do this review}

Thromboprophylaxis has been shown to be highly effective in most hospitalised patients (Geerts 2008), although in some patient groups the evidence remains scarce and the benefit-to-risk ratio of thromboprophylaxis is unclear (Bani-Hani 2008; Geerts 2008; Ramos 2008). The provision of effective thromboprophylaxis in patients undergoing thoracic or cardiac surgery has the potential to prevent the significant clinical sequelae of postoperative VTE, particularly in high-risk subgroups of patients such as those with cancer disease (Agnelli 2006; Collins 1988; Mason 2006; Nagahiro 2004; Sugarbaker 2004). Patients receiving thoracic surgery may develop VTE long after the operation (Agnelli 2006; Mason 2006). In a cohort of patients undergoing pneumonectomy for cancer, the incidence of VTE peaked seven days after the operation, when most of the patients had already been discharged from the hospital (Mason 2006). Similarly in the @RISTOS study, a prospective observational study of 2373 patients undergoing oncological surgery, $40 \%$ of postoperative VTEs occurred later than 21 days after surgery (Agnelli 2006). Prolonged thromboprophylaxis after thoracic surgery may offer advantages, as in other types of surgery (Bergqvist 2002; Geerts 2008; Kakkar 2010), however this has to be balanced against the associated risks of bleeding (Agnelli 2006; Geerts 2008). People affected by the 
results of this review include adult patients undergoing cardiac or thoracic surgery as well as healthcare personnel involved in the therapeutic care of these patients.

\section{O B J E C T I VES}

To assess the effects of primary thromboprophylaxis on the incidence of symptomatic VTE and major bleeding in patients undergoing cardiac or thoracic surgery.

We followed an in-house generated standard protocol for the definition of outcomes, searches, 'Risk of bias' assessments, data collection, and statistical analyses. The description of the methods will therefore (partly) overlap with our previous reviews in this field (Di Nisio 2012a; Di Nisio 2014).

\section{METHODS}

\section{Criteria for considering studies for this review}

\section{Types of studies}

All randomised and quasi-randomised trials were eligible.

\section{Types of participants}

We included participants over 18 years of age undergoing cardiac or thoracic surgery. We evaluated four main groups of patients undergoing surgery: open cardiac surgery, open lung surgery, thoracoscopic cardiac surgery, and thoracoscopic lung surgery patients. We excluded studies on thoracic surgery for oesophageal problems, thoracic sympathectomy, non-lung thoracic surgery, and thoracic surgery for aortic problems.

\section{Types of interventions}

Interventions included any oral or parenteral anticoagulant (for example UFH, LMWH, fondaparinux, dermatan sulphate, direct thrombin, or factor Xa inhibitors), mechanical intervention (for example, sequential compression device or graded elastic compression stockings), or cava filters.

Comparison interventions included either an inactive control intervention (placebo, no treatment, standard care) or an active control intervention (a different scheme or regimen of the same intervention, a different pharmacological type of prophylaxis, a different type of non-pharmacological prophylaxis).

We recorded the dose, regimen, and duration of oral and parenteral anticoagulants.
We excluded studies if the intervention was not used for primary prophylaxis of VTE.

\section{Types of outcome measures}

\section{Primary outcomes}

The main effectiveness outcome was symptomatic VTE (that is symptomatic DVT, symptomatic PE, or both), which is typically objectively verified by means of Doppler (compression) ultrasonography or ascending bilateral venography for (proximal and distal) DVT, and spiral computed tomography, ventilation/perfusion lung scan, pulmonary angiography, or autopsy for PE.

The main safety outcome was major bleeding, typically defined as overt bleeding associated with a fall in haemoglobin of $2 \mathrm{~g} / \mathrm{dL}$ or more, or leading to a transfusion of two or more units of packed red blood cells or whole blood, or bleeding that occurs in a critical site (intracranial, intraspinal, intraocular, pericardial, intra-articular, intramuscular with compartment syndrome, retroperitoneal), or contributing to death.

\section{Secondary outcomes}

Secondary outcomes included overall VTE (that is symptomatic and unsuspected VTE), overall mortality, VTE-related mortality, post-thrombotic syndrome, minor bleeding, heparin-induced thrombocytopenia, and the number of participants experiencing any (serious) adverse events. Serious adverse events were defined as events resulting in participant hospitalisation, prolongation of hospitalisation, persistent or significant disability, congenital abnormality or birth defect of offspring, life-threatening events, or death.

\section{Search methods for identification of studies}

\section{Electronic searches}

The Cochrane Peripheral Vascular Diseases Group Trials Search Co-ordinator (TSC) searched the Specialised Register (last searched May 2014) and the Cochrane Central Register of Controlled Trials (CENTRAL) (2014, Issue 4), part of the Cochrane Library, www.cochranelibrary.com/. See Appendix 1 for details of the search strategy which was used to search CENTRAL. The Specialised Register is maintained by the TSC and is constructed from weekly electronic searches of MEDLINE, EMBASE, CINAHL, AMED, and through handsearching relevant journals. The full list of the databases, journals and conference proceedings which have been searched, as well as the search strategies used are described in the Specialised Register section of the Cochrane Peripheral Vascular Diseases Group module in the Cochrane Library ( http://www.cochranelibrary.com/). 
The authors searched the following clinical trial registries to identify ongoing or unpublished trials (last search May 2014):

- www.clinicaltrials.gov;

- www.controlled-trials.com;

- http://apps.who.int/trialsearch/.

We used the combination of the following search terms: "thrombosis", "thoracic surgery", and "cardiac surgery".

\section{Searching other resources}

We screened the reference lists of relevant identified studies.

One review author screened the following conference proceedings:

- The American Association of Thoracic Surgery (2003 to

2012);

- European Association of Cardio-Thoracic Surgery (1999 to 2012); and

- The International Society of Thrombosis and Haemostasis (2003 to 2011);

using the following search terms "thoracic", "cardiac", "surgery", "operation”, "vein thrombosis", "venous thrombosis”, “embolism”, and "prophylaxis".

We included an abstract if adequate information could be obtained either from the abstract or from personal communication.

\section{Data collection and analysis}

\section{Selection of studies}

Two review authors (MdN and FP) independently reviewed titles and abstracts from the searches to determine whether the inclusion criteria were satisfied. Any disagreements were resolved through discussion between the review authors. The review authors were not blinded to the journal, institution, or results of the study. We applied no language restrictions. We reassessed studies with insufficient information if additional information became available from the authors. We documented reasons for excluding studies.

\section{Data extraction and management}

Two review authors (MdN and FP) independently extracted the data from the included studies on standardised forms and resolved any disagreements by consensus or by involvement of a third review author (AR). Collected information included methodological quality, quality of reporting (the reporting of primary outcomes and sample size calculations), characteristics of participants participating in the study, characteristics of the intervention and control groups, and outcome characteristics of every group of participants. Whenever possible, we extracted results from an intention-to-treat analysis. If effect sizes could not be calculated, we contacted the authors for additional data.

\section{Assessment of risk of bias in included studies}

Two review authors independently assessed the methods of randomisation, allocation, blinding, adequacy of analyses, and completeness of reporting using previously described definitions (Juni 2001; Rutjes 2009). We resolved disagreements by consensus.

We assessed two components of randomisation: generation of allocation sequences and concealment of allocation. We considered generation of an allocation sequence at low risk of bias if it resulted in an unpredictable allocation schedule. Mechanisms considered adequate included random-number tables, computer-generated random numbers, minimisation, coin tossing, shuffling cards, and drawing lots. We considered trials using an unpredictable allocation sequence to be randomised. We considered trials using potentially predictable allocation mechanisms, such as alternation or the allocation of participants according to date of birth, to be quasirandomised and at high risk of bias.

We considered concealment of allocation at low risk of bias if participants and investigators responsible for participant selection were unable to suspect before allocation which treatment was next. Methods considered adequate included central randomisation; pharmacy-controlled randomisation using identical prenumbered containers; and sequentially numbered, sealed, opaque envelopes.

We considered blinding of patients and therapists adequate if experimental and control preparations were explicitly described as indistinguishable or if a double-dummy technique was used. We considered outcome assessors blinded if this was explicitly mentioned by the investigators.

We considered analyses to be at low risk of bias if all randomised participants were included in the analysis according to the intention-to-treat principle.

We classified the item 'free of selective reporting' as at low risk of bias if we had both the protocol and the full report of a given study, where the full report presented results for all outcomes listed in the protocol. We classified a study at high risk of bias if a report did not present data on all outcomes reported in either the protocol or the methods section. In the absence of a protocol, we classified as low risk of bias if the outcomes in the methods section and the results section matched, and if major participant outcomes expected in this field of research were addressed (e.g. for the studies involving pharmacological thromboprophylaxis, any type of bleeding event). Finally, we planned to use GRADE to describe the quality of the overall body of evidence (Guyatt 2008; Higgins 2011), defined as the extent of confidence in the estimates of treatment benefits and harms.

\section{Measures of treatment effect}

Results are shown as a summary risk ratio (RR) for dichotomous variables and we determined the $95 \%$ confidence interval (CI) for each estimate. In the case of statistically significant overall estimates, we also calculated, where appropriate, clinical effect sum- 
mary statistics, such as the number needed to treat to benefit one patient (NNTB) or the number needed to treat to harm one patient (NNTH), to express the final results of the review.

\section{Assessment of heterogeneity}

We measured heterogeneity of treatment effects between trials using the $\mathrm{Chi}^{2}$ test and the $\mathrm{I}^{2}$ statistic (Higgins 2003), which describes the percentage of total variation across trials that is attributable to heterogeneity rather than to chance. $\mathrm{I}^{2}$ values of $25 \%$, $50 \%$, and $75 \%$ are typically interpreted as low, moderate, and high between-trial heterogeneity. We considered the size of trials included when interpreting the $\mathrm{I}^{2}$ statistic, as the interpretation depends on this trial characteristic (Rücker 2008).

\section{Assessment of reporting biases}

We planned to evaluate biases related to small study size, such as publication bias, using funnel plots by plotting relative risks on the vertical axis against their standard errors on the horizontal axis. We planned to assess asymmetry by the asymmetry coefficient, the difference in relative risk per unit increase in standard error (Harbord 2006), which is mainly a surrogate for sample size. Symmetry would be expected in the absence of any bias related to small study size. We planned to explore any asymmetry in stratified analyses to investigate the effects of treatment characteristics and sub-optimal design choices on the magnitude of the effects.

\section{Data synthesis}

Patients undergoing cardiac or non-cardiac thoracic surgery differ in risk profile for both VTE and adverse effects, therefore we aimed to analyse and present data in two separate sections. In the main analyses of each section, we analysed and presented data by stratifying for the type of thromboprophylaxis used. We used standard inverse-variance random-effects meta-analysis to present outcome data at end of trial (DerSimonian 1986). We performed the data analysis in RevMan version 5.3 (RevMan 2014).

\section{Subgroup analysis and investigation of heterogeneity}

We planned to explore the between-trial heterogeneity by stratifying the main outcomes for the following trial characteristics: type of lesion operated on (malignant versus benign in non-cardiac thoracic surgery trials); type of cardiac surgery (coronary artery bypass grafting versus valve surgery); urgent versus elective procedure; concealment of allocation (adequate versus inadequate or unclear); blinding (adequate versus inadequate or unclear); analysis in accordance with the intention-to-treat principle (yes versus no or unclear). We planned to use univariate random-effects meta-regression models (Thompson 1999), to determine whether treatment effects are affected by these factors.

\section{R E S U L T S}

\section{Description of studies}

See: Characteristics of included studies; Characteristics of excluded studies.

\section{Results of the search}

Our search identified 2039 reports (Figure 1). Following title and abstract screening, we considered 107 to be potentially eligible. Following full-text analysis 13 studies met the review inclusion criteria and we excluded 76 studies ( 85 reports) (Excluded studies). For one study it was not possible to retrieve either the abstract or the full-text (Ciavarella 1985). Matching of the review inclusion criteria could not be verified for the study Rajah 1983. We classified Avidan 2011; Ciavarella 1985; Ranucci 2013, and Rajah 1983 as studies awaiting classification until additional information can be retrieved from the authors. Four registered trials are ongoing (Dixon 2013; Meyer 2011; NCT01267305; NCT00789399). 
Figure I. Study flow diagram.

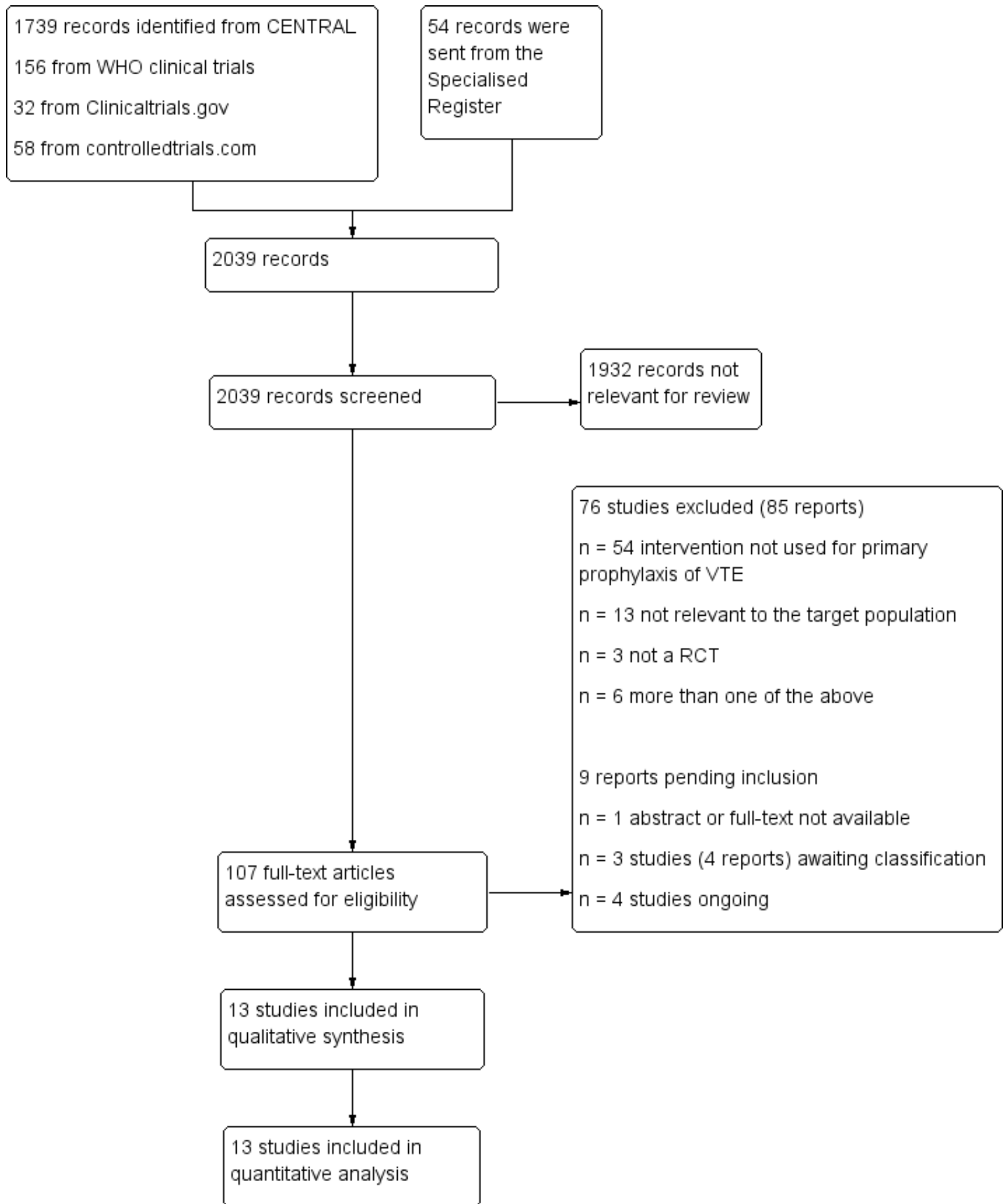




\section{Included studies}

Twelve randomised controlled trials (RCTs) and one quasi-randomised controlled trial included a total of 6923 participants. The two larger studies covered 4971 out of 6803 (72\%) included participants (Le Brigand 1981; Ramos 1996).

Six studies (3359 participants) evaluated the use of thromboprophylaxis in cardiac surgery (Beghi 1993; Goldhaber 1995; Mirhosseini 2013; Pfisterer 1989; Ramos 1996; Riess 2007). The thromboprophylaxis evaluated consisted of UFH (Beghi 1993; Riess 2007), UFH with or without aspirin (Mirhosseini 2013), UFH with or without IPC (Ramos 1996), LMWH (Beghi 1993), IPC with or without graded elastic compression stockings (Goldhaber 1995), vitamin K antagonists (VKAs) (Pfisterer 1989), and lepirudin (Riess 2007).

Seven studies (3564 participants) evaluated the use of thromboprophylaxis in thoracic surgery (Azorin 1997; Dahan 1990; Gallus 1973; Le Brigand 1981; Marchetti 1983; Rizzi 1987; van Geloven 1977). The thromboprophylaxis evaluated consisted of UFH (Dahan 1990; Gallus 1973; Le Brigand 1981; Marchetti 1983; Rizzi 1987; van Geloven 1977), LMWH (Azorin 1997; Dahan 1990), defibrotide (Rizzi 1987), and VKAs with or without dextran (van Geloven 1977).

\section{Cardiac surgery}

Beghi 1993 recruited patients $(n=39)$ undergoing open cardiac surgery for myocardial revascularisation $(92.3 \%)$, atrial myxoma $(2.6 \%)$, or atrial septal defect $(5.1 \%)$. Participants were randomised to LMWH (parnaparin 3200 IU once daily (od) subcutaneous) versus UFH (5000 IU three times daily (tid) subcutaneous) starting on the first day after surgery and continuing for four postoperative days.

Goldhaber 1995 recruited consecutive patients $(\mathrm{n}=344)$ undergoing coronary artery bypass without concomitant valve surgery or coronary endarterectomy. Participants were randomised to IPC plus graded elastic compression stockings versus graded elastic compression stockings alone. Mechanical prophylaxis was started postoperatively within four hours to more than 24 hours postoperatively.

Mirhosseini 2013 recruited patients $(n=120)$ undergoing elective off-pump coronary artery bypass graft and randomised them to aspirin (80 mg daily orally) plus heparin (5000 U unfractionated heparin every eight hours subcutaneously) versus heparin (5000 U unfractionated heparin every eight hours subcutaneously) alone. Study treatments were given from admission to discharge.

Pfisterer 1989 recruited consecutive patients $(\mathrm{n}=285)$ undergoing aortocoronary vein bypass surgery and randomised them to VKAs or platelet inhibitors (dipyridamole plus aspirin) for three or 12 months.

Ramos 1996 recruited consecutive patients ( $\mathrm{n}=2551)$ who underwent open heart surgery including coronary artery bypass surgery (CABG), CABG plus valve replacement, CABG plus left ventricle aneurysmectomy, CABG plus automatic implantable cardiac defibrillator, valve replacement, shunt repair, and atrial myxoma resection. Participants were randomised to UFH (5000 IU twice daily subcutaneous) with or without bilateral IPC. Both mechanical and pharmacological prophylaxis was started immediately after surgery and continued for four to five days or until participants were fully ambulatory.

Riess 2007 recruited patients $(n=20)$ with coronary artery disease requiring coronary artery bypass grafting with at least two bypass grafts. Participants were randomised to lepirudin or UFH. Study treatment was started intravenously and continued subcutaneously from the third day in the lepirudin group and from the second day in the UFH group.

\section{Thoracic surgery}

Azorin 1997 recruited patients $(\mathrm{n}=150)$ undergoing lung cancer surgery and randomised them to fixed-dose LMWH (nadroparin 3075 IU od subcutaneous) versus weight-adjusted dose LMWH (nadroparin 4100 IU or 6150 IU based on the weight). The first injection of LMWH was given 12 hours before surgery and LMWH was continued for eight days post-surgery.

Dahan 1990 recruited 18 to 80 -year old patients $(n=100)$, with body weight $50 \mathrm{~kg}$ to $80 \mathrm{~kg}$, undergoing elective lung cancer surgery and randomised them to UFH or LMWH. The first phase of the study was double-blinded and included the period from the day before surgery to two days after the operation. Participants were randomised to LMWH (nadroparin, 7500 IU subcutaneous, first injection 12 hours before surgery, second injection 12 hours after surgery, and then nadroparin 5000 IU subcutaneous od) or UFH (calciparine with the first injection two hours before surgery, second injection 12 hours after surgery, and then tid). The second phase of the study was open and included the period from the third to the seventh day after surgery. In this phase participants received LMWH (nadroparin 10000 IU od subcutaneous) or UFH (calciparine twice daily with dose adjusted to activated partial thromboplastin time (aPTT)).

Gallus 1973 recruited patients $(n=350)$ over 40 years old admitted for elective surgery, or for emergency surgery after fracture of the femoral neck and medical patients suspected of having myocardial infarction. Of the total study population only nine $(2.6 \%)$ participants underwent thoracic surgery. Participants were randomised to UFH (5000 IU tid subcutaneous) versus no UFH. UFH was started two hours before surgery and then tid beginning eight to 10 hours after the preoperative dose. Treatment was continued

Primary prophylaxis for venous thromboembolism in patients undergoing cardiac or thoracic surgery (Review) 
until the participant was fully mobile.

Le Brigand 1981 recruited patients $(n=2420)$ of 21 to 70 years old undergoing thoracic surgery and randomised them to UFH (5000 IU subcutaneous twice daily) starting before or after surgery versus no UFH in case of participants with contraindication or undergoing minor surgical procedures. UFH was continued until discharge or for 15 to 21 days.

Marchetti 1983 recruited patients $(n=29)$ with lung cancer who underwent pneumonectomy (52\%) or lobectomy (48\%). Participants were randomised to UFH (5000 IU tid subcutaneous) versus placebo. The starting time, end, and duration of study thromboprophylaxis was not reported.

Rizzi 1987 recruited consecutive patients $(\mathrm{n}=184)$ undergoing thoracic surgery, which included exploratory thoracotomy, lung excision for lung cancer, lobectomy, pleurectomy, cancer excision, or other. Participants were randomised to defibrotide $(400 \mathrm{mg}$ twice daily intravenous) versus UFH (calcium-heparin 5000 IU tid subcutaneous) starting the day before surgery and continuing until there was mobility considered sufficient to reduce the risk of venous stasis (mean of 7.7 days in the group treated with defibrotide and 7.8 days in the UFH group).

van Geloven 1977 recruited patients $(\mathrm{n}=331)$ over 40 years undergoing elective laparotomy, thoracotomy $(\mathrm{n}=83,26 \%)$, or hip replacement. Participants were randomised in a double-blind fashion to postoperative VKAs, dextran plus postoperative VKAs, $\mathrm{UFH}$, and UFH plus postoperative VKAs.

\section{Excluded studies}

We excluded a total of 76 studies (85 reports) and the reasons for exclusions were: intervention not used for primary prophylaxis of VTE (Acar 1996; Ageno 2001; Altman 1991; Altman 1996; Aramendi 2005; Attaran 2010; Buchanan 2002; Chesebro 1983; Colli 2007; Dale 1977; Dauphin 2008; Dixon 2008; Dong 2011; Dyke 2006; Eitz 2008; Francis 2003; Ghaffari 2011; Gherli 2004; Gohlke 1981; Hassouna 2000; Hayashi 1994; Hering 2005; Iliuta 2003; Kaiser 1981; Koertke 2000; Koertke 2003; Koertke 2007; Koertke 2010; Kuitunen 1997; Laffort 2000; Meschengieser 1997; Mirow 2001; Mok 1985; Ovrum 1996; Pappalardo 2006; Pengo 1997; Pengo 2007; Pogliani 1982; Pogliani 1993; Pruefer 2001; Rafiq 2013; Renda 2007; Saour 1990; Schlitt 2003; Segesser 1992; Starkman 1982; Swiniarska 2009; Torella 2010; Turpie 1988; Turpie 1993; van der Meer 1994; Voith 1997; Walenga 2001; Warkentin 2013), population included various types of surgery and data were not provided separately for thoracic or cardiac surgery (Cade 1983; Cade 1987; Di Carlo 1999; DiSerio 1985; Gallus 1993; Hartshorn 1969; Liezorovicz 1991; Samama 1988; Xia 2011), participants included were children (Jensen 2004; Keidan 2004; Monagle 2011; Pessotti 2012), not a RCT (Haas 2012; Jackaman 1978; Konkle 2001), and more than one of the above (Blair 1994; Kawazoe 1990; Körtke 2001; Ljungstrom 1985; Mehta 2007; Montalescot 2000).

\section{Risk of bias in included studies}

The risk of bias in the included studies is shown in Figure 2 and Figure 3.

Figure 2. 'Risk of bias' graph: review authors' judgements about each risk of bias item presented as percentages across all included studies.

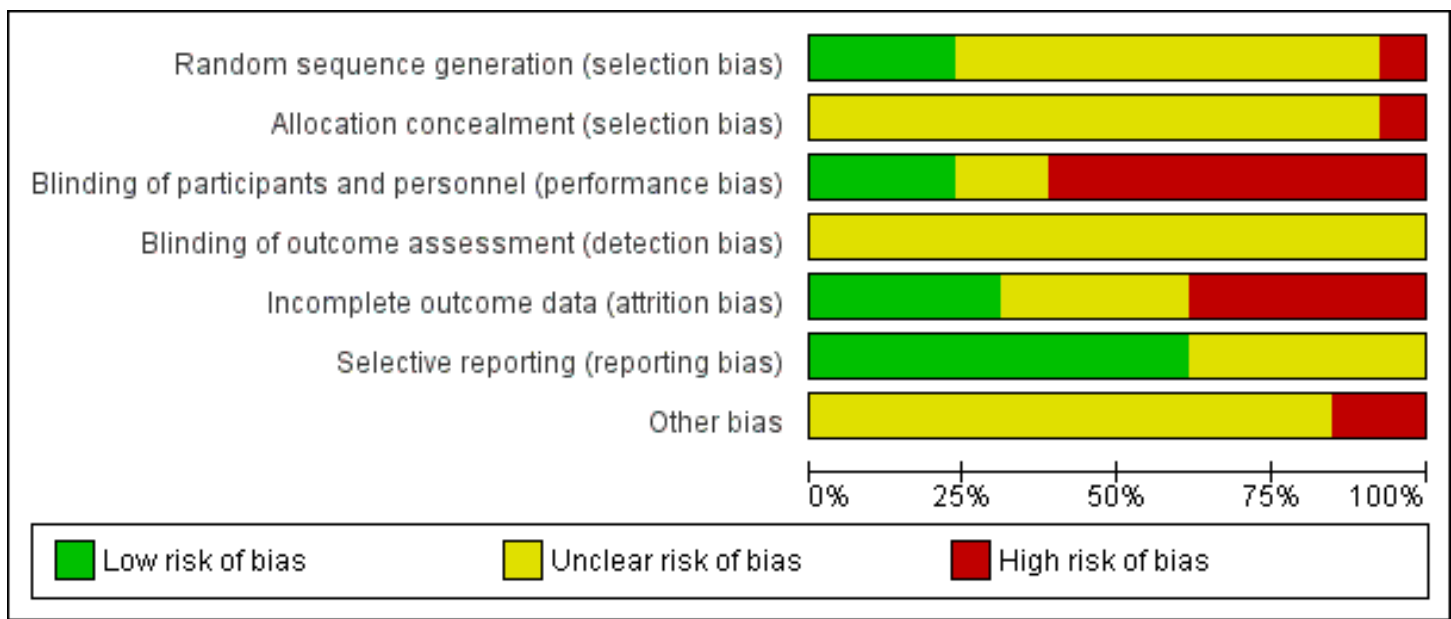

Primary prophylaxis for venous thromboembolism in patients undergoing cardiac or thoracic surgery (Review) 
Figure 3. 'Risk of bias' summary: review authors' judgements about each risk of bias item for each included study.

\begin{tabular}{|c|c|c|c|c|c|c|c|}
\hline & 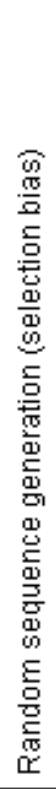 & 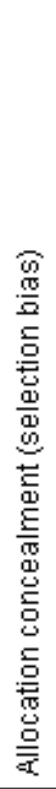 & 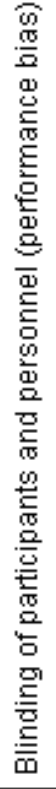 & 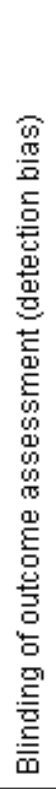 & 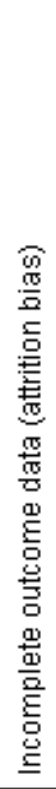 & 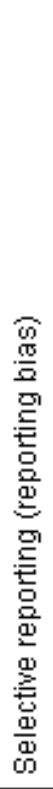 & 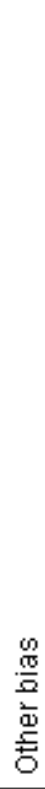 \\
\hline Azorin 1997 & $?$ & $?$ & & $?$ & & 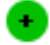 & $?$ \\
\hline Beghi 1993 & $?$ & $?$ & $?$ & $?$ & $?$ & + & ? \\
\hline Dahan 1990 & $?$ & $?$ & & $?$ & $?$ & + & \\
\hline Gallus 1973 & $?$ & $?$ & & $?$ & C & + & ? \\
\hline Goldhaber 1995 & $?$ & $?$ & & $?$ & & & ? \\
\hline Le Brigand 1981 & & & & $?$ & & $?$ & \\
\hline Marchetti 1983 & $?$ & $?$ & $?$ & $?$ & $?$ & $?$ & ? \\
\hline Mirhosseini 2013 & $?$ & $?$ & & $?$ & & $?$ & ? \\
\hline Pfisterer 1989 & $?$ & $?$ & & $?$ & & $?$ & ? \\
\hline Ramos 1996 & 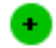 & $?$ & & $?$ & & $?$ & ? \\
\hline Riess 2007 & $?$ & $?$ & & $?$ & 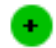 & + & ? \\
\hline Rizzi 1987 & + & $?$ & & $?$ & $?$ & & ? \\
\hline van Geloven 1977 & + & $?$ & $=$ & $?$ & & + & ? \\
\hline
\end{tabular}

Primary prophylaxis for venous thromboembolism in patients undergoing cardiac or thoracic surgery (Review)

Copyright $\odot 2015$ The Cochrane Collaboration. Published by John Wiley \& Sons, Ltd. 


\section{Allocation}

The random sequence was adequately generated in three studies (Ramos 1996; Rizzi 1987; van Geloven 1977), inadequate in one (Le Brigand 1981), and unclear in the remainder due to poor reporting (Azorin 1997; Beghi 1993; Dahan 1990; Gallus 1973; Goldhaber 1995; Marchetti 1983; Mirhosseini 2013; Pfisterer 1989; Riess 2007).

Allocation was inadequate in one (Le Brigand 1981), and unclear in the remainder (Azorin 1997; Beghi 1993; Dahan 1990; Gallus 1973; Goldhaber 1995; Marchetti 1983; Mirhosseini 2013; Pfisterer 1989; Ramos 1996; Riess 2007; Rizzi 1987; van Geloven 1977). In one of the two largest studies, the quasi-randomised trial of Le Brigand 1981, allocation was predictable, driven by operation times, which were influenced by the risk profile of the participants.

\section{Blinding}

Three studies blinded participants and personnel (Mirhosseini 2013; Pfisterer 1989; van Geloven 1977), eight were open (Azorin 1997; Dahan 1990; Gallus 1973; Goldhaber 1995; Le Brigand 1981; Ramos 1996; Riess 2007; Rizzi 1987), and in two blinding was unclear due to poor reporting (Beghi 1993; Marchetti 1983). In Dahan 1990, the first phase of the study was double-blinded while the second part was open-label. Blinding of study outcomes assessment was unclear in all studies.

\section{Incomplete outcome data}

Four studies performed the analysis according to the intention-totreat principle (Gallus 1973; Le Brigand 1981; Mirhosseini 2013; Riess 2007), while in five studies the percentages of participants randomised and subsequently excluded from the analysis ranged from 1.3\% to 12\% (Azorin 1997; Goldhaber 1995; Pfisterer 1989; Ramos 1996; van Geloven 1977). In four studies it was unclear if all participants enrolled were considered in the analysis (Beghi 1993; Dahan 1990; Marchetti 1983; Rizzi 1987).

\section{Selective reporting}

For five studies selective reporting was unclear due to poor reporting (Le Brigand 1981; Marchetti 1983; Mirhosseini 2013; Pfisterer 1989; Ramos 1996). In all other studies all expected outcomes were reported.

\section{Other potential sources of bias}

We judged two studies to be at high risk of bias as clinically suspected cases of PE were followed up clinically without an objective verification of PE, potentially leading to misclassifications for the occurrence of PE (Dahan 1990; Le Brigand 1981). In three studies it was not reported whether all clinically suspected cases of VTE were systematically verified by objective testing (Pfisterer 1989; Riess 2007; van Geloven 1977). In addition to the verification method of VTE, we verified if participant inclusion was consecutive and whether risk factors for VTE were reported. Only four studies reported that inclusion was done consecutively (Goldhaber 1995; Pfisterer 1989; Ramos 1996; Rizzi 1987). In the remainder, the representativeness of the study population for the respective surgical populations seen in practice remained unclear. In nine studies participant characteristics and risk factors for VTE were not described or poorly reported so that the applicability of the findings could not be interpreted (Beghi 1993; Dahan 1990; Gallus 1973; Marchetti 1983; Mirhosseini 2013; Pfisterer 1989; Ramos 1996; Riess 2007; van Geloven 1977).

\section{Effects of interventions}

As none of the trials could be statistically combined with another trial, we have presented estimates of effect on a trial level and no stratified analysis or funnel plot explorations were possible.

\section{Cardiac surgery}

We identified four studies evaluating pharmacological thromboprophylaxis versus inactive or active control (Beghi 1993; Mirhosseini 2013; Pfisterer 1989; Riess 2007), and two evaluating the impact of mechanical interventions on patient-relevant outcomes (Goldhaber 1995; Ramos 1996).

\section{Primary outcomes}

The effect of UFH versus LMWH on symptomatic VTE was evaluated in the small study of Beghi and colleagues (Beghi 1993), who reported no cases of VTE in either trial arm (Analysis 1.1). The effect of mechanical interventions on symptomatic VTE was evaluated in two studies, which reported a total number of 71 events in 2881 participants (Goldhaber 1995; Ramos 1996; Analysis 1.2; Analysis 1.3). Goldhaber 1995 observed one case of symptomatic VTE both in participants with IPC plus graded elastic compression stockings and in those with graded elastic compression stockings. In Ramos 1996, the combination of UFH with IPC was associated with a significant $61 \%$ reduction of symptomatic VTE compared to UFH alone (1.5\% versus 4.0\%; RR 0.39; $95 \% \mathrm{CI}$ 0.23 to 0.64 , P value $=0.0002$, NNTB 40; 95\% CI 26 to 83) In Mirhosseini 2013, there were no PEs in the UFH group nor in the UFH plus aspirin group (Analysis 1.4).

Major bleeding events were only reported in the study Pfisterer 1989, where VKAs were associated with a significantly higher incidence of major bleeds relative to platelet inhibitors $(11.3 \%$ versus

Primary prophylaxis for venous thromboembolism in patients undergoing cardiac or thoracic surgery (Review) 
$1.6 \%$, RR 7.06; 95\% CI 1.64 to 30.40 , P value $=0.009, \mathrm{NNTH}$ $11 ; 95 \%$ CI 6 to 27 ; Analysis 3.1).

\section{Secondary outcomes}

None of the studies reported on VTE-related mortality, postthrombotic syndrome, heparin-induced thrombocytopenia, or serious adverse events. In Riess 2007, we did not consider the incidentally reported PE $(n=1)$ in the lepirudin group nor the thromboembolic events $(n=0)$ in the UFH group as outcome data. In Mirhosseini 2013 there were significantly fewer unsuspected DVTs in the UFH plus aspirin group compared to the UFH group (3.3\% versus $16.6 \%$, RR 0.20 ; $95 \%$ CI 0.05 to 0.87 ). In Pfisterer 1989 , overall VTE was not significantly different between VKAs and platelet inhibitors ( $0 \%$ versus $3.2 \%$; RR 0.11 ; $95 \%$ CI 0.01 to 2.06). In Beghi 1993, a zero count was reported in both trial arms so that the RR could not be estimated. The effect of mechanical interventions on overall VTE was assessed in Goldhaber 1995, who reported that the event rate was comparable between IPC plus graded elastic compression stockings versus graded elastic compression stockings alone (19\% versus $22 \%$, RR 0.87; $95 \%$ CI 0.57 to 1.34 ).

Regarding the remaining secondary outcomes, none of the studies showed any statistically significant difference between thromboprophylaxis and control interventions (Data and analyses).

Overall mortality was only reported in the study Pfisterer 1989, where VKAs were associated with a non-significant four-fold risk increase compared to platelet inhibitors (6.5\% versus $1.6 \%$; RR 4.03; $95 \%$ CI 0.87 to 18.61 ).

The effect of pharmacological thromboprophylaxis on minor bleeding was evaluated by Beghi 1993 and Pfisterer 1989. Beghi 1993 reported 4/19 and 0/20 minor bleeds in the UFH and LMWH groups, respectively. Pfisterer 1989 found no significant differences in minor bleeding between VKAs and platelet inhibitors (RR 2.02; 95\% CI 0.52 to 7.88). We identified no study that evaluated the effect of mechanical interventions on minor bleeding.

The effect of pharmacological thromboprophylaxis on adverse events was reported in Pfisterer 1989, where VKAs were associated with a $70 \%$ lower incidence of adverse events compared to platelet inhibitors (RR 0.30 ; $95 \%$ CI 0.13 to 0.73 ).

\section{Thoracic surgery}

We identified seven studies evaluating pharmacological thromboprophylaxis versus inactive or active control (Azorin 1997; Dahan 1990; Gallus 1973; Le Brigand 1981; Marchetti 1983; Rizzi 1987; van Geloven 1977). None of the studies evaluated the impact of mechanical interventions.

\section{Primary outcomes}

None of the studies showed any statistically significant difference between pharmacological thromboprophylaxis on any of the primary outcomes.

Across the six studies reporting on symptomatic VTEs in 2890 participants undergoing thoracic surgery, 15 symptomatic VTEs occurred in total (Azorin 1997; Dahan 1990; Gallus 1973; Le Brigand 1981; Marchetti 1983; Rizzi 1987).

Three studies evaluated the impact of heparin versus inactive control on symptomatic VTE (Gallus 1973; Le Brigand 1981; Marchetti 1983), but the risk ratio could not be estimated in two of these, because of zero event rates in both trial arms (Gallus 1973; Marchetti 1983; Analysis 2.1). The third study by Le Brigand 1981 could not detect a statistically significant difference in symptomatic VTE between UFH and inactive control treatment $(0.7 \%$ versus $0 \%$; RR $6.71 ; 95 \%$ CI 0.40 to 112.65 ). Three additional studies studied the effect of heparin versus active control on symptomatic VTE (Azorin 1997; Dahan 1990; Rizzi 1987; Analysis 2.2; Analysis 2.3; Analysis 2.4). In the small study by Rizzi 1987, there were two symptomatic VTEs in the UFH group and none with defibrotide, while no VTE was observed in either trial arm in the studies of Azorin 1997 and Dahan 1990.

Major bleeding was reported in two studies (Azorin 1997; Dahan 1990), which found no difference between the experimental and control groups. In the study Azorin 1997, major bleeds occurred in $2.7 \%$ of participants receiving fixed-dose LMWH compared to $8.1 \%$ in those on weight-adjusted LMWH (RR 0.33; $95 \%$ CI 0.07 to 1.60 ). In Dahan 1990 , these occurred in $6 \%$ in the UFH and in $4 \%$ in the LMWH groups (RR 1.50; $95 \%$ CI 0.26 to 8.60).

\section{Secondary outcomes}

None of the studies reported on symptomatic PE, overall or VTErelated mortality, post-thrombotic syndrome, or heparin-induced thrombocytopenia. None of the studies showed any statistically significant difference between pharmacological thromboprophylaxis on any of the remaining secondary outcomes (Data and analyses). Four studies reported on overall VTE (Azorin 1997; Dahan 1990; Gallus 1973; van Geloven 1977). In both Gallus 1973 and Dahan 1990, there were no events in the intervention or control group. Azorin 1997 reported one VTE in 74 participants in the fixed-dose LMWH group versus none in the weight-adjusted dose LMWH group (RR 3.00; 95\% CI 0.12 to 72.47 ). No difference in overall VTE was observed in the study van Geloven 1977, with three VTEs in 19 participants in the UFH and five VTEs in 22 participants in the VKA groups (RR 0.69; 95\% CI 0.19 to 2.53 ).

Minor bleeding was reported in two studies (Azorin 1997; Dahan 1990). In Dahan 1990, there were eight out of 50 versus two out of 50 events in the UFH and LMWH groups, respectively (RR 4.00 ; $95 \%$ CI 0.89 to 17.91 ). Similarly, no difference in minor bleeding was reported by Azorin 1997 (RR 0.50; 95\% CI 0.05 to 5.40). 
Azorin 1997 was the only study in thoracic surgery that reported on serious adverse events and adverse events. There were two out of 74 versus three out of 74 serious adverse events in the fixed-dose and weight-adjusted dose LMWH groups, respectively (RR 0.67; $95 \%$ CI 0.11 to 3.87 ), and three adverse events in both groups (RR 1.00; 95\% CI 0.21 to 4.79 ).

\section{I SCUSSION}

\section{Summary of main results}

The evidence about the efficacy and safety of thromboprophylaxis in cardiac and thoracic surgery is limited to few studies with substantial methodological problems. Overall, unfractionated heparin (UFH) was the form of thromboprophylaxis most often evaluated in both types of surgery, whereas data on other types thromboprophylaxis were scarce or not available as for fondaparinux, the new oral anticoagulants, or caval filters. In cardiac surgery, the combination of intermittent pneumatic compression (IPC) and UFH seemed to significantly reduce symptomatic venous thromboembolism (VTE) compared to UFH alone, as demonstrated in a single study of low quality. None of the study designs, however, allowed us to evaluate if UFH itself is associated with an increased benefit or harm. In thoracic surgery, even the largest study, Le Brigand 1981, was underpowered to show a significant effect of UFH versus inactive control on symptomatic VTE (RR 6.71; $95 \%$ CI 0.40 to 112.65 ). No significant differences between any prophylactic regimen and control could be demonstrated for any of the outcomes in thoracic surgery. In both type of operations, the absolute rate of events was low, resulting in broad confidence intervals around the estimates. Furthermore, although the studies typically addressed some type of bleeding outcome in their reports, the definition of major bleeding was addressed in three studies out of 13 only, which further hampered the risk-benefit evaluations. In conclusion, there is currently no evidence to recommend routine thromboprophylaxis in patients undergoing cardiac or thoracic surgery. No definite conclusion can be made about the effectiveness of IPC, as future studies are likely to have a substantial impact on our confidence in the estimate of effect and may change the estimate.

\section{Overall completeness and applicability of evidence}

For both cardiac and thoracic surgery, one study contributed to more than two-thirds of the population included in the review for that type of surgery (Ramos 1996 and Le Brigand 1981, respectively). In Ramos 1996, poor reporting was an obstacle to a proper evaluation of study quality and no data were provided for major efficacy and safety outcomes such as deep vein thrombosis (DVT), major bleeding, or overall mortality. Interestingly, the authors reported a relatively high incidence of symptomatic pulmonary embolism (PE) (2.7\%), which was possibly explained by the short duration of thromboprophylaxis after surgery. Le Brigand 1981 had major methodological limitations, potentially introducing significant bias. The incomplete outcome reporting within and across trials hampered a comprehensive assessment of the safety and effectiveness of the treatments under evaluation. As an example, of nine studies reporting on symptomatic VTE only two provided data on major bleeding events. Additionally, it was often unclear how systematically these endpoints were searched for and verified. The secondary outcomes as formulated for this review were infrequently reported, and none of the trials reported all secondary outcomes of interest. The reporting of patient characteristics and the risk profile for the development of thromboembolic events was poorly or not described in the studies, so that we were unable to interpret the general applicability of the research findings. We observed a considerable variation in the event rates of symptomatic VTE across the studies, which could be the result of the lack of a systematic and objective verification of suspected cases, differences in the duration of thromboprophylaxis, characteristics of the study populations such as the type of cardiac or thoracic surgery, or the presence of concomitant VTE risk factors. Only one randomised controlled trial (RCT) in cardiac surgery (Pfisterer 1989), and two in thoracic surgery (Azorin 1997; Dahan 1990), reported on major bleeding. Pfisterer 1989 randomised participants to vitamin K antagonists or platelet inhibitors, which represent unusual types of prophylaxis for VTE in the surgical setting. Both Azorin 1997 and Dahan 1990 suggested a high risk of major bleeding with rates up to $8 \%$ with heparin prophylaxis. All three studies lacked a control group with no pharmacological prophylaxis, which hampered any assessment of the residual risk of major bleeding without intervention.

\section{Quality of the evidence}

The methodological quality of the included studies was low to very low (Higgins 2011). Poor reporting did not allow proper scoring of relevant study design features such as sequence generation and allocation concealment in the majority of included studies and we classified none of the studies as at an overall low risk of bias (Figure 2; Figure 3). Concerning the quality of the evidence at the outcome level, we downgraded all outcomes in all comparisons for methodological shortcomings. In addition, except for one outcome in one comparison, estimates were imprecise with wide confidence intervals including both negligible, appreciable beneficial, and appreciable harmful effects (Ramos 1996). The only precise effect was found for IPC on symptomatic VTE, where the upper limit of the confidence interval still represented an appreciable benefit, but we downgraded the quality for this outcome to low confidence in the estimate of the effect because of methodological 
shortcomings (Ramos 1996). There was not enough evidence to judge publication bias or the risk of bias for incomplete outcome reporting at the trial level. The directness or applicability of the evidence was generally unclear, as described in the previous section.

\section{Potential biases in the review process}

Our systematic approach to searching, study selection, and data extraction followed that of the Cochrane Handbook for Systematic Reviews of Interventions (Higgins 2011). In addition, we used an in-house made protocol for classification of the of methodological items, which some of our authors have applied in their previous research (Di Nisio 2012a; Rutjes 2009). Our search was sufficiently broad and as we did not apply language restrictions, therefore we feel confident we have identified all or at least most published reports. We cannot exclude the possibility of having missed unpublished work.

The main limitation of this review is that it identified few studies that were adequately powered and none of the studies could be statistically pooled. The included studies did not compare the same type of treatments for the same study outcomes and, where they did, they still could not be combined because of the zero event counts in both trial arms (Azorin 1997; Beghi 1993; Dahan 1990; Gallus 1973; Marchetti 1983). The 'no difference' findings for a specific outcome may thus be the result of the insufficient power of the analysis to show a difference between treatment groups as well as the absence of a true effect. Due to the paucity of data, it was impossible to conduct stratified analyses for the primary efficacy outcomes to evaluate the interaction of trial characteristics with treatment effects.

\section{Agreements and disagreements with other studies or reviews}

The evidence on the use of thromboprophylaxis in patients undergoing cardiac and thoracic surgery was recently summarised and discussed in the guidelines of the American College of Chest Physicians (Gould 2012). In that review only two studies were included for both cardiac and thoracic surgery. Despite the fact that our search strategy identified 10 additional studies, the conclusions are similar.

In a previous Cochrane review, $\mathrm{Akl}$ and colleagues summarised the evidence for perioperative thromboprophylaxis in patients with cancer from 16 studies including 11,847 participants (Akl 2011). This review focused on LMWH and UFH as interventions and included only cancer patients undergoing any type of surgery, so that only one study appears in both reviews (Dahan 1990). Akl 2011 concluded that no difference could be found between perioperative thromboprophylaxis with LMWH or UFH in terms of mortality and embolic outcomes.

\section{AUTHORS' CONCLUSIONS}

\section{Implications for practice}

When deciding whether to use primary antithrombotic prophylaxis in patients undergoing cardiac or thoracic surgery, a clinician needs to determine the patients' baseline risk of venous thromboembolism (VTE) and weigh the magnitude of benefit on clinically major endpoints against the risk of bleeding. Co-morbidities predisposing to bleeding, which often represent an exclusion criterion in randomised controlled studies on anticoagulants, might result in higher rates of major bleeding and limit the use of thromboprophylaxis in 'real life'. The review data appear too preliminary to clearly establish the risk-to-benefit ratio of thromboprophylaxis, suggesting caution in the adoption of any pharmacological thromboprophylaxis. In the absence of evidence, mechanical types of prophylaxis may be suggested for cardiac and thoracic surgery and pharmacological prophylaxis may be considered in patients with an estimated lower risk of bleeding and higher risk of VTE (Gould 2012).

\section{Implications for research}

Additional randomised studies are needed to clearly establish the risk-to-benefit ratio of pharmacological and non-pharmacological prophylaxis. Studies have to report on clinically relevant outcomes such as symptomatic pulmonary embolism (PE) and major bleeding, while possibly addressing the patient preferences and the effects on quality of life. As well as the type of prophylaxis and its starting time (postoperative versus preoperative), the duration should be studied as some preliminary data suggest a persisting risk of VTE long after the operation (Agnelli 2006; Mason 2006).

\section{ACKNOWLEDGEMENTS}

This study did not have an external funding sources.

We would like to thank Dr Karen Welch and Dr Marlene Stewart of Cochrane Peripheral Vascular Diseases for their assistance and advice throughout the review process.

Primary prophylaxis for venous thromboembolism in patients undergoing cardiac or thoracic surgery (Review) 


\section{R E F E R E N C E S}

\section{References to studies included in this review}

Azorin 1997 \{published data only\}

Azorin JF, Regnard JF, Dahan M, Pansart M. Efficacy and safety of Fraxiparine (R) in the prevention of thromboembolic events in lung cancer surgery [Efficacite et tolerance de Fraxiparine rho dans la prevention des accidents thrombo-embolique en chirurgie thoracique oncologique]. Annales de Cardiologie et D'Angeiologie 1997;46:341-7.

Beghi 1993 \{published data only\}

Beghi C, Fragnito C, Antonelli A, Reverberi C, Ferrari P, Saccani $\mathrm{S}$, et al. Prevention of deep venous thrombosis by a new low molecular weight heparin (Fluxum) in cardiac surgery. International Angiology 1993;12:383-6.

Dahan 1990 \{published data only\} Dahan M, Boneu B, Renella J, Berjaud J, Bogaty J, Durand J, et al. Prevention of deep venous thromboses in cancer thoracic surgery with a low-molecular-weight heparin: Fraxiparine. A comparative randomized trial. In: Bounameaux H, Samama M, ten Cate JW editor (s). Fraxiparine Second International Symposium Recent Pharmacological and Clinical Data. New York, NY: John Wiley and Sons Inc, 1990:27-31.

Gallus 1973 \{published data only\} Gallus AS, Hirsh J, Tuttle RJ, Trebilcock R, O’Brien SE, Carroll JJ, et al. Small subcutaneous doses of heparin in prevention of venous thrombosis. New England Journal of Medicine 1973;288:545-51.

Goldhaber 1995 \{published data only\} Goldhaber SZ, Hirsch DR, MacDougall RC, Polak JF, Creager MA, Cohn LH. Prevention of venous thrombosis after coronary artery bypass surgery (a randomized trial comparing two mechanical prophylaxis strategies). American Journal of Cardiology 1995;76:993-6.

Le Brigand 1981 \{published data only\} Le Brigand H, Morille P, Garnier B, Bogaty YJ, Samama M, Spriet A. Prevention of postoperative thrombo-embolic accidents following thoracic surgery by low-dose calcium heparinate: a comparative study. Semaine des Hopitaux 1981;57:972-7.

\section{Marchetti 1983 \{published data only\}}

Marchetti V, Beati C, Pogliani EM, Vincre G. Low doses of calcium heparin in thoracic surgery: Bleeding, modifications of coagulation and of fibrinolysis. Minerva Medica 1983;74:1745-8.

Mirhosseini 2013 \{published data only\}

Mirhosseini SJ, Forouzannia SK, Mostafavi Pour Manshadi SMY, li-Hassan-Sayegh S, Naderi N, Sanatkar M. Comparison of aspirin plus heparin with heparin alone on asymptomatic perioperative deep vein thrombosis in candidates for elective off-pump coronary artery bypass graft: A randomized clinical trial. Cardiology Journal 2013; 20:139-43.
Pfisterer 1989 \{published data only\}

Pfisterer M, Burkart F, Jockers G, Meyer B, Regenass $S$, Burckhardt D, et al. Trial of low-dose aspirin plus dipyridamole versus anticoagulants for prevention of aortocoronary vein graft occlusion. Lancet 1989;2:1-7.

Ramos 1996 \{published data only\}

Ramos R, Salem BI, De-Pawlikowski MP, Coordes C, Eisenberg S, Leidenfrost R. The efficacy of pneumatic compression stockings in the prevention of pulmonary embolism after cardiac surgery. Chest 1996;109:82-5.

Riess 2007 \{published data only\}

Riess FC, Poetzsch B, Madlener K, Cramer E, Doll KN, Doll S, et al. Recombinant hirudin for cardiopulmonary bypass anticoagulation: a randomized, prospective, and heparin-controlled pilot study. Thoracic and Cardiovascular Surgeon 2007;55:233-8.

Rizzi 1987 \{published data only\} Rizzi A, Radaelli F, Pisano M, Orro S, Nazzari M, Ratti $G$, et al. Prevention of deep venous thrombosis with defibrotide in chest surgery. Controlled multicenter study versus heparin. Minerva Medica 1987;78:745-50.

van Geloven 1977 \{published data only\} van Geloven F, Wittebol P, Sixma JJ. Comparison of postoperative coumarin, dextran 40 and subcutaneous heparin in the prevention of postoperative deep vein thrombosis. Acta Medica Scandinavica 1977;202:367-72.

\section{References to studies excluded from this review}

Acar 1996 \{published data only\}

Acar J, Iung B, Boissel JP, Samama MM, Michel PL, Teppe JP, et al. AREVA: multicenter randomized comparison of low-dose versus standard-dose anticoagulation in patients with mechanical prosthetic heart valves. Circulation 1996; 94:2107-12.

Ageno 2001 \{published data only\}

Ageno W, Turpie AG, Steidl L, Ambrosini F, Cattaneo R, Codari RL, et al. Comparison of a daily fixed 2.5$\mathrm{mg}$ warfarin dose with a 5-mg, international normalized ratio adjusted, warfarin dose initially following heart valve replacement. American Journal of Cardiology 2001;88:40-4.

Altman 1991 \{published data only\}

Altman R, Rouvier J, Gurfinkel E, D’Ortencio O, Manzanel R, de-La FL, et al. Comparison of two levels of anticoagulant therapy in patients with substitute heart valves. Journal of Thoracic and Cardiovascular Surgery 1991; 101:427-31.

\section{Altman 1996 \{published data only\}}

Altman R, Rouvier J, Gurfinkel E, Scazziota A, Turpie AG. Comparison of high-dose with low-dose aspirin in patients with mechanical heart valve replacement treated with oral anticoagulant. Circulation 1996;94:2113-6. 
Aramendi 2005 \{published data only\}

Aramendi JI, Mestres CA, Mestres CA, Martinez LJ, Campos $\mathrm{V}$, Muñoz G, et al. Triflusal versus oral anticoagulation for primary prevention of thromboembolism after bioprosthetic valve replacement (trac): prospective, randomized, cooperative trial. European Journal of Cardio-thoracic Surgery 2005;27:854-60.

Attaran 2010 \{published data only\}

Attaran S, Somov P, Awad WI. Randomised high- and low-dose heparin prophylaxis in patients undergoing thoracotomy for benign and malignant disease: effect on thrombo-elastography. European Journal of Cardio-thoracic Surgery 2010;37:1384-90.

Blair 1994 \{published data only\}

Blair KL, Hatton AC, White WD, Smith LR, Lowe JE, Wolfe WG, et al. Comparison of anticoagulation regimens after Carpentier-Edwards aortic or mitral valve replacement. Circulation 1994;90:II214-9.

Buchanan 2002 \{published data only\}

Buchanan LB, Levetan BN, Lombard CJ, Commerford PJ. Fixed-dose versus adjusted-dose warfarin in patients with prosthetic heart valves in a peri-urban impoverished population. Journal of Heart Valve Disease 2002;11:583-92.

Cade 1983 \{published data only\}

Cade JF, Clegg EA, Westlake GW. Prophylaxis of venous thrombosis after major thoracic surgery. Australian and New Zealand Journal of Surgery 1983;53:301-4.

Cade 1987 \{published data only\}

Cade JF, Wood M, Magnani HN, Westlake GW. Early clinical experience of a new heparinoid, Org 10172, in prevention of deep venous thrombosis. Thrombosis Research 1987;45:497-503.

Chesebro 1983 \{published data only\}

Chesebro JH, Fuster V, Elveback LR, McGoon DC, Pluth JR, Puga FJ, et al. Trial of combined warfarin plus dipyridamole or aspirin therapy in prosthetic heart valve replacement: danger of aspirin compared with dipyridamole. American Journal of Cardiology 1983;51: 1537-41.

Colli 2007 \{published data only\}

Colli A, Mestres CA, Castella M, Gherli T. Comparing warfarin to aspirin (WoA) after aortic valve replacement with the St. Jude Medical Epic heart valve bioprosthesis: results of the WoA Epic pilot trial. Journal of Heart Valve Disease 2007;16:667-71.

Dale 1977 \{published data only\}

Dale J, Myhre E. Prevention of arterial embolism by acetylsalicylic acid and anticoagulants in patients with heart valve prosthesis. Tidsskrift for Den Norske Lageforening 1976;28:1483-5.

* Dale J, Myhre E, Storstein O, Stormorken H, Efskind L. Prevention of arterial thromboembolism with acetylsalicylic acid. American Heart Journal 1977;94:101-11.

Dauphin 2008 \{published data only\}

Dauphin C, Legault B, Jaffeux P, Motreff P, Azarnoush K, Joly $\mathrm{H}$, et al. Comparison of INR stability between self- monitoring and standard laboratory method: preliminary results of a prospective study in 67 mechanical heart valve patients. Archives of Cardiovascular Diseases 2008;101: 753-61.

Di Carlo 1999 \{published data only\}

Di Carlo V, Agnelli G, Prandoni P, Coccheri S, Gensini GF, Gianese F, et al. Dermatan sulphate for the prevention of postoperative venous thromboembolism in patients with cancer. Thrombosis and Haemostasis 1999;82:30-4.

DiSerio 1985 \{published data only\}

* DiSerio FJ, Sasahara AA. United States trial of dihydroergotamine and heparin prophylaxis of deep vein thrombosis. American Journal of Surgery 1985;150:25-32. The Multicenter Trial Committee. Dihydroergotamineheparin prophylaxis of postoperative deep vein thrombosis. A multicenter trial. JAMA 1984;251:2960-6.

Dixon 2008 \{published data only\}

Dixon B, Campbell DJ, Santamaria JD. Elevated pulmonary dead space and coagulation abnormalities suggest lung microvascular thrombosis in patients undergoing cardiac surgery. Intensive Care Medicine 2008;34:1216-23.

Dong 2011 \{published data only\} Dong MF, Ma ZS, Ma SJ, Chai SD, Tang PZ, Yao DK. Anticoagulation therapy with combined low dose aspirin and warfarin following mechanical heart valve replacement. Thrombosis Research 2011;128:e91-4.

Dyke 2006 \{published data only\}

Dyke CM, Smedira NG, Koster A, Aronson S, McCarthy HL, Kirshner R, et al. A comparison of bivalirudin to heparin with protamine reversal in patients undergoing cardiac surgery with cardiopulmonary bypass: the EVOLUTION-ON study. Journal of Thoracic and Cardiovascular Surgery 2006;131:533-9.

Eitz 2008 \{published data only\}

Eitz T, Schenk S, Fritzsche D, Bairaktaris A, Wagner O, Koertke $\mathrm{H}$, et al. International normalized ratio selfmanagement lowers the risk of thromboembolic events after prosthetic heart valve replacement. Annals of Thoracic Surgery 2008;85:949-54.

Francis 2003 \{published data only\}

Francis JL, Palmer GJ, Moroose R, Drexler A. Comparison of bovine and porcine heparin in heparin antibody formation after cardiac surgery. Annals of Thoracic Surgery 2003;75:17-22.

Gallus 1993 \{published data only\}

Gallus A, Cade J, Ockelford P, Hepburn S, Maas M, Magnani H, et al. Orgaran (Org 10172) or heparin for preventing venous thrombosis after elective surgery for malignant disease? A double-blind, randomised, multicentre comparison. Thrombosis and Haemostasis 1993; 70:562-7.

Ghaffari 2011 \{published data only\}

Ghaffari S, Sohrabi B, Aslanabadi N, Mogadam AR, Sepehrvand N, Pourafkari L, et al. Percutaneous transvenous mitral commissurotomy: with or without heparin? A 
randomised double blind study. Kardiologia Polska 2011; 69:445-50.

\section{Gherli 2004 \{published data only\}}

Gherli T, Colli A, Fragnito C, Nicolini F, Borrello B, Saccani $\mathrm{S}$, et al. Comparing warfarin with aspirin after biological aortic valve replacement: a prospective study. Circulation 2004;110:496-500.

Gohlke 1981 \{published data only\}

Gohlke H, Gohlke-Barwolf C, Stürzenhofecker P, Görnandt L, Ritter B, Reichelt M, et al. Improved graft patency with anticoagulant therapy after aortocoronary bypass surgery: a prospective, randomized study. Circulation 1981;64: II22-7.

Haas 2012 \{published data only\}

Haas S, Hohmann V, Bramlage P. Prevention of venous thromboembolism using enoxaparin in day surgery: results of the SMART noninterventional study. Clinical and Applied Thrombosis/hemostasis 2012;18:265-71.

Hartshorn 1969 \{published data only\} Hartshorn JW, Teale SN, Faiz M. Dextran 75 and postoperative phlebitis. Evaluation of dextran 75 in the prophylaxis of postoperative thrombophlebitis, pulmonary embolism, and myocardial infarction. Archives of Surgery 1969;98:694-7.

Hassouna 2000 \{published data only\} Hassouna A, Allam H, Awad A, Hassaballah F. Standard versus low-level anticoagulation combined to low-dose dipyridamole after mitral valve replacement. Cardiovascular Surgery (London, England) 2000;8:491-8.

Hayashi 1994 \{published data only\}

Hayashi J, Nakazawa S, Oguma F, Miyamura H, Eguchi S. Combined warfarin and antiplatelet therapy after St. Jude Medical valve replacement for mitral valve disease. Journal of the American College of Cardiology 1994;23:672-7.

Hering 2005 \{published data only\}

* Hering D, Piper C, Bergemann R, Hillenbach C, Dahm M, Huth C, et al. Thromboembolic and bleeding complications following St. Jude Medical valve replacement: results of the German experience with low-intensity anticoagulation study. Chest 2005;127:53-9.

Horstkotte D, Bergemann R, Althaus U, Babin EJ, Chares M, Dahm M, et al. German experience with low intensity anticoagulation (GELIA): protocol of a multi-center randomized, prospective study with the St. Jude Medical valve. Journal of Heart Valve Disease 1993;2:411-9. Huth C, Friedl A, Rost A. Intensity of oral anticoagulation after implantation of St. Jude Medical aortic prosthesis: Analysis of the GELIA database (GELIA 4). European Heart Journal Supplements 2001;3:Q33-8.

Iliuta 2003 \{published data only\}

Iliuta L, Candea V, Vasilescu A, Moldovan H, Gherghiceanu DP, Macarie C. Fraxiparine versus unfractionated heparin for the perioperative anticoagulant therapy in patients undergoing mechanical prosthetic heart valve replacement. Archives de L'Union Medicale Balkanique 2003;38:141-8.
Jackaman 1978 \{published data only\}

Jackaman FR, Perry BJ, Siddons H. Deep vein thrombosis after thoracotomy. Thorax 1978;33:761-3.

Jensen 2004 \{published data only\} Jensen E, Andréasson S, Bengtsson A, Berggren H, Ekroth $\mathrm{R}$, Larsson LE, et al. Changes in hemostasis during pediatric heart surgery: impact of a biocompatible heparin-coated perfusion system. Annals of Thoracic Surgery 2004;77: 962-7.

Kaiser 1981 \{published data only\} Kaiser D, Hau H, Strey M. Prevention of venous thromboembolism during and after surgery for lung cancer. Praxis und Klinik der Pneumologie 1981;35:918-21.

Kawazoe 1990 \{published data only\} Kawazoe K, Fujita T, Manabe H. Dipyridamole combined with anticoagulant in prevention of early postoperative thromboembolism after cardiac valve replacement. Thrombosis Research. Supplement 1990;57:27-33.

Keidan 2004 \{published data only\} Keidan I, Mardor Y, Preisman S, Mishaly D. Venous embolization during sternotomy in children undergoing corrective heart surgery. Journal of Thoracic and Cardiovascular Surgery 2004;128:636-8.

Koertke 2000 \{published data only\} Koertke H, Minami K, Bairaktaris A, Wagner O, Koerfer R. INR self-management following mechanical heart valve replacement. Journal of Thrombosis and Thrombolysis 2000; 9 Suppl 1:S41-5.

Koertke 2003 \{published data only\}

* Koertke H, Minami K, Boethig D, Breymann T, Seifert $\mathrm{D}$, Wagner $\mathrm{O}$, et al. INR self-management permits lower anticoagulation levels after mechanical heart valve replacement. Circulation 2003;108 Suppl 1:II75-8. Koertke H, Zittermann A, Tenderich G, Wagner O, El AM, Krian A, et al. Low-dose oral anticoagulation in patients with mechanical heart valve prostheses: final report from the early self-management anticoagulation trial II. European Heart Journal 2007;28:2479-84.

Koertke, H, Zittermann A, Minami K, Tenderich G, Wagner O, El-Arousy M, et al. Low-dose international normalized ratio self-management: a promising tool to achieve low complication rates after mechanical heart valve replacement. Annals of Thoracic Surgery 2005;79:1909-14.

Koertke 2007 \{published data only\}

* Koertke H, Zittermann A, Wagner O, Koerfer R. Selfmanagement of oral anticoagulation therapy improves long-term survival in patients with mechanical heart valve replacement. Annals of Thoracic Surgery 2007;83:24-9. Körtke H, Körfer R. International normalized ratio selfmanagement after mechanical heart valve replacement: is an early start advantageous?. Annals of Thoracic Surgery 2001; 72:44-8.

Koertke 2010 \{published data only\} Koertke H, Zittermann A, Wagner O, Ennker J, Saggau W, Sack FU, et al. Efficacy and safety of very low-dose self-management of oral anticoagulation in patients with 
mechanical heart valve replacement. Annals of Thoracic

Surgery 2010;90:1487-93.

Konkle 2001 \{published data only\}

Konkle BA, Bauer TL, Arepally G, Cines DB, Poncz M, McNulty S, et al. Heparin-induced thrombocytopenia: bovine versus porcine heparin in cardiopulmonary bypass surgery. Annals of Thoracic Surgery 2001;71:1920-4.

Körtke 2001 \{published data only\}

Körtke H, Minami K, Breymann T, Seifert D, Baraktaris A, Wagner $\mathrm{O}$, et al. INR self-management after mechanical heart valve replacement: ESCAT (Early Self-Controlled Anticoagulation Trial). Zeitschrift für Kardiologie 2001;90 Suppl 6:118-24.

Kuitunen 1997 \{published data only\} Kuitunen AH, Heikkilä LJ, Salmenperä MT. Cardiopulmonary bypass with heparin-coated circuits and reduced systemic anticoagulation. Annals of Thoracic Surgery 1997;63:438-44.

Laffort 2000 \{published data only\}

Laffort P, Roudaut R, Roques X, Lafitte S, Deville C, Bonnet J, et al. Early and long-term (one-year) effects of the association of aspirin and oral anticoagulant on thrombi and morbidity after replacement of the mitral valve with the St. Jude medical prosthesis: a clinical and transesophageal echocardiographic study. Journal of the American College of Cardiology 2000;35:739-46.

\section{Liezorovicz 1991 \{published data only\}}

Liezorovicz A, Picolet H, Peyrieux JC, Boissel JP. Prevention of perioperative deep vein thrombosis in general surgery: a multicentre double blind study comparing two doses of Logiparin and standard heparin. British Journal of Surgery 1991;78:412-6.

Ljungstrom 1985 \{published data only\}

Ljungstrom KG. Deep-vein thrombosis after major noncardiovascular thoracic surgery. Scandinavian Journal of Thoracic and Cardiovascular Surgery 1985;19:161-4.

Mehta 2007 \{published data only\}

Mehta SR, Granger CB, Eikelboom JW, Bassand JP, Wallentin L, Faxon DP, et al. Efficacy and safety of fondaparinux versus enoxaparin in patients with acute coronary syndromes undergoing percutaneous coronary intervention: results from the OASIS-5 trial. Journal of the American College of Cardiology 2007;50:1742-51.

Meschengieser 1997 \{published data only\} Meschengieser SS, Fondevila CG, Frontroth J, Santarelli MT, Lazzari MA. Low-intensity oral anticoagulation plus low-dose aspirin versus high-intensity oral anticoagulation alone: a randomized trial in patients with mechanical prosthetic heart valves. Journal of Thoracic and Cardiovascular Surgery 1997;113:910-6.

Mirow 2001 \{published data only\}

Mirow N, Brinkmann T, Minami K, Tenderich G, Kleesiek K, Körfer R. Heparin-coated extracorporeal circulation with full and low dose heparinization: comparison of thrombin related coagulatory effects. Artificial Organs 2001;25:

480-5.

* Mirow N, Minami K, Reiss N, Knobl H, Kind K, Korfer R. Heparin coated extracorporeal circulation and low dose heparinization: technical considerations and specific risks. Cardiovascular Engineering (Dordrecht, Netherlands) 2000;5: $11-5$.

Mok 1985 \{published data only\}

Mok CK, Boey J, Wang R, Chan TK, Cheung KL, Lee $\mathrm{PK}$, et al. Warfarin versus dipyridamole-aspirin and pentoxifylline-aspirin for the prevention of prosthetic heart valve thromboembolism: a prospective randomized clinical trial. Circulation 1985;72:1059-63.

Monagle 2011 \{published data only\}

Monagle P, Cochrane A, Roberts R, Manlhiot C, Weintraub $\mathrm{R}$, Szechtman B, et al. A multicenter, randomized trial comparing heparin/warfarin and acetylsalicylic acid as primary thromboprophylaxis for 2 years after the Fontan procedure in children. Journal of the American College of Cardiology 2011;58:645-51.

Montalescot 2000 \{published data only\} Montalescot G, Polle V, Collet JP, Leprince P, Bellanger A, Gandjbakhch I, et al. Low molecular weight heparin after mechanical heart valve replacement. Circulation 2000;101: 1083-6.

Ovrum 1996 \{published data only\} Ovrum E, Brosstad F, Am HE, Tangen G, Abdelnoor M, Oystese R. Complete heparin-coated (CBAS) cardiopulmonary bypass and reduced systemic heparin dose; effects on coagulation and fibrinolysis. European Journal of Cardio-Thoracic Surgery 1996;10(6):449-55.

Pappalardo 2006 \{published data only\} Pappalardo F, Franco A, Crescenzi G, De SF, Torracca L, Zangrillo A. Anticoagulation management in patients undergoing open heart surgery by activated clotting time and whole blood heparin concentration. Perfusion 2006;21: 285-90.

Pengo 1997 \{published data only\} Pengo V, Barbero F, Banzato A, Garelli E, Noventa F, Biasiolo A, et al. A comparison of a moderate with moderate-high intensity oral anticoagulant treatment in patients with mechanical heart valve prostheses. Thrombosis and Haemostasis 1997;77:839-44.

Pengo 2007 \{published data only\}

Pengo V, Palareti G, Cucchini U, Molinatti M, Del BR, Baudo F, et al. Low-intensity oral anticoagulant plus lowdose aspirin during the first six months versus standardintensity oral anticoagulant therapy after mechanical heart valve replacement: a pilot study of low-intensity warfarin and aspirin in cardiac prostheses (LIWACAP). Clinical and Applied Thrombosis/hemostasis 2007;13:241-8.

Pessotti 2012 \{published data only\}

Pessotti C. A comparative study of oral anticoagulants and antiplatelet prophylaxis of thrombosis and thromboembolic events in the Fontan operation using extracardiac conduit. http://www.ensaiosclinicos.gov.br/rg/RBR-4z9wdg/. 
Pogliani 1982 \{published data only\}

Pogliani EM, Vigo A, Cofrancesco E, Colombi M, Cristoforetti G, Marchetti G, et al. Low-dose heparin in thoracic surgery: effect on blood coagulation and fibrinolysis system. Thrombosis Research 1982;27:211-9.

Pogliani 1993 \{published data only\}

Pogliani EM, Salvatore M, Baragetti I, Settembrini PG, Pezzuoli G, Polli EE. Effect of a low-molecular-weight heparin, calcium nadroparine (CY216), on fibrinolysis in patients undergoing surgery. Current Therapeutic Research, Clinical and Experimental 1993;53:180-7.

Pruefer 2001 \{published data only\}

Pruefer D, Dahm M, Dohmen G, Horstkotte D, Bergemann R, Oelert H. Intensity of oral anticoagulation after implantation of St. Jude Medical mitral or multiple valve replacement: lessons learned from GELIA (GELIA 5). European Heart Journal Supplements 2001;3:Q39-43.

Rafiq 2013 \{published data only\}

Rafiq S, Steinbruchel DA, Moeller CH, Lund J, Thiis JJ, Koeber L, et al. Early anticoagulation therapy after bioprosthetic aortic valve implantation: comparing warfarin versus aspirin. Interactive Cardiovascular and Thoracic Surgery 2013;17:S125-6.

Renda 2007 \{published data only\}

Renda G, Di PR, D'Alleva A, Sciartilli A, Zimarino $\mathrm{M}$, De CE, et al. Surgical bleeding after pre-operative unfractionated heparin and low molecular weight heparin for coronary bypass surgery. Haematologica 2007;92: 366-73.

Samama 1988 \{published data only\}

* Samama M, Bernard P, Bonnardot JP, Combe TS, Lanson Y, Tissot E. Low molecular weight heparin compared with unfractionated heparin in prevention of postoperative thrombosis. British Journal of Surgery 1988;75:128-31. Samama M, Combe $S$. Prevention of thromboembolic disease in general surgery with enoxaparin (Clexane). Acta Chirurgica Scandinavica Supplementum 1990;556:91-5.

Saour 1990 \{published data only\}

Saour JN, Sieck JO, Mamo LA, Gallus AS. Trial of different intensities of anticoagulation in patients with prosthetic heart valves. New England Journal of Medicine 1990;322: 428-32.

Schlitt 2003 \{published data only\}

Schlitt A, von-Bardeleben RS, Ehrlich A, Eimermacher A, Peetz D, Dahm M, et al. Clopidogrel and aspirin in the prevention of thromboembolic complications after mechanical aortic valve replacement (CAPTA). Thrombosis Research 2003;109:131-5.

Segesser 1992 \{published data only\}

Segesser LK, Weiss BM, Garcia E, Felten A, Turina MI. Reduction and elimination of systemic heparinization during cardiopulmonary bypass. Journal of Thoracic and Cardiovascular Surgery 1992;103:790-8.

Starkman 1982 \{published data only\}

Starkman C, Estampes B, Vernant P, Acar J. Prevention of systemic thromboembolic accidents in patients with artificial valve prostheses. Prospective study of an antivitamins Kdipyridamole combination. Archives des Maladies du Coeur et des Vaisseaux 1982;75:85-8.

Swiniarska 2009 \{published data only\}

Swiniarska J, Zekanowska E, Dancewicz M, Bella M, Szczesny TJ, Kowalewski J. Pneumonectomy due to lung cancer results in a more pronounced activation of coagulation system than lobectomy. European Journal of Cardio-thoracic Surgery 2009;36:1064-8.

Torella 2010 \{published data only\}

Torella M, Torella D, Chiodini P, Franciulli M, Romano G, De SL, et al. LOWERing the INtensity of oral anticoaGulant Therapy in patients with bileaflet mechanical aortic valve replacement: results from the "LOWERINGIT" Trial. American Heart Journal 2010;160:171-8.

Turpie 1988 \{published data only\}

Turpie AG, Gunstensen J, Hirsh J, Nelson H, Gent M. Randomised comparison of two intensities of oral anticoagulant therapy after tissue heart valve replacement. Lancet 1988;1:1242-5.

Turpie 1993 \{published data only\}

Turpie AG, Gent M, Laupacis A, Latour Y, Gunstensen $\mathrm{J}$, Basile $\mathrm{F}$, et al. A comparison of aspirin with placebo in patients treated with warfarin after heart-valve replacement. New England Journal of Medicine 1993;329:524-9.

van der Meer 1994 \{published data only\} van-der MJ, Brutel-de-la RA, van-Gilst WH, Hillege HL, Pfisterer M, Kootstra GJ, et al. Effects of low dose aspirin (50 mg/day), low dose aspirin plus dipyridamole, and oral anticoagulant agents after internal mammary artery bypass grafting: patency and clinical outcome at 1 year. Journal of the American College of Cardiology 1994;24:1181-8.

Voith 1997 \{published data only\}

Voith L, Pfliegler G, Hegedús I, Medgyesi F, Bódi A, Csapó $\mathrm{K}$, et al. Coumarin combined with low-dose acetylsalicylic acid in the prevention of thromboembolic complications in patients with mitral and aortic valve prostheses. Orvosi Hetilap 1997;138:925-9.

Walenga 2001 \{published data only\} Walenga JM, Hoppensteadt D, Pifarré R, Fox NL, Forman $S$, Hunninghake DB, et al. The hemostatic effects of warfarin titration in post CABG patients in comparison to placebo treatment. Journal of Thrombosis and Thrombolysis 2001;11:143-9.

Warkentin 2013 \{published data only\} Warkentin TE, Sheppard JI, Sun JC, Jung H, Eikelboom JW. Anti-PF4/heparin antibodies and venous graft occlusion in postcoronary artery bypass surgery patients randomized to postoperative unfractionated heparin or fondaparinux thromboprophylaxis. Journal of Thrombosis and Haemostasis : JTH 2013;11:253-60.

Xia 2011 \{published data only\}

Xia X-YT, Shan Z. Enoxaparin for the prevention of postsurgical pulmonary embolism. Zhongguo wei zhong bing ji jiu yi xue [Chinese Critical Care Medicine] 2011;23:661-4. 


\section{References to studies awaiting assessment}

Avidan 2011 \{published data only\}

* Avidan MS, Smith JR, Skrupky LP, Hill L, Jacobsohn E, Burnside B, et al. The occurrence of antibodies to heparinplatelet factor 4 in cardiac and thoracic surgical patients receiving desirudin or heparin for postoperative venous thrombosis prophylaxis. Thrombosis Research 2011;128: 524-9.

NCT00329433. The use of desirudin versus heparin for thrombosis prophylaxis in cardiothoracic surgery patients. http://www.clinicaltrials.gov/ct2/show/NCT00329433? term.

Ciavarella 1985 \{published data only\} Ciavarella N, Antoncecchi S, D’Elia N. Dipyridamole and warfarin in patients with prosthetic heart valves: a controlled double blind study. Cardiologia 1985;30:301-7.

Rajah 1983 \{published data only\}

Rajah SM, Salter MCP, Donaldson DR, Crow MJ, Rao RS, Watson DA. A clinical trial comprising 2500 IU heparin and $0.5 \mathrm{mg}$ dihydroergotamine (DHE) with 5000 IU heparin in the prophylaxis of deep venous thrombosis following thoracic surgery. Thrombosis and Haemostasis 1983;50:9 [abstract no:0002].

Ranucci 2013 \{published data only\} Ranucci M, Baryshnikova E, Crapelli GB, Woodward MK, Paez A, Pelissero G. Preoperative antithrombin supplementation in cardiac surgery: a randomized controlled trial. Journal of Thoracic and Cardiovascular Surgery 2013;145:1393-9.

\section{References to ongoing studies}

Dixon 2013 \{published data only\}

Dixon B. Use of heparin to prevent lung microvascular thrombosis in patients administered aprotinin undergoing cardiac surgery for ischemic heart disease for ischemic heart disease. https://www.anzctr.org.au/Trial/Registration/ TrialReview.aspx?id=1327. [: ACTRN12606000328572]

Meyer 2011 \{published data only\}

Meyer G, Besse B, Friard S, Girard P, Corbi P, Azarian R, et al. Effect of tinzaparin on survival in non-small-cell lung cancer after surgery. TILT: tinzaparin in lung tumours. Revue des Maladies Respiratoires 2011;28:654-9.

NCT00789399 \{published data only\}

NCT00789399. A study of the efficacy of preventive dosing of fondaparinux sodium versus placebo for the prevention of venous thromboembolism (VTE) in patients undergoing coronary bypass surgery receiving routine mechanical prophylaxis. http://www.clinicaltrials.gov/ct2/ show/NCT00789399?term=NCT00789399\&rank=1. [: NCT00789399]

NCT01267305 \{published data only\}

NCT01267305. The impact of different anticoagulant therapy on hemorrhage and coagulation after thoracic surgery. http://clinicaltrials.gov/show/NCT01267305. [: NCT01267305]

\section{Additional references}

Agnelli 2006

Agnelli G, Bolis G, Capussotti L, Scarpa RM, Tonelli F, Bonizzoni E, et al. A clinical outcome-based prospective study on venous thromboembolism after cancer surgery. The @RISTOS Project. Annals of Surgery 2006;243(1):8995.

\section{Akl 2011}

Akl EA, Labedi N, Terrenato I, Barba M, Sperati F, Sempos EV, et al. Low molecular weight heparin versus unfractionated heparin for perioperative thromboprophylaxis in patients with cancer. Cochrane Database of Systematic Reviews 2011, Issue 11. [DOI: 10.1002/14651858.CD009447]

\section{Ambrosetti 2004}

Ambrosetti M, Salerno M, Zambelli M, Mastropasqua F, Tramarin R, Pedretti RF. Deep vein thrombosis among patients entering cardiac rehabilitation after coronary artery bypass surgery. Chest 2004;125(1):191-6.

Bani-Hani 2008

Bani-Hani M, Titi MA, Jaradat I, Al-Khaffaf $\mathrm{H}$. Interventions for preventing venous thromboembolism following abdominal aortic surgery. Cochrane Database of Systematic Reviews 2008, Issue 1. [DOI: 10.1002/ 14651858.CD005509.pub2]

\section{Bergqvist 2002}

Bergqvist D, Agnelli G, Cohen AT, Eldor A, Nilsson PE, Le Moigne-Amrani A, et al for the ENOXACAN II Investigators. Duration of prophylaxis against venous thromboembolism with enoxaparin after surgery for cancer. New England Journal of Medicine 2002;346:975-80.

Collins 1988

Collins R, Scrimgeour A, Yusuf S, Peto R. Reduction in fatal pulmonary embolism and venous thrombosis by perioperative administration of subcutaneous heparin. Overview of results of randomized trials in general, orthopedic, and urologic surgery. New England Journal of Medicine 1988;318(18):1162-73.

\section{DeLaria 1991}

DeLaria GA, Hunter JA. Deep venous thrombosis. Implications after open heart surgery. Chest 1991;99(2): 284-8.

\section{DerSimonian 1986}

DerSimonian R, Laird N. Meta-analysis in clinical trials. Controlled Clinical Trials 1986;7(3):177-88.

Di Nisio 2012a

Di Nisio M, Porreca E, Ferrante N, Otten HM, Cuccurullo F, Rutjes AWS. Primary prophylaxis for venous thromboembolism in ambulatory cancer patients receiving chemotherapy. Cochrane Database of Systematic Reviews 2012, Issue 2. [DOI: 10.1002/ 14651858.CD008500.pub2]

Di Nisio 2014

Di Nisio M, Porreca E, Otten HM, Rutjes AW. Primary prophylaxis for venous thromboembolism in ambulatory 
cancer patients receiving chemotherapy. Cochrane Database of Systematic Reviews 2014, Issue 8. [DOI: 10.1002/ 14651858.CD008500.pub3; PUBMED: 25171736]

\section{Gangireddy 2007}

Gangireddy C, Rectenwald JR, Upchurch GR, WakefieldTW, Khuri S, Henderson WG, et al. Risk factors and clinical impact of postoperative symptomatic venous thromboembolism. Journal of Vascular Surgery 2007;45(2): $335-42$.

\section{Geerts 2008}

Geerts WH, Bergqvist D, Pineo GF, Heit JA, Samama CM, Lassen MR, et al. Prevention of venous thromboembolism; American College of Chest Physicians Evidence-Based Clinical Practice Guidelines (8th Edition). Chest 2008;133 $\operatorname{Suppl}(6): 381-453$.

\section{Gillinov 1992}

Gillinov AM, Davis EA, Alberg AJ, Rykiel M, Gardner TJ, Cameron DE. Pulmonary embolism in the cardiac surgical patient. Annals of Thoracic Surgery 1992;53:988-91.

\section{Gould 2012}

Gould MK, Garcia DA, Wren SM, Karanicolas PJ, Arcelus JI, Heit JA, et al. Prevention of VTE in nonorthopedic surgical patients: Antithrombotic Therapy and Prevention of Thrombosis, 9th ed: American College of Chest Physicians Evidence-Based Clinical Practice Guidelines. Chest 2012;141(2 Suppl):e227S-77S.

\section{Guyatt 2008}

Guyatt G, Oxman AD, Vist GE, Kunz R, Falck-Ytter Y, Alonso-Coello P, for the GRADE Working Group. GRADE: an emerging consensus on rating quality of evidence and strength of recommendations. BMJ 2008;336 (7650):924-6.

\section{Hannan 2003}

Hannan EL, Racz MJ, Walford G, Ryan TJ, Isom OW, Bennett E, et al. Predictors of readmission for complications of coronary artery bypass graft surgery. JAMA 2003;290(6): $773-80$.

\section{Harbord 2006}

Harbord RM, Egger M, Sterne JA. A modified test for small-study effects in meta-analyses of controlled trials with binary endpoints. Statistics in Medicine 2006;25(20): 3443-57.

Higgins 2003

Higgins JP, Thompson SG, Deeks JJ, Altman DG. Measuring inconsistency in meta-analyses. BMJ 2003;327 (7414):557-60.

\section{Higgins 2011}

Higgins JPT, Green S (editors). Cochrane Handbook for Systematic Reviews of Interventions Version 5.1.0 [updated March 2011]. The Cochrane Collaboration, 2011. Available from www.cochrane-handbook.org.

\section{Jackman 1978}

Jackaman FR, Perry BJ, Siddons H. Deep vein thrombosis after thoracotomy. Thorax 1978;33:761-3.

\section{Josa 1993}

Josa M, Siouffi SY, Silverman AB, Barsamian EM, Khuri SF, Sharma GV. Pulmonary embolism after cardiac surgery. Journal of the American College of Cardiology 1993;21: 990-6.

Juni 2001

Juni P, Altman DG, Egger M. Systematic reviews in health care: assessing the quality of controlled clinical trials. $B M J$ 2001;323(7303):42-6.

\section{Kakkar 2009}

Kakkar AK. Prevention of venous thromboembolism in the cancer surgical patient. Journal of Clinical Oncology 2009; 27:4881-4

Kakkar 2010

Kakkar VV, Balibrea JL, Martínez-González J, Prandoni P, on behalf of the CANBESURE Study Group. Extended prophylaxis with bemiparin for the prevention of venous thromboembolism after abdominal or pelvic surgery for cancer: the CANBESURE randomized study. Journal of Thrombosis and Haemostasis 2010;8(6):1223-9.

\section{Kalweit 1994}

Kalweit G, Huwer H, Volkmer I, Petzold T, Gams E. Pulmonary embolism: a frequent cause of acute fatality after lung resection. European Journal of Cardio-Thoracic Surgery 1996;10(4):242-6, discussion 246-7.

\section{Mason 2006}

Mason DP, Quader MA, Blackstone EH, Rajeswaran J, DeCamp MM, Murthy SC, et al. Thromboembolism after pneumonectomy for malignancy: an independent marker of poor outcome. Journal of Thoracic and Cardiovascular Surgery 2006;131(3):711-8.

\section{Nagahiro 2004}

Nagahiro I, Andou A, Aoe M, Sano Y, Date H, Shimizu $\mathrm{N}$. Intermittent pneumatic compression is effective in preventing symptomatic pulmonary embolism after thoracic surgery. Surgery Today 2004;34(1):6-10.

Ramos 2008

Ramos J, Perrotta C, Badariotti G, Berenstein G. Interventions for preventing venous thromboembolism in adults undergoing knee arthroscopy. Cochrane Database of Systematic Reviews 2008, Issue 4. [DOI: 10.1002/ 14651858.CD005259.pub3]

\section{Reis 1991}

Reis SE, Polak JF, Hirsch DR, Cohn LH, Creager MA, Donovan BC, et al. Frequency of deep venous thrombosis in asymptomatic patients with coronary artery bypass grafts. American Heart Journal 1991;122(2):478-82.

RevMan 2014

The Nordic Cochrane Centre, The Cochrane Collaboration. Review Manager (RevMan). 5.3. Copenhagen: The Nordic Cochrane Centre, The Cochrane Collaboration, 2014.

Rutjes 2009

Rutjes AWS, Nüesch E, Sterchi R, Kalichman L, Hendriks E, Osiri M, et al. Transcutaneous electrostimulation for osteoarthritis of the knee. Cochrane Database of 
Systematic Reviews 2009, Issue 4. [DOI: 10.1002/ 14651858.CD002823.pub2]

Rücker 2008

Rücker G, Schwarzer G, Carpenter JR, Schumacher M. Undue reliance on $\mathrm{I} 2$ in assessing heterogeneity may mislead. BMC Medical Research Methodology 2008;8(1):79.

Sugarbaker 2004

Sugarbaker DJ, Jaklitsch MT, Bueno R, Richards W, Lukanich J, Mentzer SJ, et al. Prevention, early detection, and management of complications after 328 consecutive extrapleural pneumonectomies. Journal of Thoracic and Cardiovascular Surgery 2004;128:138-46.

Thompson 1999

Thompson SG, Sharp SJ. Explaining heterogeneity in metaanalysis: a comparison of methods. Statistics in Medicine
1999;18(20):2693-708.

White 2003

White RH, Zhou H, Romano PS. Incidence of symptomatic venous thromboembolism after different elective or urgent surgical procedures. Thrombosis and Haemostasis 2003;90 (3):446-55.

\section{References to other published versions of this review}

Di Nisio 2012b

Di Nisio M, Porreca E, Ferrante N, Rutjes AWS. Primary prophylaxis for venous thromboembolism in patients undergoing cardiac or thoracic surgery. Cochrane Database of Systematic Reviews 2012, Issue 2. [DOI: 10.1002/ 14651858.CD009658]

* Indicates the major publication for the study 


\section{CHARACTERISTICS OF STUDIES}

\section{Characteristics of included studies [ordered by study ID]}

\section{Azorin 1997}

\begin{tabular}{|c|c|}
\hline Methods & RCT, open, prospective, multicentre \\
\hline Participants & $\begin{array}{l}\text { Patients }(n=150 \text { randomised, } 148 \text { treated }) \text { undergoing lung cancer surgery } \\
\text { Age }( \pm S D): 56.8( \pm 1.4) \text { in the fixed-dose LMWH and } 58.9( \pm 1.3) \text { in the adjusted dose; } \\
\text { males were } 86.5 \% \text { and } 82.4 \% \text {, respectively }\end{array}$ \\
\hline Interventions & $\begin{array}{l}\text { - Fixed-dose LMWH, nadroparin ( } 3075 \mathrm{IU} \text { Anti-Xa subcutaneous injection) } \\
\text { - Adjusted-dose LMWH, nadroparin ( } 4100 \mathrm{IU} / 6150 \mathrm{IU} \text { Anti-Xa subcutaneous injection } \\
\text { in participants with body weight } 40 \mathrm{~kg} \text { to } 70 \mathrm{~kg} / 71 \mathrm{~kg} \text { to } 110 \mathrm{~kg} \text { ) } \\
\text { The first injection of LMWH was given } 12 \text { hours before surgery and LMWH was } \\
\text { continued for } 8 \text { days post-surgery }\end{array}$ \\
\hline Outcomes & $\begin{array}{l}\text { DVT, PE, major bleeding, overall VTE, minor bleeding, SAE and AE } \\
\text { DVT was confirmed by Doppler compression ultrasonography. Bilateral ascending phle- } \\
\text { bography was used to confirm positive findings on ultrasonography. PE was confirmed } \\
\text { by pulmonary angiography }\end{array}$ \\
\hline Notes & - \\
\hline
\end{tabular}

\section{Risk of bias}

\begin{tabular}{l|l|l}
\hline Bias & Authors' judgement & Support for judgement \\
\hline $\begin{array}{l}\text { Random sequence generation (selection } \\
\text { bias) }\end{array}$ & Unclear risk & $\begin{array}{l}\text { Method of random sequence generation not re- } \\
\text { ported }\end{array}$ \\
\hline $\begin{array}{l}\text { Allocation concealment (selection bias) } \\
\begin{array}{l}\text { Blinding of participants and personnel } \\
\text { (performance bias) } \\
\text { All outcomes }\end{array}\end{array}$ & High risk & Method of allocation concealment not reported \\
\hline
\end{tabular}

Blinding of outcome assessment (detection Unclear risk

Not reported if outcome assessment was blinded bias)

All outcomes

Incomplete outcome data (attrition bias) High risk All outcomes

2 participants enrolled (1.3\%) not included in the analysis

Selective reporting (reporting bias)

Low risk

Study not registered. No published protocol. All outcomes mentioned in the methods section were addressed in the results section 
Azorin 1997 (Continued)

\begin{tabular}{|c|c|c|}
\hline Other bias & Unclear risk & $\begin{array}{l}\text { Participant characteristics are not reported. Un- } \\
\text { clear if participants were consecutively included }\end{array}$ \\
\hline
\end{tabular}

\section{Beghi 1993}

\begin{tabular}{ll}
\hline Methods & RCT \\
\hline Participants & $\begin{array}{l}\text { Patients }(\mathrm{n}=39) \text { undergoing open cardiac surgery, 20 were randomised to the LMWH } \\
\text { group and } 19 \text { to the calcium-heparin group. Mean age was } 60.2( \pm 1.9) \text { years in LMWH } \\
\text { and } 60.5( \pm 2.4) \text { years in calcium-heparin; } 31 / 39(79 \%) \text { were males. One or more } \\
\text { risk factors for DVT were reported in } 100 \% \text { of LMWH and } 72 \% \text { of calcium-heparin } \\
\text { patients. Indication for surgery: myocardial revascularisation }(92.3 \%) \text {, atrial myxoma } \\
(2.6 \%) \text {, atrial septal defect }(5.1 \%)\end{array}$ \\
\hline Interventions & $\begin{array}{l}\text { LMWH, parnaparin }(3200 \text { IU od subcutaneous) } \\
- \text { Calcium-heparin }(5000 \text { IU tid subcutaneous) }\end{array}$ \\
\hline $\begin{array}{l}\text { Thromboprophylaxis was started on the first day after surgery and continued for } 4 \\
\text { postoperative days }\end{array}$ \\
\hline Outcomes & $\begin{array}{l}\text { Symptomatic and asymptomatic DVT. Physical examination and colour Doppler ultra- } \\
\text { sonography were used to diagnose DVT }\end{array}$ \\
\hline Notes & - \\
\hline
\end{tabular}

\section{Risk of bias}

\begin{tabular}{|c|c|c|}
\hline Bias & Authors' judgement & Support for judgement \\
\hline $\begin{array}{l}\text { Random sequence generation (selection } \\
\text { bias) }\end{array}$ & Unclear risk & Method of random sequence generation not reported \\
\hline Allocation concealment (selection bias) & Unclear risk & Method of allocation concealment not reported \\
\hline $\begin{array}{l}\text { Blinding of participants and personnel } \\
\text { (performance bias) } \\
\text { All outcomes }\end{array}$ & Unclear risk & $\begin{array}{l}\text { Not reported if participants and personnel were blinded to study } \\
\text { treatment }\end{array}$ \\
\hline $\begin{array}{l}\text { Blinding of outcome assessment (detection } \\
\text { bias) } \\
\text { All outcomes }\end{array}$ & Unclear risk & Not reported if outcome assessment was blinded \\
\hline $\begin{array}{l}\text { Incomplete outcome data (attrition bias) } \\
\text { All outcomes }\end{array}$ & Unclear risk & $\begin{array}{l}\text { It is unclear if all participants enrolled were subsequently con- } \\
\text { sidered in the analysis }\end{array}$ \\
\hline Selective reporting (reporting bias) & Low risk & $\begin{array}{l}\text { Study not registered. No published protocol. All outcomes men- } \\
\text { tioned in the methods section were addressed in the results sec- } \\
\text { tion }\end{array}$ \\
\hline
\end{tabular}


Beghi 1993 (Continued)

Other bias

Unclear risk

Participant characteristics are not reported. Unclear if participants were consecutively included

Dahan 1990

Methods Prospective, multicentre, randomised study

Participants

Of 100 patients undergoing elective lung cancer surgery, 50 were randomised to the LMWH group and 50 to the UFH group. Mean age was 59 years; males: $92 \%$

Interventions

First phase (double-blinded) from the day before surgery to 2 days after the operation:

- LMWH, nadroparin (7500 IU subcutaneous), first injection 12 hours before surgery, second injection 12 hours after surgery, and then nadroparin (5000 IU subcutaneous) od

- UFH, calciparine, first injection 2 hours before surgery, second injection 12 hours after surgery, and then tid

Second phase (open-label) from the 3rd to the 7th day after surgery

- LMWH, nadroparin (10000 IU od subcutaneous)

- UFH, calciparine twice daily with dose adjusted to aPTT

Outcomes

DVT, major and minor bleeding, clinical symptoms of PE. DVT was verified by ${ }^{125} \mathrm{I}$ fibrinogen test and confirmed by bilateral phlebography if the former test was positive

Notes

Antiplatelet agents and oral anticoagulants were forbidden from 10 days before to 7 days after surgery. From recovery to discharge from the surgical ward, participants wore venous support stockings

\section{Risk of bias}

\begin{tabular}{|c|c|c|}
\hline Bias & Authors' judgement & Support for judgement \\
\hline $\begin{array}{l}\text { Random sequence generation (selection } \\
\text { bias) }\end{array}$ & Unclear risk & $\begin{array}{l}\text { Method of random sequence generation } \\
\text { not reported. Quote: "randomized study" }\end{array}$ \\
\hline Allocation concealment (selection bias) & Unclear risk & $\begin{array}{l}\text { Method of allocation concealment not re- } \\
\text { ported }\end{array}$ \\
\hline $\begin{array}{l}\text { Blinding of participants and personnel } \\
\text { (performance bias) } \\
\text { All outcomes }\end{array}$ & High risk & $\begin{array}{l}\text { The first phase of the study (up to day } \\
2 \text { post-surgery) was double-blinded, the } \\
\text { second phase was open. The outcomes } \\
\text { were evaluated at end of the second phase, } \\
\text { which may have introduced performance } \\
\text { bias. Quotes: "partially double blind"; "first } \\
\text { phase conducted double blind"; "second } \\
\text { open phase was conducted" }\end{array}$ \\
\hline
\end{tabular}

Primary prophylaxis for venous thromboembolism in patients undergoing cardiac or thoracic surgery (Review) 
Dahan 1990 (Continued)

\begin{tabular}{|c|c|c|}
\hline $\begin{array}{l}\text { Blinding of outcome assessment (detection } \\
\text { bias) } \\
\text { All outcomes }\end{array}$ & Unclear risk & $\begin{array}{l}\text { Not reported if outcome assessment was } \\
\text { blinded }\end{array}$ \\
\hline $\begin{array}{l}\text { Incomplete outcome data (attrition bias) } \\
\text { All outcomes }\end{array}$ & Unclear risk & $\begin{array}{l}\text { It is not clear nor reported if all included } \\
\text { participants completed follow-up nor the } \\
\text { exact duration of the observation period }\end{array}$ \\
\hline Selective reporting (reporting bias) & Low risk & $\begin{array}{l}\text { Study not registered. No published proto- } \\
\text { col. All outcomes mentioned in the meth- } \\
\text { ods section were addressed in the results } \\
\text { section }\end{array}$ \\
\hline Other bias & High risk & $\begin{array}{l}\text { Participant characteristics and risk factors } \\
\text { for VTE are poorly reported. It is not re- } \\
\text { ported if clinically suspected PE was objec- } \\
\text { tively confirmed. The timing of outcome } \\
\text { assessment was not reported and it was un- } \\
\text { clear if all participants completed follow- } \\
\text { up. Due to the very poor quality of report- } \\
\text { ing, we judged the risk to be high }\end{array}$ \\
\hline
\end{tabular}

Gallus 1973

\begin{tabular}{l|l}
\hline Methods & RCT \\
\hline Participants & $\begin{array}{l}\text { Patients }(\mathrm{n}=350) \text { over } 40 \text { years old admitted for elective surgery, or for emergency } \\
\text { surgery after fracture of the femoral neck and medical patients suspected of having } \\
\text { myocardial infarction. Mean age and gender were not reported separately for thoracic } \\
\text { surgery patients, which represented less than } 3 \% \text { of the study population }\end{array}$ \\
\hline Interventions & $\begin{array}{l}\text { - UFH } 5000 \text { IU sc } 2 \text { hours before surgery and then tid starting } 8 \text { to } 10 \text { hours after the } \\
\text { preoperative dose. Treatment was continued until the participant was fully mobile } \\
\text { - Control: no UFH }\end{array}$ \\
\hline Outcomes & $\begin{array}{l}\text { DVT and bleeding. DVT was objectively verified by }{ }^{125} \text { I-fibrinogen scanning performed } \\
\text { before surgery, within } 4 \text { hours of the end of surgery, and then daily until fully mobile } \\
\text { or discharge. Venography was performed if the }{ }^{125} \text { I-fibrinogen scanning suggested the } \\
\text { presence of thrombosis of the popliteal or femoral veins }\end{array}$ \\
\hline Notes & \begin{tabular}{l} 
- \\
\hline
\end{tabular}
\end{tabular}

\section{Risk of bias}

\section{Bias}

Random sequence generation (selection Unclear risk bias)

\section{Authors' judgement Support for judgement}

Method of random sequence generation not reported: “...were randomized separately" 


\section{Gallus 1973 (Continued)}

\begin{tabular}{|c|c|c|}
\hline Allocation concealment (selection bias) & Unclear risk & $\begin{array}{l}\text { Numbered, sealed envelopes. It remained unclear whether en- } \\
\text { velopes were opaque }\end{array}$ \\
\hline $\begin{array}{l}\text { Blinding of participants and personnel } \\
\text { (performance bias) } \\
\text { All outcomes }\end{array}$ & High risk & $\begin{array}{l}\text { Surgeons were unaware of study treatment. Participants were } \\
\text { not blinded and it is not reported if the other study personnel } \\
\text { were blinded }\end{array}$ \\
\hline $\begin{array}{l}\text { Blinding of outcome assessment (detection } \\
\text { bias) } \\
\text { All outcomes }\end{array}$ & Unclear risk & Not reported if outcome assessment was blinded \\
\hline $\begin{array}{l}\text { Incomplete outcome data (attrition bias) } \\
\text { All outcomes }\end{array}$ & Low risk & All participants included were considered in the analysis \\
\hline Selective reporting (reporting bias) & Low risk & $\begin{array}{l}\text { Study not registered. No published protocol. All outcomes men- } \\
\text { tioned in the methods section were addressed in the results sec- } \\
\text { tion }\end{array}$ \\
\hline Other bias & Unclear risk & $\begin{array}{l}\text { Participant characteristics are not reported. Unclear if partici- } \\
\text { pants were consecutively included }\end{array}$ \\
\hline
\end{tabular}

\section{Goldhaber 1995}

\begin{tabular}{l|l}
\hline Methods & RCT, multicentre \\
\hline Participants & $\begin{array}{l}\text { Consecutive patients }(\mathrm{n}=344) \text { undergoing coronary artery bypass without concomitant } \\
\text { valve surgery or coronary endarterectomy. Males: } 80 \% \text { in the IPC plus graded elastic } \\
\text { compression stockings and } 89 \% \text { in graded elastic compression stockings; age: } 63.2( \pm 9 . \\
7) \text { and } 64.3( \pm 9.8), \text { respectively }\end{array}$ \\
\hline
\end{tabular}

Interventions

- IPC (Sequential Compression Device) plus graded elastic compression stockings - Graded elastic compression stockings

The IPC device delivered compression of $45 \mathrm{mmHg}$ at the ankle, $40 \mathrm{mmHg}$ at the calf, and $30 \mathrm{mmHg}$ at the thigh. Prophylaxis was started within 4 hours postoperatively in most participants although in some participants prophylaxis was instituted 12 hours or more than 24 hours postoperatively

Outcomes

Pre-discharge DVT verified by colour Doppler compression ultrasonography on or after the 4 th postoperative day

Notes

All participants received aspirin $(325 \mathrm{mg} /$ day $)$

\section{Risk of bias}

Bias

Random sequence generation (selection Unclear risk bias)

\section{Authors' judgement Support for judgement}

Method of random sequence generation not reported 


\begin{tabular}{l|l|l}
\hline Allocation concealment (selection bias) & Unclear risk & Method of allocation concealment not reported \\
\hline $\begin{array}{l}\text { Blinding of participants and personnel } \\
\text { (performance bias) } \\
\text { All outcomes }\end{array}$ & High risk & $\begin{array}{l}\text { Blinding of participants and personnel is not reported but it is } \\
\text { likely an open study }\end{array}$ \\
\hline $\begin{array}{l}\text { Blinding of outcome assessment (detection } \\
\text { bias) } \\
\text { All outcomes }\end{array}$ & Unclear risk & Not reported if outcome assessment was blinded \\
\hline $\begin{array}{l}\text { Incomplete outcome data (attrition bias) } \\
\text { All outcomes }\end{array}$ & High risk & $\begin{array}{l}14 / 344 \text { participants (4\%) did not undergo pre-discharge ultra- } \\
\text { sonography }\end{array}$ \\
\hline Selective reporting (reporting bias) & Low risk & $\begin{array}{l}\text { Study not registered. No published protocol. All outcomes men- } \\
\text { tioned in the methods section were addressed in the results sec- } \\
\text { tion }\end{array}$ \\
\hline Other bias & Unclear risk & $\begin{array}{l}\text { Consecutive series of participants. Participant characteristics in- } \\
\text { completely reported }\end{array}$ \\
\hline
\end{tabular}

\section{Le Brigand 1981}

\begin{tabular}{|c|c|}
\hline Methods & Quasi-randomised, single-centre study \\
\hline Participants & Patients $(n=2420)$ of 21 to 70 years old undergoing thoracic surgery \\
\hline Interventions & $\begin{array}{l}\text { - Group A: UFH } 5000 \text { IU subcutaneous starting } 2 \text { hours and } 30 \text { minutes before surgery } \\
\text { and then twice daily } \\
\text { - Group B: UFH } 5000 \text { IU subcutaneous starting } 24 \text { to } 72 \text { hours after surgery then twice } \\
\text { daily } \\
\text { - Control: no UFH because of contraindication or minor surgical procedures } \\
\text { UFH doses were increased after the } 4 \text { th day to maintain a difference in partial throm- } \\
\text { boplastin time between participant and control between } 7 \text { and } 14 \text { seconds. UFH was } \\
\text { continued until discharge or for } 15 \text { to } 21 \text { days } \\
\text { UFH doses were increased postoperatively to therapeutic levels in case of clinically sus- } \\
\text { pected VTE }\end{array}$ \\
\hline Outcomes & $\begin{array}{l}\text { Fatal and non fatal PE. The authors did not report if all suspected cases of PE and/or } \\
\text { DVT underwent objective test confirmation }\end{array}$ \\
\hline Notes & - \\
\hline \multicolumn{2}{|l|}{ Risk of bias } \\
\hline Bias & Support for judgement \\
\hline
\end{tabular}




\section{Le Brigand 1981 (Continued)}

\begin{tabular}{|c|c|c|}
\hline $\begin{array}{l}\text { Random sequence generation (selection } \\
\text { bias) }\end{array}$ & High risk & $\begin{array}{l}\text { This was a quasi-randomised trial in which } \\
\text { participants were allocated to study treatment } \\
\text { according to the time of operation. However, } \\
\text { the time of surgery was influenced by the pres- } \\
\text { ence or absence of contraindications and the } \\
\text { type of surgical procedure (minor versus ma- } \\
\text { jor) }\end{array}$ \\
\hline Allocation concealment (selection bias) & High risk & $\begin{array}{l}\text { The allocation was not concealed but planned } \\
\text { and thus predictable }\end{array}$ \\
\hline $\begin{array}{l}\text { Blinding of participants and personnel } \\
\text { (performance bias) } \\
\text { All outcomes }\end{array}$ & High risk & $\begin{array}{l}\text { It is not explicitly reported whether person- } \\
\text { nel or participants were blinded but, given the } \\
\text { type of interventions considered, it is likely } \\
\text { that the study was open }\end{array}$ \\
\hline $\begin{array}{l}\text { Blinding of outcome assessment (detection } \\
\text { bias) } \\
\text { All outcomes }\end{array}$ & Unclear risk & $\begin{array}{l}\text { It is not explicitly reported whether outcome } \\
\text { assessment was blinded }\end{array}$ \\
\hline $\begin{array}{l}\text { Incomplete outcome data (attrition bias) } \\
\text { All outcomes }\end{array}$ & Low risk & $\begin{array}{l}\text { All included participants were considered in } \\
\text { the analysis }\end{array}$ \\
\hline Selective reporting (reporting bias) & Unclear risk & $\begin{array}{l}\text { Outcomes are not clearly specified in the re- } \\
\text { port and no protocol is available }\end{array}$ \\
\hline Other bias & High risk & $\begin{array}{l}\text { Participants in the study treatment groups had } \\
\text { a different prognosis before the surgical pro- } \\
\text { cedure and, accordingly, could have a differ- } \\
\text { ent risk of VTE. Clinically suspected cases of } \\
\text { PE were followed up clinically but it is not re- } \\
\text { ported if they all underwent an objective test } \\
\text { for PE }\end{array}$ \\
\hline
\end{tabular}

Marchetti 1983

\begin{tabular}{ll}
\hline Methods & RCT \\
\hline Participants & $\begin{array}{l}\text { Patients }(\mathrm{n}=29) \text { with lung cancer. } 18(62 \%) \text { were males; age between } 40 \text { and } 62 \text { years; } \\
\text { type of surgery: } 15(52 \%) \text { pneumonectomy, } 14(48 \%) \text { lobectomy }\end{array}$ \\
\hline Interventions & - UFH, calcium-heparin (5000 IU tid subcutaneous) \\
& $\begin{array}{l}\text { - Placebo } \\
\text { The duration of thromboprophylaxis is not reported }\end{array}$ \\
\hline Outcomes & Symptomatic VTE. It is unclear if the suspected cases were objectively verified \\
\hline Notes & -
\end{tabular}

Primary prophylaxis for venous thromboembolism in patients undergoing cardiac or thoracic surgery (Review)

Copyright $\odot 2015$ The Cochrane Collaboration. Published by John Wiley \& Sons, Ltd. 
Marchetti 1983 (Continued)

\section{Risk of bias}

\begin{tabular}{|c|c|c|}
\hline Bias & Authors' judgement & Support for judgement \\
\hline $\begin{array}{l}\text { Random sequence generation (selection } \\
\text { bias) }\end{array}$ & Unclear risk & Method of random sequence generation not reported \\
\hline Allocation concealment (selection bias) & Unclear risk & Method of allocation concealment not reported \\
\hline $\begin{array}{l}\text { Blinding of participants and personnel } \\
\text { (performance bias) } \\
\text { All outcomes }\end{array}$ & Unclear risk & $\begin{array}{l}\text { This is a placebo-controlled study, however, it is not reported if } \\
\text { the vials and solutions were indistinguishable }\end{array}$ \\
\hline $\begin{array}{l}\text { Blinding of outcome assessment (detection } \\
\text { bias) } \\
\text { All outcomes }\end{array}$ & Unclear risk & Not reported if outcome assessment was blinded \\
\hline $\begin{array}{l}\text { Incomplete outcome data (attrition bias) } \\
\text { All outcomes }\end{array}$ & Unclear risk & $\begin{array}{l}\text { It is unclear if all participants enrolled were subsequently con- } \\
\text { sidered in the analysis }\end{array}$ \\
\hline Selective reporting (reporting bias) & Unclear risk & $\begin{array}{l}\text { Outcomes are not clearly specified a priori and the protocol is } \\
\text { not available }\end{array}$ \\
\hline Other bias & Unclear risk & $\begin{array}{l}\text { Participant characteristics are not reported. Unclear if partici- } \\
\text { pants were consecutively included }\end{array}$ \\
\hline
\end{tabular}

Mirhosseini 2013

\begin{tabular}{ll}
\hline Methods & Prospective, double-blind, RCT \\
\hline Participants & $\begin{array}{l}\text { Patients }(\mathrm{n}=120) \text { undergoing elective off-pump coronary artery bypass graft. Mean } \\
\text { age: } 63.41 \pm 10.71 \text { heparin group and } 60.80 \pm 10.64 \text { heparin plus aspirin group. Male/ } \\
\text { female: } 42 / 18 \text { and } 41 / 19, \text { respectively }\end{array}$ \\
\hline Interventions & $\begin{array}{l}\text { Intervention: aspirin }(80 \text { mg daily orally) plus heparin }(5000 \text { U unfractionated heparin } \\
\text { every } 8 \text { hours subcutaneously) } \\
\text { Control: heparin }(5000 \text { U unfractionated heparin every } 8 \text { hours subcutaneously) } \\
\text { Study treatments were given from admission to discharge }\end{array}$ \\
\hline Outcomes & $\begin{array}{l}\text { Deep vein thrombosis, bleeding, and pulmonary embolism } \\
\text { All participants underwent right and left leg venous ultrasound examination during } \\
\text { hospitalisation }\end{array}$ \\
\hline Notes & Conflict of interest: none declared \\
\hline
\end{tabular}

\section{Risk of bias}


Mirhosseini 2013 (Continued)

\begin{tabular}{|c|c|c|}
\hline Bias & Authors' judgement & Support for judgement \\
\hline $\begin{array}{l}\text { Random sequence generation (selection } \\
\text { bias) }\end{array}$ & Unclear risk & $\begin{array}{l}\text { Method of sequence generation not reported. Quote: } \\
\text { "The patients were randomly assigned into two } \\
\text { groups" }\end{array}$ \\
\hline Allocation concealment (selection bias) & Unclear risk & $\begin{array}{l}\text { Method of allocation concealment not reported. } \\
\text { Quote: "The patients were randomly assigned into } \\
\text { two groups" }\end{array}$ \\
\hline
\end{tabular}

Blinding of participants and personnel Low risk (performance bias)

All outcomes

Quote: "The nurse (observer) who took the medicine to the patients (participants) and the patients themselves were blinded."

Blinding of outcome assessment (detection Unclear risk bias)

All outcomes

Blinding of outcome assessment not reported. Quote: "Ultrasonography was performed by an experienced and expert physician"

Incomplete outcome data (attrition bias) Low risk All outcomes

From Table 3 (Mirhosseini 2013), it appears that all participants randomised were included in the analysis

Selective reporting (reporting bias) Unclear risk

Outcomes are not clearly specified in the methods. Quote: “...post-operation early complications such as bleeding and pulmonary embolism (PE), were recorded."

Other bias

Unclear risk

It is unclear if participants were consecutively included. Risk factors for VTE are poorly reported

Pfisterer 1989

\begin{tabular}{|c|c|}
\hline Methods & Prospective, randomised study \\
\hline Participants & $\begin{array}{l}\text { Consecutive patients }(\mathrm{n}=285) \text { undergoing aortocoronary vein bypass surgery. Mean age } \\
\text { (range): } 55(35 \text { to } 75) \text { in the } 12 \text {-month VKAs, } 56(39 \text { to } 75) \text { in the } 3 \text {-month VKAs, } 57 \\
\text { ( } 40 \text { to } 69) \text { in the } 12 \text {-month platelet inhibitors, and } 55(35 \text { to } 70) \text { in the } 3 \text {-month platelet } \\
\text { inhibitors. The percentage of men was } 88 \%, 92 \%, 87 \% \text {, and } 94 \% \text { respectively }\end{array}$ \\
\hline Interventions & $\begin{array}{l}\text { - VKAs, phenprocoumon, for } 12 \text { months } \\
\text { - VKAs, phenprocoumon, for } 3 \text { months followed by placebo for } 9 \text { months } \\
\text { Phenprocoumon was started on the first postoperative day and given at doses adjusted } \\
\text { according to prothrombin time } \\
\text { - Platelet inhibitors, dipyridamole, and aspirin, for } 12 \text { months } \\
\text { - Platelet inhibitors, dipyridamole, and aspirin, for } 3 \text { months followed by placebo for } 9 \\
\text { months } \\
\text { Treatment with platelet inhibitors consisted of dipyridamole ( } 200 \text { mg twice daily) started } \\
2 \text { days preoperatively and followed by a combination of dipyridamole ( } 200 \mathrm{mg} \text { twice } \\
\text { daily) and aspirin ( } 25 \mathrm{mg} \text { twice daily) starting on the morning of surgery }\end{array}$ \\
\hline
\end{tabular}

Primary prophylaxis for venous thromboembolism in patients undergoing cardiac or thoracic surgery (Review) 
Pfisterer 1989 (Continued)

\begin{tabular}{ll} 
Outcomes & $\begin{array}{l}\text { Death, bleeding (major and minor), venous thromboembolism (unclear if symptomatic, } \\
\text { asymptomatic, or both), adverse events }\end{array}$ \\
\hline Notes & $\begin{array}{l}\text { All participants were fully heparinised during extracorporeal circulation with heparin } \\
\text { stopped immediately after bypass. The rate of preoperative treatment with anticoagulants } \\
\text { was 39\% in the } 12 \text {-month anticoagulants, } 40 \% \text { in the } 3 \text {-month anticoagulants, } 47 \% \\
\text { in the } 12 \text {-month platelet inhibitors, and } 29 \% \text { in the } 3 \text {-month platelet inhibitors. The } \\
\text { corresponding rates of preoperative use of platelet inhibitors were } 17 \%, 12 \%, 15 \%, \text { and } \\
21 \%\end{array}$ \\
\hline
\end{tabular}

Risk of bias

\begin{tabular}{|c|c|c|}
\hline Bias & Authors' judgement & Support for judgement \\
\hline $\begin{array}{l}\text { Random sequence generation (selection } \\
\text { bias) }\end{array}$ & Unclear risk & Method of random sequence generation not reported \\
\hline Allocation concealment (selection bias) & Unclear risk & $\begin{array}{l}\text { Numbered, sealed envelopes. It remained unclear } \\
\text { whether envelopes were opaque }\end{array}$ \\
\hline $\begin{array}{l}\text { Blinding of participants and personnel } \\
\text { (performance bias) } \\
\text { All outcomes }\end{array}$ & Low risk & Double-blind study \\
\hline $\begin{array}{l}\text { Blinding of outcome assessment (detection } \\
\text { bias) } \\
\text { All outcomes }\end{array}$ & Unclear risk & Not reported if outcome assessment was blinded \\
\hline $\begin{array}{l}\text { Incomplete outcome data (attrition bias) } \\
\text { All outcomes }\end{array}$ & High risk & $\begin{array}{l}36 \text { out of } 289 \text { participants ( } 12 \%) \text { were excluded from } \\
\text { the final analysis. } 2 \text { additional participants were lost to } \\
\text { follow-up }\end{array}$ \\
\hline Selective reporting (reporting bias) & Unclear risk & $\begin{array}{l}\text { Outcomes are not clearly listed in the methods and a } \\
\text { protocol was not available }\end{array}$ \\
\hline Other bias & Unclear risk & $\begin{array}{l}\text { Participant characteristics and VTE risk factors are not } \\
\text { clearly reported for the treatment groups. The authors } \\
\text { do not report if all clinically suspected cases of VTE } \\
\text { were systematically verified by objective testing }\end{array}$ \\
\hline
\end{tabular}

Primary prophylaxis for venous thromboembolism in patients undergoing cardiac or thoracic surgery (Review) 


\begin{tabular}{|c|c|c|}
\hline Methods & \multicolumn{2}{|l|}{ Randomised study } \\
\hline Participants & \multicolumn{2}{|c|}{$\begin{array}{l}\text { Consecutive patients }(\mathrm{n}=2551) \text { who underwent open heart surgery. The type of surgery } \\
\text { included coronary artery bypass surgery }(C A B G), C A B G \text { plus valve replacement, CABG } \\
\text { plus left ventricle aneurysmectomy, CABG plus automatic implantable cardiac defibril- } \\
\text { lator, valve replacement, shunt repair, and atrial myxoma resection. Mean age }( \pm S D) \text { : } \\
65 \pm 11 \text { in the UFH group and } 63 \pm 13 \text { in the UFH plus IPC group. Males: } 68 \% \text { and } \\
71 \% \text {, respectively }\end{array}$} \\
\hline Interventions & \multicolumn{2}{|c|}{$\begin{array}{l}\text { - UFH (5000 IU twice daily subcutaneous) } \\
\text { - UFH (5000 IU twice daily subcutaneous) plus bilateral IPC } \\
\text { Both mechanical and pharmacological prophylaxis was started immediately after surgery } \\
\text { and continued for } 4 \text { to } 5 \text { days or until participants were fully ambulatory }\end{array}$} \\
\hline Outcomes & \multicolumn{2}{|c|}{$\begin{array}{l}\text { Symptomatic pulmonary embolism objectively verified by ventilation perfusion scans, } \\
\text { pulmonary angiography, and/or autopsy }\end{array}$} \\
\hline Notes & \multicolumn{2}{|l|}{-} \\
\hline \multicolumn{3}{|l|}{ Risk of bias } \\
\hline Bias & Authors' judgement & Support for judgement \\
\hline $\begin{array}{l}\text { Random sequence generation (selection } \\
\text { bias) }\end{array}$ & Low risk & Participants were randomised using a table of random numbers \\
\hline Allocation concealment (selection bias) & Unclear risk & Method of allocation concealment not reported \\
\hline $\begin{array}{l}\text { Blinding of participants and personnel } \\
\text { (performance bias) } \\
\text { All outcomes }\end{array}$ & High risk & $\begin{array}{l}\text { Blinding of participants and personnel not reported, but the } \\
\text { study is likely open }\end{array}$ \\
\hline $\begin{array}{l}\text { Blinding of outcome assessment (detection } \\
\text { bias) } \\
\text { All outcomes }\end{array}$ & Unclear risk & Not reported if outcome assessment was blinded \\
\hline $\begin{array}{l}\text { Incomplete outcome data (attrition bias) } \\
\text { All outcomes }\end{array}$ & High risk & $\begin{array}{l}235 \text { of the } 2786 \text { participants randomised }(8.4 \%) \text { were subse- } \\
\text { quently excluded from the analysis }\end{array}$ \\
\hline Selective reporting (reporting bias) & Unclear risk & $\begin{array}{l}\text { Apart from symptomatic PE, other outcomes are not reported } \\
\text { and no protocol is available }\end{array}$ \\
\hline Other bias & Unclear risk & $\begin{array}{l}\text { Participant characteristics and risk factors for VTE are not re- } \\
\text { ported in detail }\end{array}$ \\
\hline
\end{tabular}


Riess 2007

\begin{tabular}{|c|c|}
\hline Methods & Randomised study \\
\hline Participants & $\begin{array}{l}\text { Patients }(n=20) \text { with coronary artery disease requiring coronary artery bypass grafting } \\
\text { with at least } 2 \text { bypass grafts. Mean age }( \pm S D): 55.0 \pm 0.6 \text { in the lepirudin group and } 59 \text {. } \\
0 \pm 0.5 \text { in the UFH group }\end{array}$ \\
\hline Interventions & $\begin{array}{l}\text { - Lepirudin }(0.25 \mathrm{mg} / \mathrm{kg} \text { intravenous bolus and } 0.2 \mathrm{mg} / \mathrm{kg} \text { added to cardiopulmonary } \\
\text { bypass priming followed by additional } 5 \mathrm{mg} \text { lepirudin boluses to maintain lepirudin } \\
\text { concentrations above } 4 \mu \mathrm{g} / \mathrm{mL} \text { ) monitored using the ecarin clotting time. During the first } \\
2 \text { days after operation, anticoagulation was performed with an intravenous and aPTT } \\
\text { adjusted (target range: } 45 \text { to } 60 \text { seconds) lepirudin infusion (initial dosage } 0.05 \mathrm{mg} / \mathrm{kg} \text { ) } \\
\text { From the third postoperative day lepirudin was given subcutaneously until complete } \\
\text { mobilisation } \\
\text { - UFH ( } 400 \mathrm{IU} / \mathrm{kg} \text { bolus prior to connection to the cardiopulmonary bypass followed } \\
\text { by additional } 5000 \mathrm{IU} \text { UFH boluses to maintain an activated clotting time above } 400 \\
\text { seconds). After the end of the operation, UFH ( } 4 \mathrm{IU} / \mathrm{kg} / \mathrm{h} \text { intravenous) starting } 4 \text { hours } \\
\text { after surgery if the aPTT was below } 45 \text { seconds. UFH was increased to } 8 \mathrm{IU} / \mathrm{kg} / \mathrm{h} 24 \\
\text { hours later, and } 48 \text { hours after the operation UFH ( } 7500 \text { IU twice daily) was given } \\
\text { subcutaneously until complete mobilisation }\end{array}$ \\
\hline
\end{tabular}

Outcomes

Blood clots within the cardiopulmonary bypass circuits, perioperative blood loss, haematologic values, blood chemistry, coagulation values

Notes

After the end of subcutaneous anticoagulation treatment, participants in both groups received acetylsalicylic acid $(100 \mathrm{mg} /$ day $)$

\section{Risk of bias}

Bias

Random sequence generation (selection Unclear risk bias)
Method of random sequence generation not reported Method of allocation concealment not reported

Blinding of participants and personnel High risk Open study (performance bias)

All outcomes

Blinding of outcome assessment (detection Unclear risk bias)

Open study, but blinding of outcome assessors not specifically addressed

All outcomes

Incomplete outcome data (attrition bias) Low risk

All participants enrolled were subsequently considered in the analysis

Selective reporting (reporting bias) Low risk
Study not registered. No published protocol. All outcomes mentioned in the methods section were addressed in the results section 
Riess 2007 (Continued)

\begin{tabular}{|c|c|c|}
\hline Other bias & Unclear risk & $\begin{array}{l}\text { Participant characteristics and risk factors for VTE are not re- } \\
\text { ported. It is not reported if all participants with clinically sus- } \\
\text { pected DVT and/or PE were systematically verified by objective } \\
\text { testing }\end{array}$ \\
\hline
\end{tabular}

Rizzi 1987

\begin{tabular}{ll} 
Methods & Randomised study \\
\hline Participants & $\begin{array}{l}\text { Consecutive patients }(\mathrm{n}=184) \text { undergoing thoracic surgery. Males: } 79 \% \text { in the defi- } \\
\text { brotide group and } 81 \% \text { in the UFH group. Type of surgery: exploratory thoracotomy } \\
18 \% \text { and } 15 \%, \text { lung excision for lung cancer } 20 \% \text { and } 24 \%, \text { lobectomy } 33 \% \text { and } 41 \%, \\
\text { pleurectomy } 13 \% \text { and } 10 \%, \text { cancer excision } 14 \% \text { and } 9 \%, \text { other } 2 \% \text { and } 0 \%\end{array}$ \\
\hline Interventions & - Defibrotide 400 mg twice daily intravenous \\
& - UFH, calcium-heparin 5000 IU tid subcutaneous \\
& Thromboprophylaxis was started the day before surgery and continued until there was \\
& a mobility considered sufficient to reduce the risk of venous stasis (mean of 7.7 days in \\
the group treated with defibrotide and 7.8 days in the UFH group)
\end{tabular}

Outcomes

Speed of wound repair, symptomatic VTE, bleeding. It is not reported if VTE was objectively verified

Notes

Risk of bias

Bias

Authors' judgement Support for judgement

Random sequence generation (selection Low risk bias)

\begin{tabular}{l|l|l}
\hline Allocation concealment (selection bias) & Unclear risk & Method of allocation concealment not reported \\
\hline $\begin{array}{l}\text { Blinding of participants and personnel } \\
\text { (performance bias) }\end{array}$ & High risk & Open study \\
\hline \begin{tabular}{l} 
All outcomes \\
\hline
\end{tabular}
\end{tabular}

Blinding of outcome assessment (detection Unclear risk Not reported if outcome assessment was blinded

bias)

All outcomes

Incomplete outcome data (attrition bias) Unclear risk

All outcomes

Selective reporting (reporting bias)
Low risk
Sequence was generated with the use of a random list

It is unclear if all participants enrolled were subsequently considered in the analysis

Study not registered. No published protocol. All outcomes mentioned in the methods section were addressed in the results section 
Rizzi 1987 (Continued)

\begin{tabular}{l|l|l}
\hline Other bias & Unclear risk & Participant characteristics are not reported
\end{tabular}

\section{van Geloven 1977}

\begin{tabular}{|c|c|c|}
\hline Methods & \multicolumn{2}{|c|}{ Randomised, double-blind study } \\
\hline Participants & \multicolumn{2}{|c|}{$\begin{array}{l}\text { Patients }(n=331) \text { over } 40 \text { years undergoing elective laparotomy, thoracotomy }(n=83 \text {, } \\
26 \%) \text {, or hip replacement }\end{array}$} \\
\hline Interventions & \multicolumn{2}{|c|}{$\begin{array}{l}\text { - Postoperative VKAs (Sintrom, acenocoumarol started on the first postoperative day) } \\
\text { plus a placebo dextran infusion (during the operation and } 24 \text { hours on the first post- } \\
\text { operative day) plus placebo UFH (twice daily subcutaneous starting } 2 \text { hours before the } \\
\text { operation) } \\
\text { - Dextran ( } 500 \mathrm{ml} \text { dextran } 40 \text { and } 500 \mathrm{ml} 24 \text { hours later on the first postoperative day) } \\
\text { plus postoperative VKAs (Sintrom, acenocoumarol started on the first postoperative day) } \\
\text { plus placebo UFH (twice daily subcutaneous starting } 2 \text { hours before the operation) } \\
\text { - UFH ( } 5000 \mathrm{IU} \text { twice daily subcutaneous starting } 2 \text { hours before the operation) plus } \\
\text { placebo VKAs (Sintrom, acenocoumarol started on the first postoperative day) plus a } \\
\text { placebo dextran infusion (during the operation and } 24 \text { hours on the first postoperative } \\
\text { day) } \\
\text { - UFH ( } 5000 \text { IU twice daily subcutaneous starting } 2 \text { hours before the operation) plus } \\
\text { postoperative VKAs (acenocoumarol) plus a placebo dextran infusion (during the oper- } \\
\text { ation and } 24 \text { hours on the first postoperative day). UFH was continued for } 4 \text { days and } \\
\text { then replaced by placebo } \\
\text { It is not reported how long the study treatments were continued after the operation }\end{array}$} \\
\hline Outcomes & \multicolumn{2}{|c|}{$\begin{array}{l}\text { DVT, PE, blood loss. All participants with a positive }{ }^{125} \text { I fibrinogen uptake scan under- } \\
\text { went a chest X-ray and pulmonary perfusion scintigraphy with }{ }^{99 m} \text { Tc-labelled macroag- } \\
\text { gregates of human albumin }\end{array}$} \\
\hline Notes & \multicolumn{2}{|c|}{$\begin{array}{l}\text { The authors report that lower than expected doses of heparin (about } 4000 \text { IU twice } \\
\text { daily) were accidentally administered during the first part of the study in the heparin } \\
\text { groups }\end{array}$} \\
\hline \multicolumn{3}{|l|}{ Risk of bias } \\
\hline Bias & Authors' judgement & Support for judgement \\
\hline $\begin{array}{l}\text { Random sequence generation (selection } \\
\text { bias) }\end{array}$ & Low risk & Table of random numbers \\
\hline Allocation concealment (selection bias) & Unclear risk & Method of allocation concealment not reported \\
\hline $\begin{array}{l}\text { Blinding of participants and personnel } \\
\text { (performance bias) } \\
\text { All outcomes }\end{array}$ & Low risk & Double-blind study \\
\hline
\end{tabular}

Primary prophylaxis for venous thromboembolism in patients undergoing cardiac or thoracic surgery (Review) 


\begin{tabular}{|c|c|c|}
\hline $\begin{array}{l}\text { Blinding of outcome assessment (detection } \\
\text { bias) } \\
\text { All outcomes }\end{array}$ & Unclear risk & Not reported if outcome assessment was blinded \\
\hline $\begin{array}{l}\text { Incomplete outcome data (attrition bias) } \\
\text { All outcomes }\end{array}$ & High risk & $\begin{array}{l}18 \text { of the } 331 \text { participants enrolled }(5.4 \%) \text { were ex- } \\
\text { cluded from the analysis }\end{array}$ \\
\hline Selective reporting (reporting bias) & Low risk & $\begin{array}{l}\text { Study not registered. No published protocol. All } \\
\text { outcomes mentioned in the methods section were } \\
\text { addressed in the results section }\end{array}$ \\
\hline Other bias & Unclear risk & $\begin{array}{l}\text { Participant characteristics and risk factors for VTE } \\
\text { are not reported. It is not reported if all participants } \\
\text { with clinically suspected DVT and/or PE were sys- } \\
\text { tematically verified by objective testing. Not clear if } \\
\text { participants were consecutively enrolled }\end{array}$ \\
\hline
\end{tabular}

\author{
AE: adverse events \\ aPTT: activated partial thromboplastin time \\ DVT: deep vein thrombosis \\ IPC: intermittent pneumatic compression \\ LMWH: low molecular weight heparin \\ od: once daily \\ PE: pulmonary embolism \\ RCT: randomised controlled trial \\ SAE: serious adverse events \\ sc: subcutaneous \\ SD: standard deviation \\ tid: three times daily \\ VKA: vitamin $\mathrm{K}$ antagonist \\ VTE: venous thromboembolism
}

\title{
Characteristics of excluded studies [ordered by study ID]
}

\begin{tabular}{ll}
\hline Study & Reason for exclusion \\
\hline Acar 1996 & Intervention not used for primary prophylaxis of VTE \\
\hline Ageno 2001 & Intervention not used for primary prophylaxis of VTE \\
\hline Altman 1991 & Intervention not used for primary prophylaxis of VTE \\
\hline Altman 1996 & Intervention not used for primary prophylaxis of VTE
\end{tabular}


(Continued)

\begin{tabular}{|c|c|}
\hline Aramendi 2005 & Intervention not used for primary prophylaxis of VTE \\
\hline Attaran 2010 & Intervention not used for primary prophylaxis of VTE \\
\hline Blair 1994 & Not a RCT and intervention not used for primary prophylaxis of VTE \\
\hline Buchanan 2002 & Intervention not used for primary prophylaxis of VTE \\
\hline Cade 1983 & $\begin{array}{l}\text { Both oesophagus and thoracic lung surgery included and data are not provided separately for thoracic lung } \\
\text { surgery }\end{array}$ \\
\hline Cade 1987 & Both abdominal and thoracic surgery included and data are not provided separately for thoracic surgery \\
\hline Chesebro 1983 & Intervention not used for primary prophylaxis of VTE \\
\hline Colli 2007 & Intervention not used for primary prophylaxis of VTE \\
\hline Dale 1977 & Intervention not used for primary prophylaxis of VTE \\
\hline Dauphin 2008 & Intervention not used for primary prophylaxis of VTE \\
\hline Di Carlo 1999 & $\begin{array}{l}\text { Abdominal, gynaecological, urological, and thoracic surgery included and data not provided separately for } \\
\text { thoracic surgery }\end{array}$ \\
\hline DiSerio 1985 & $\begin{array}{l}\text { Patients undergoing mastectomy and other (non-specified) types of thoracic surgery not further specified are } \\
\text { analysed together with those receiving thoracic lung surgery and data are not provided separately for thoracic } \\
\text { lung surgery }\end{array}$ \\
\hline Dixon 2008 & Intervention not used for primary prophylaxis of VTE \\
\hline Dong 2011 & Intervention not used for primary prophylaxis of VTE \\
\hline Dyke 2006 & Intervention not used for primary prophylaxis of VTE \\
\hline Eitz 2008 & Intervention not used for primary prophylaxis of VTE \\
\hline Francis 2003 & Intervention not used for primary prophylaxis of VTE \\
\hline Gallus 1993 & Both abdominal and thoracic surgery included and data not provided separately for thoracic surgery \\
\hline Ghaffari 2011 & Intervention not used for primary prophylaxis of VTE \\
\hline Gherli 2004 & Intervention not used for primary prophylaxis of VTE \\
\hline Gohlke 1981 & Intervention not used for primary prophylaxis of VTE \\
\hline Haas 2012 & Not a RCT \\
\hline
\end{tabular}


(Continued)

\begin{tabular}{|c|c|}
\hline Hartshorn 1969 & Not relevant to the target population \\
\hline Hassouna 2000 & Intervention not used for primary prophylaxis of VTE \\
\hline Hayashi 1994 & Intervention not used for primary prophylaxis of VTE \\
\hline Hering 2005 & Intervention not used for primary prophylaxis of VTE \\
\hline Iliuta 2003 & Intervention not used for primary prophylaxis of VTE \\
\hline Jackaman 1978 & Not a RCT \\
\hline Jensen 2004 & Population included represented by children \\
\hline Kaiser 1981 & Intervention not used for primary prophylaxis of VTE \\
\hline Kawazoe 1990 & Not a RCT and intervention not used for primary prophylaxis of VTE \\
\hline Keidan 2004 & Population included represented by children \\
\hline Koertke 2000 & Intervention not used for primary prophylaxis of VTE \\
\hline Koertke 2003 & Intervention not used for primary prophylaxis of VTE \\
\hline Koertke 2007 & Intervention not used for primary prophylaxis of VTE \\
\hline Koertke 2010 & Intervention not used for primary prophylaxis of VTE \\
\hline Konkle 2001 & $\begin{array}{l}\text { Not a RCT: randomisation regards only preoperative heparin, whereas post-surgery prophylaxis is not assigned } \\
\text { randomly }\end{array}$ \\
\hline Kuitunen 1997 & Intervention not used for primary prophylaxis of VTE \\
\hline Körtke 2001 & Not a RCT and intervention not used for primary prophylaxis of VTE \\
\hline Laffort 2000 & Intervention not used for primary prophylaxis of VTE \\
\hline Liezorovicz 1991 & $\begin{array}{l}\text { Abdominal, gynaecological, urological, and thoracic surgery included and data not provided separately for } \\
\text { thoracic surgery }\end{array}$ \\
\hline Ljungstrom 1985 & Not a RCT and intervention not used for primary prophylaxis of VTE \\
\hline Mehta 2007 & $\begin{array}{l}\text { Population included not undergoing surgery cardiac or thoracic surgery, and intervention not used for primary } \\
\text { prophylaxis of VTE }\end{array}$ \\
\hline Meschengieser 1997 & Intervention not used for primary prophylaxis of VTE \\
\hline
\end{tabular}

Primary prophylaxis for venous thromboembolism in patients undergoing cardiac or thoracic surgery (Review) 
(Continued)

\begin{tabular}{|c|c|}
\hline Mirow 2001 & Intervention not used for primary prophylaxis of VTE \\
\hline Mok 1985 & Intervention not used for primary prophylaxis of VTE \\
\hline Monagle 2011 & Population included represented by children \\
\hline Montalescot 2000 & Not a RCT and intervention not used for primary prophylaxis of VTE \\
\hline Ovrum 1996 & Intervention not used for primary prophylaxis of VTE \\
\hline Pappalardo 2006 & Intervention not used for primary prophylaxis of VTE \\
\hline Pengo 1997 & Intervention not used for primary prophylaxis of VTE \\
\hline Pengo 2007 & Intervention not used for primary prophylaxis of VTE \\
\hline Pessotti 2012 & Population included represented by children \\
\hline Pogliani 1982 & Intervention not used for primary prophylaxis of VTE \\
\hline Pogliani 1993 & Intervention not used for primary prophylaxis of VTE \\
\hline Pruefer 2001 & Intervention not used for primary prophylaxis of VTE \\
\hline Rafiq 2013 & Intervention not used for primary prophylaxis of VTE \\
\hline Renda 2007 & Intervention not used for primary prophylaxis of VTE \\
\hline Samama 1988 & $\begin{array}{l}\text { Abdominal, gynaecological, urological, and thoracic surgery included and data not provided separately for } \\
\text { thoracic surgery }\end{array}$ \\
\hline Saour 1990 & Intervention not used for primary prophylaxis of VTE \\
\hline Schlitt 2003 & Intervention not used for primary prophylaxis of VTE \\
\hline Segesser 1992 & Intervention not used for primary prophylaxis of VTE \\
\hline Starkman 1982 & Intervention not used for primary prophylaxis of VTE \\
\hline Swiniarska 2009 & Intervention not used for primary prophylaxis of VTE \\
\hline Torella 2010 & Intervention not used for primary prophylaxis of VTE \\
\hline Turpie 1988 & Intervention not used for primary prophylaxis of VTE \\
\hline Turpie 1993 & Intervention not used for primary prophylaxis of VTE \\
\hline
\end{tabular}

Primary prophylaxis for venous thromboembolism in patients undergoing cardiac or thoracic surgery (Review)

Copyright $\odot 2015$ The Cochrane Collaboration. Published by John Wiley \& Sons, Ltd. 
(Continued)

\begin{tabular}{ll}
\hline van der Meer 1994 & Intervention not used for primary prophylaxis of VTE \\
\hline Voith 1997 & Intervention not used for primary prophylaxis of VTE \\
\hline Walenga 2001 & Intervention not used for primary prophylaxis of VTE \\
\hline Warkentin 2013 & Intervention not used for primary prophylaxis of VTE \\
\hline Xia 2011 & General surgery included and data not provided separately for thoracic surgery \\
\hline
\end{tabular}

RCT: randomised controlled trial

VTE: venous thromboembolism

\section{Characteristics of studies awaiting assessment [ordered by study ID]}

\section{Avidan 2011}

\begin{tabular}{ll}
\hline Methods & Randomised, double-blind study \\
\hline Participants & Adult patients $(\mathrm{n}=120)$ scheduled for elective cardiac $(\mathrm{n}=40)$ or thoracic surgery $(\mathrm{n}=80)$ \\
\hline Interventions & $\begin{array}{l}\text { Intervention: desirudin (Iprivask; Canyon Pharmaceuticals, Hunt Valley, Maryland) } 15 \text { mg sc twice daily } \\
\text { Control: unfractionated heparin } 5000 \text { units sc thrice daily with saline placebo given once daily } \\
\text { Duration of thrombosis prophylaxis was determined by the treating physician } \\
\text { Quote: "Both treatment groups also received mechanical prophylaxis via sequential compression devices. All patients } \\
\text { who underwent cardiac surgery received heparin during the procedure. For these patients, enrolment into the study } \\
\text { occurred if thrombosis prophylaxis was required at any time from postoperative day } 1 \text { through the end of hospitaliza- } \\
\text { tion and if no exclusion criteria were met. Thoracic surgery patients who were assigned to the heparin treatment arm } \\
\text { received heparin during the procedure; those assigned to the desirudin arm received desirudin during the procedure. } \\
\text { For these patients, enrolment occurred when the patient received the first dose of thrombosis prophylaxis either pre- } \\
\text { or intra-operatively." }\end{array}$ \\
\hline Outcomes & $\begin{array}{l}\text { Primary outcome: incidence of new antibody formation directed against platelet factor } 4 \text { (PF4)/heparin complex } \\
\text { Secondary outcomes included bleeding and thrombotic complications (symptomatic and asymptomatic deep vein } \\
\text { thrombosis or symptomatic pulmonary embolism) }\end{array}$ \\
\hline Notes & $\begin{array}{l}\text { This study included patients undergoing surgery types representing exclusion criteria for this review. The authors } \\
\text { have been contacted to try to obtain data for the patients matching the review inclusion criteria }\end{array}$ \\
\hline
\end{tabular}

Primary prophylaxis for venous thromboembolism in patients undergoing cardiac or thoracic surgery (Review) 
Ciavarella 1985

Methods Double-blind study. Other methodological aspects are unclear since the full text is not yet available

Participants Patients with prosthetic heart valves

Interventions Dipyridamole and warfarin

Outcomes Unclear, full text not retrieved

Notes -

Rajah 1983

\begin{tabular}{ll}
\hline Methods & RCT \\
\hline Participants & Patients $(\mathrm{n}=327)$ undergoing major thoracic surgery \\
\hline Interventions & $\begin{array}{l}\text { - Heparin } 5000 \text { IU subcutaneous } \\
\text { - Low-dose heparin } 2500 \text { IU subcutaneous plus dihydroergotamine } 0.5 \text { mg subcutaneous } \\
\text { - No thromboprophylaxis } \\
\text { Study treatment was given tid for } 10 \text { days after surgery }\end{array}$ \\
\hline Outcomes & $\begin{array}{l}\text { DVT. }{ }^{125} \text { I fibrinogen uptake scan was used to diagnose DVT and all patients with a positive scan had a bilateral } \\
\text { ascending venography to confirm the diagnosis }\end{array}$ \\
\hline Notes & $\begin{array}{l}\text { The type of thoracic surgery is not specified thus it remains unclear whether this study fulfils the inclusion criteria } \\
\text { of the review }\end{array}$ \\
\hline
\end{tabular}

Ranucci 2013

\begin{tabular}{ll}
\hline Methods & Phase II, single-centre, single-blinded, RCT \\
\hline Participants & $\begin{array}{l}\text { Patients of at least } 18 \text { years undergoing an elective heart surgery with cardiopulmonary bypass. To be eligible, patients } \\
\text { had to present a baseline antithrombin activity }<100 \% \text { and }>60 \%\end{array}$ \\
\hline Interventions & $\begin{array}{l}\text { Intervention: antithrombin (purified human plasma derived antithrombin, Anbinex; Instituto Grifols S.A., Barcelona, } \\
\text { Spain) administered immediately after anaesthesia induction as a single dose targeted to achieve a level of antithrombin } \\
\text { activity of } 120 \% \\
\text { Control: no antithrombin } \\
\text { Quote: "Unfractionated heparin was intraoperatively administered before cardiopulmonary bypass to reach and main- } \\
\text { tain a target activated clotting time of } 450 \text { seconds during CPB." “..Further heparin doses during cardiopulmonary } \\
\text { bypass were administered as a bolus of } 100 \text { IU/kg if needed to maintain the desired activated clotting time value." }\end{array}$ \\
\hline Outcomes & $\begin{array}{l}\text { Primary: antithrombin activity levels at admission and percentage of patients with antithrombin activity < } \\
\text { Secondary efficacy: heparin resistance, blood loss, number of plasma and packed red cells units needed during the } \\
\text { intensive care unit (ICU) stay, mechanical ventilation duration, ICU and hospital stay } \\
\text { Safety outcomes: surgical re-exploration, low cardiac output syndrome, myocardial infarction, adverse neurologic } \\
\text { outcome, acute kidney injury, thromboembolic events (myocardial infarction, stroke, mesenteric infarction, or pe- } \\
\text { ripheral or pulmonary thromboembolism), and in-hospital mortality }\end{array}$
\end{tabular}

Primary prophylaxis for venous thromboembolism in patients undergoing cardiac or thoracic surgery (Review) 
Ranucci 2013 (Continued)

Notes This study reported pulmonary embolism as a secondary safety outcome in the methods section, but no information is provided in the results section. The authors have been contacted to try to obtain this information

DVT: deep vein thrombosis

RCT: randomised clinical trial

Characteristics of ongoing studies [ordered by study ID]

Dixon 2013

\begin{tabular}{ll}
\hline Trial name or title & $\begin{array}{l}\text { "Use of heparin to prevent lung microvascular thrombosis in patients administered aprotinin undergoing } \\
\text { cardiac surgery for ischemic heart disease for ischemic heart disease" }\end{array}$ \\
\hline Methods & Phase II, RCT, blinded \\
\hline Participants & Patients 18 years or older undergoing elective cardiac surgery \\
\hline Interventions & $\begin{array}{l}\text { Intervention: heparin intravenous infusion }(18 \mathrm{U} / \mathrm{kg} / \mathrm{hr}) \text { over the } 3 \text { hours prior to commencement of surgery } \\
\text { Control: placebo (equivalent infusion of } 5 \% \text { dextrose with no active drug }\end{array}$ \\
\hline Outcomes & $\begin{array}{l}\text { Primary outcome: evidence of microvascular thrombosis on lung biopsy taken at the end of cardiac surgery } \\
\text { Secondary outcome: alveolar dead space }\end{array}$ \\
\hline Starting date & 2006 \\
\hline Contact information & barry.dixon@svhm.org.au \\
\hline Notes & Trial ID: ACTRN1260600328572. The study is not yet recruiting \\
\hline
\end{tabular}

Meyer 2011

Trial name or title "Effect of low molecular weight heparin on survival of stage I, II or IIIA non small cell lung cancer. A multicenter, open, randomised controlled trial"

Methods Phase III, prospective, multicentric, randomised, open trial in parallel groups with a blind adjudication of all endpoint criteria

Participants Patients with completely resected non-small cell lung cancer of stage I, II, or IIIA T3N1 confirmed by histology. Patients who had preoperative chemotherapy, those who are selected for adjuvant chemotherapy and those who are not candidates for adjuvant chemotherapy (because they have a contraindication to chemotherapy or they have a stage I cancer) are eligible for the study

Interventions Tinzaparin sodium $100 \mathrm{UI} / \mathrm{kg}$ od for 12 weeks along with usual postoperative care including chemotherapy Control: usual postoperative care including chemotherapy 


\section{Meyer 2011 (Continued)}

\begin{tabular}{l|l}
\hline Outcomes & $\begin{array}{l}\text { Primary endpoint: overall 3-year mortality } \\
\text { Secondary outcomes: major bleeding time, symptomatic VTE, cancer-related mortality, disease-free survival }\end{array}$ \\
\hline Starting date & June 2007 \\
\hline Contact information & Guy Meyer guy.meyer@egp.aphp.fr \\
\hline Notes & ClinicalTrials.gov Identifier: NCT00475098 \\
\hline
\end{tabular}

\section{NCT00789399}

Trial name or title

"A study of the efficacy of preventive dosing of fondaparinux sodium versus placebo for the prevention of venous thromboembolism (VTE) in patients undergoing coronary bypass surgery receiving routine mechanical prophylaxis"

Methods $\quad$ Prospective, single-centre, phase II randomised study, single-blind (investigator)

Participants Consecutive patients aged 18 years or older undergoing isolated or redo isolated CABG

Interventions $\quad$ Fondaparinux $(2.5 \mathrm{mg}$ subcutaneous daily) starting $12+/-2$ hours post-wound closure or the following day in the morning (at the discretion of the cardiothoracic surgeon). The second dose would be administered 24 hours later and the dosing will then be once a day

The group randomised to placebo will receive subcutaneous equivalent volume of isotonic saline at the same time points described above

Patients will receive fondaparinux or placebo for a total of 3 to 9 days post CABG with day 1 being the day of surgery. The drug will be discontinued if the patient is discharged before day 9 . If the patient stays for more than 9 days inside hospital, a duplex would be obtained per protocol and further DVT prevention measures would be instituted per the discretion of treating physician

Both groups will receive routine mechanical prophylaxis as determined by the treating physicians

Outcomes $\quad$ Primary outcome: rate of asymptomatic proximal DVT

Secondary outcome: asymptomatic distal DVT

Starting date $\quad$ October 2009

Contact information Cynthia Deitrick (cdeitrick@prairieresearch.com). Principal investigator: Raghu Kolluri

Notes ClinicalTrials.gov identifier: NCT00789399

\section{NCT01267305}

Trial name or title "The impact of different anticoagulant therapy on haemorrhage and coagulation after thoracic surgery"

Methods Randomised, open-label 


\section{NCT01267305 (Continued)}

$\begin{array}{ll}\text { Participants } & \text { Patients with a clinical diagnosis of oesophageal carcinoma and planned for oesophagectomy or patients with } \\ \text { a clinical diagnosis of lung carcinoma and planned for lung resection }\end{array}$

Interventions $\quad$ Nadroparin Calcium 4100 Axa IU once daily after operation

Nadroparin Calcium 4100 Axa IU twice daily after operation

Fondaparinux $2.5 \mathrm{mg}$ IH once daily after operation

Outcomes Primary outcome: thromboelastography values

Secondary outcomes: bleeding quantity of chest drainage, incidence rate of DVT, in-hospital mortality

Starting date January 2011

Contact information Principal investigator: Lizhen Xuan, Shanghai Zhongshan Hospital

Notes

ClinicalTrials.gov Identifier: NCT01267305

CABG: coronary artery bypass surgery

DVT: deep vein thrombosis

HIT: heparin-induced thrombocytopaenia

OD: once daily

VTE: venous thromboembolism 
DATA ANDANALYSES

Comparison 1. Cardiac surgery: symptomatic VTE

\begin{tabular}{|c|c|c|c|c|}
\hline Outcome or subgroup title & $\begin{array}{l}\text { No. of } \\
\text { studies }\end{array}$ & $\begin{array}{c}\text { No. of } \\
\text { participants }\end{array}$ & Statistical method & Effect size \\
\hline $1 \mathrm{UFH}$ versus $\mathrm{LMWH}$ & 1 & & Risk Ratio (IV, Random, 95\% CI) & Totals not selected \\
\hline $\begin{array}{l}2 \text { Intermittent pneumatic } \\
\text { compression plus graded elastic } \\
\text { compression stockings versus } \\
\text { graded elastic compression } \\
\text { stockings }\end{array}$ & 1 & & Risk Ratio (IV, Random, 95\% CI) & Totals not selected \\
\hline 3 UFH plus IPC versus UFH & 1 & & Risk Ratio (IV, Random, 95\% CI) & Totals not selected \\
\hline 4 UFH plus aspirin versus UFH & 1 & & Risk Ratio (IV, Random, 95\% CI) & Totals not selected \\
\hline
\end{tabular}

Comparison 2. Thoracic surgery: symptomatic VTE

\begin{tabular}{lcclc} 
Outcome or subgroup title & $\begin{array}{c}\text { No. of } \\
\text { studies }\end{array}$ & $\begin{array}{c}\text { No. of } \\
\text { participants }\end{array}$ & Statistical method & Effect size \\
\hline 1 Heparin versus inactive control & 3 & 2458 & Risk Ratio (IV, Random, 95\% CI) & $6.71[0.40,112.65]$ \\
$\quad 1.1$ UFH versus placebo & 1 & 29 & Risk Ratio (IV, Random, 95\% CI) & $0.0[0.0,0.0]$ \\
1.2 UFH versus no UFH & 2 & 2429 & Risk Ratio (IV, Random, 95\% CI) & $6.71[0.40,112.65]$ \\
2 UFH versus defibrotide & 1 & & Risk Ratio (IV, Random, 95\% CI) & Totals not selected \\
3 UFH versus LMWH & 1 & & Risk Ratio (IV, Random, 95\% CI) & Totals not selected \\
4 Fixed-dose LMWH versus & 1 & & Risk Ratio (IV, Random, 95\% CI) & Totals not selected \\
$\quad$ weight-adjusted dose LMWH & & & & \\
\hline
\end{tabular}

\section{Comparison 3. Cardiac surgery: major bleeding}

\begin{tabular}{|c|c|c|c|c|}
\hline Outcome or subgroup title & $\begin{array}{l}\text { No. of } \\
\text { studies }\end{array}$ & $\begin{array}{c}\text { No. of } \\
\text { participants }\end{array}$ & Statistical method & Effect size \\
\hline 1 VKAs versus platelet inhibitor & 1 & & Risk Ratio (IV, Random, 95\% CI) & Totals not selected \\
\hline $\begin{array}{l}2 \text { 3-month VKAs versus 3-month } \\
\text { platelet inhibitor }\end{array}$ & 1 & & Risk Ratio (IV, Random, 95\% CI) & Totals not selected \\
\hline
\end{tabular}

Primary prophylaxis for venous thromboembolism in patients undergoing cardiac or thoracic surgery (Review) 


\begin{tabular}{|c|c|c|c|c|}
\hline Outcome or subgroup title & $\begin{array}{l}\text { No. of } \\
\text { studies }\end{array}$ & $\begin{array}{c}\text { No. of } \\
\text { participants }\end{array}$ & Statistical method & Effect size \\
\hline $1 \mathrm{UFH}$ versus LMWH & 1 & & Risk Ratio (IV, Random, 95\% CI) & Totals not selected \\
\hline $\begin{array}{l}2 \text { Fixed-dose LMWH versus } \\
\text { weight-adjusted dose LMWH }\end{array}$ & 1 & & Risk Ratio (IV, Random, 95\% CI) & Totals not selected \\
\hline
\end{tabular}

Comparison 5. Cardiac surgery: overall VTE

\begin{tabular}{|c|c|c|c|c|}
\hline Outcome or subgroup title & $\begin{array}{l}\text { No. of } \\
\text { studies }\end{array}$ & $\begin{array}{c}\text { No. of } \\
\text { participants }\end{array}$ & Statistical method & Effect size \\
\hline $1 \mathrm{UFH}$ versus LMWH & 1 & & Risk Ratio (IV, Random, 95\% CI) & Totals not selected \\
\hline $\begin{array}{l}2 \text { Intermittent pneumatic } \\
\text { compression plus graded elastic } \\
\text { compression stockings versus } \\
\text { graded elastic compression } \\
\text { stockings }\end{array}$ & 1 & & Risk Ratio (IV, Random, 95\% CI) & Totals not selected \\
\hline 3 VKAs versus platelet inhibitor & 1 & & Risk Ratio (IV, Random, 95\% CI) & Totals not selected \\
\hline $\begin{array}{l}4 \text { 3-month VKAs versus 3-month } \\
\text { platelet inhibitor }\end{array}$ & 1 & & Risk Ratio (IV, Random, 95\% CI) & Totals not selected \\
\hline 5 UFH plus aspirin versus UFH & 1 & & Risk Ratio (IV, Random, 95\% CI) & Totals not selected \\
\hline
\end{tabular}

Comparison 6. Thoracic surgery: overall VTE

\begin{tabular}{|c|c|c|c|c|}
\hline Outcome or subgroup title & $\begin{array}{l}\text { No. of } \\
\text { studies }\end{array}$ & $\begin{array}{c}\text { No. of } \\
\text { participants }\end{array}$ & Statistical method & Effect size \\
\hline 1 UFH versus inactive control & 1 & & Risk Ratio (IV, Random, 95\% CI) & Totals not selected \\
\hline $2 \mathrm{UFH}$ versus $\mathrm{LMWH}$ & 1 & & Risk Ratio (IV, Random, 95\% CI) & Totals not selected \\
\hline $\begin{array}{l}3 \text { Fixed-dose LMWH versus } \\
\text { weight-adjusted dose LMWH }\end{array}$ & 1 & & Risk Ratio (IV, Random, 95\% CI) & Totals not selected \\
\hline 4 UFH versus VKAs & 1 & & Risk Ratio (IV, Random, 95\% CI) & Totals not selected \\
\hline
\end{tabular}

Primary prophylaxis for venous thromboembolism in patients undergoing cardiac or thoracic surgery (Review) 


\begin{tabular}{|c|c|c|c|c|}
\hline Outcome or subgroup title & $\begin{array}{l}\text { No. of } \\
\text { studies }\end{array}$ & $\begin{array}{c}\text { No. of } \\
\text { participants }\end{array}$ & Statistical method & Effect size \\
\hline 1 VKAs versus platelet inhibitor & 1 & & Risk Ratio (IV, Random, 95\% CI) & Totals not selected \\
\hline $\begin{array}{l}23 \text {-month VKAs versus 3-month } \\
\text { platelet inhibitor }\end{array}$ & 1 & & Risk Ratio (IV, Random, 95\% CI) & Totals not selected \\
\hline
\end{tabular}

Comparison 8. Cardiac surgery: minor bleeding

\begin{tabular}{lcll} 
Outcome or subgroup title & $\begin{array}{c}\text { No. of } \\
\text { studies }\end{array}$ & $\begin{array}{c}\text { No. of } \\
\text { participants }\end{array}$ & Statistical method \\
\hline 1 UFH versus LMWH & 1 & Risk Ratio (IV, Random, 95\% CI) & Totals not selected \\
$\begin{array}{l}\text { 2 VKAs versus platelet inhibitor } \\
\text { 3 3-month VKAs versus 3-month }\end{array}$ & 1 & Risk Ratio (IV, Random, 95\% CI) & Totals not selected \\
$\begin{array}{l}\text { platelet inhibitor } \\
\text { 4 UFH plus aspirin versus UFH }\end{array}$ & 1 & Risk Ratio (IV, Random, 95\% CI) & Totals not selected \\
\hline
\end{tabular}

Comparison 9. Thoracic surgery: minor bleeding

\begin{tabular}{|c|c|c|c|c|}
\hline Outcome or subgroup title & $\begin{array}{l}\text { No. of } \\
\text { studies }\end{array}$ & $\begin{array}{c}\text { No. of } \\
\text { participants }\end{array}$ & Statistical method & Effect size \\
\hline 1 UFH versus LMWH & 1 & & Risk Ratio (IV, Random, 95\% CI) & Totals not selected \\
\hline $\begin{array}{l}2 \text { Fixed-dose LMWH versus } \\
\text { weight-adjusted dose LMWH }\end{array}$ & 1 & & Risk Ratio (IV, Random, 95\% CI) & Totals not selected \\
\hline
\end{tabular}

Comparison 10. Thoracic surgery: serious adverse events

\begin{tabular}{|c|c|c|c|c|}
\hline Outcome or subgroup title & $\begin{array}{l}\text { No. of } \\
\text { studies }\end{array}$ & $\begin{array}{c}\text { No. of } \\
\text { participants }\end{array}$ & Statistical method & Effect size \\
\hline $\begin{array}{l}1 \text { Fixed-dose LMWH versus } \\
\text { weight-adjusted dose LMWH }\end{array}$ & 1 & & Risk Ratio (IV, Random, 95\% CI) & Totals not selected \\
\hline
\end{tabular}

Primary prophylaxis for venous thromboembolism in patients undergoing cardiac or thoracic surgery (Review) 
Comparison 11. Cardiac surgery: adverse events

\begin{tabular}{|c|c|c|c|c|}
\hline Outcome or subgroup title & $\begin{array}{l}\text { No. of } \\
\text { studies }\end{array}$ & $\begin{array}{c}\text { No. of } \\
\text { participants }\end{array}$ & Statistical method & Effect size \\
\hline 1 VKAs versus platelet inhibitor & 1 & & Risk Ratio (IV, Random, 95\% CI) & Totals not selected \\
\hline $\begin{array}{l}23 \text {-month VKAs versus 3-month } \\
\text { platelet inhibitor }\end{array}$ & 1 & & Risk Ratio (IV, Random, 95\% CI) & Totals not selected \\
\hline
\end{tabular}

Comparison 12. Thoracic surgery: adverse events

\begin{tabular}{|c|c|c|c|c|}
\hline Outcome or subgroup title & $\begin{array}{l}\text { No. of } \\
\text { studies }\end{array}$ & $\begin{array}{c}\text { No. of } \\
\text { participants }\end{array}$ & Statistical method & Effect size \\
\hline $\begin{array}{c}1 \text { Fixed-dose LMWH versus } \\
\text { weight-adjusted LMWH }\end{array}$ & 1 & & Risk Ratio (IV, Random, 95\% CI) & Totals not selected \\
\hline
\end{tabular}

\section{Analysis I.I. Comparison I Cardiac surgery: symptomatic VTE, Outcome I UFH versus LMWH.}

Review: Primary prophylaxis for venous thromboembolism in patients undergoing cardiac or thoracic surgery

Comparison: I Cardiac surgery: symptomatic VTE

Outcome: I UFH versus LMWH

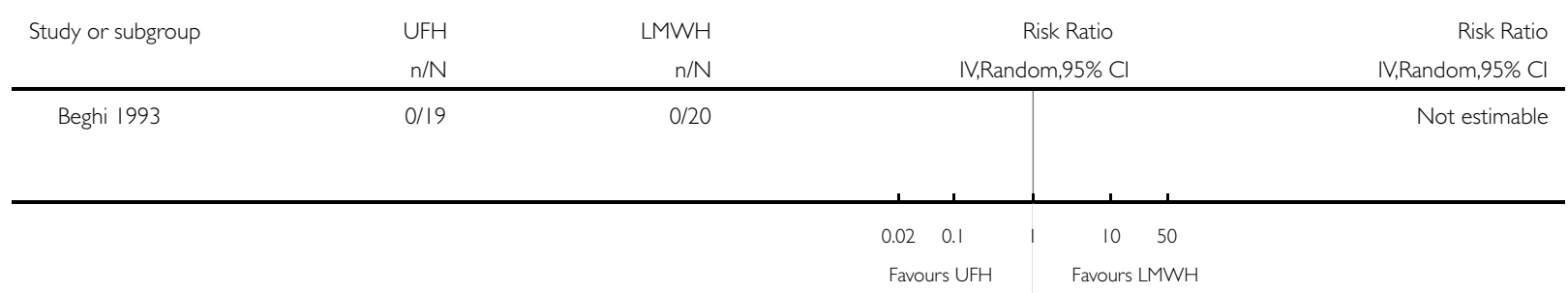


Analysis I.2. Comparison I Cardiac surgery: symptomatic VTE, Outcome 2 Intermittent pneumatic compression plus graded elastic compression stockings versus graded elastic compression stockings.

Review: Primary prophylaxis for venous thromboembolism in patients undergoing cardiac or thoracic surgery

Comparison: I Cardiac surgery: symptomatic VTE

Outcome: 2 Intermittent pneumatic compression plus graded elastic compression stockings versus graded elastic compression stockings

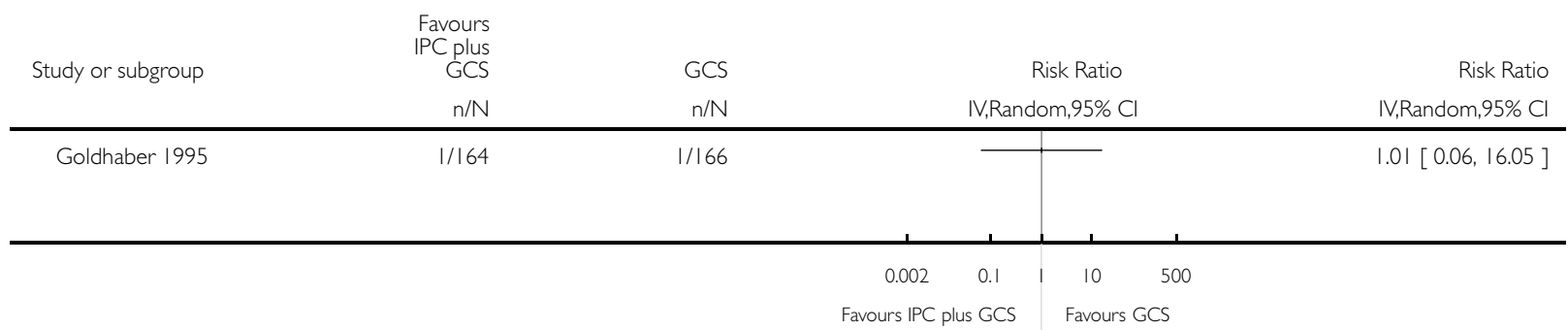

Analysis I.3. Comparison I Cardiac surgery: symptomatic VTE, Outcome 3 UFH plus IPC versus UFH.

Review: Primary prophylaxis for venous thromboembolism in patients undergoing cardiac or thoracic surgery

Comparison: I Cardiac surgery: symptomatic VTE

Outcome: 3 UFH plus IPC versus UFH

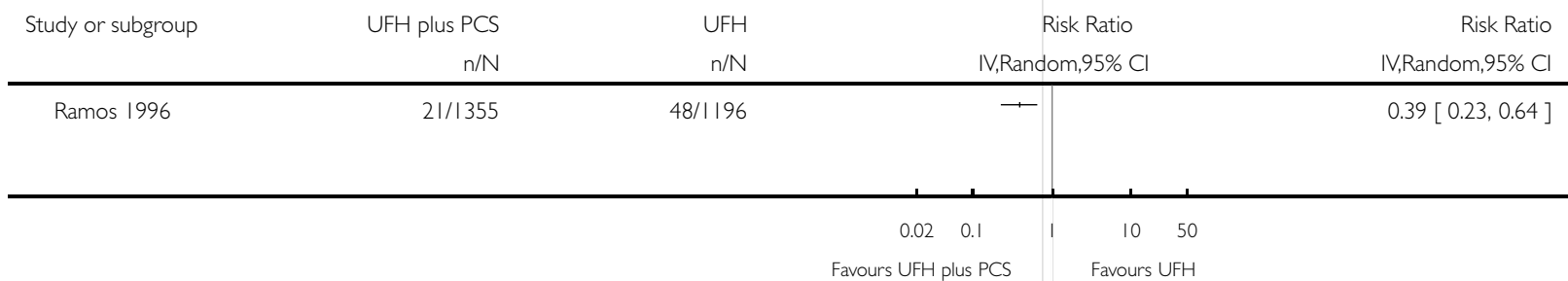




\section{Analysis I.4. Comparison I Cardiac surgery: symptomatic VTE, Outcome 4 UFH plus aspirin versus UFH.}

Review: Primary prophylaxis for venous thromboembolism in patients undergoing cardiac or thoracic surgery

Comparison: I Cardiac surgery: symptomatic VTE

Outcome: 4 UFH plus aspirin versus UFH

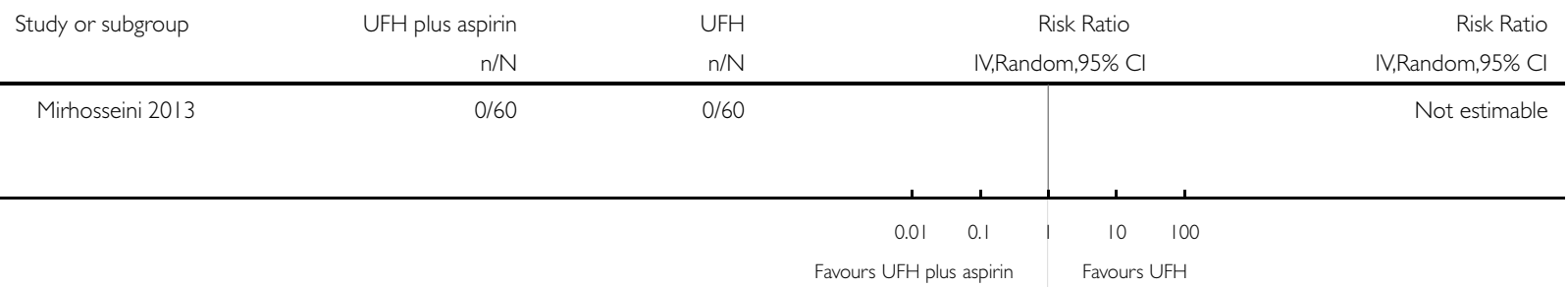

\section{Analysis 2.I. Comparison 2 Thoracic surgery: symptomatic VTE, Outcome I Heparin versus inactive} control.

Review: Primary prophylaxis for venous thromboembolism in patients undergoing cardiac or thoracic surgery

Comparison: 2 Thoracic surgery: symptomatic VTE

Outcome: I Heparin versus inactive control

Study or subgroup $\quad$ Heparin $\quad$ Control Risk Ratio $\quad$ Wisk Ratio

$\mathrm{n} / \mathrm{N} \quad \mathrm{n} / \mathrm{N} \quad \mathrm{N}, \mathrm{Random}, 95 \% \mathrm{Cl} \quad \mathrm{IV}, \mathrm{Random}, 95 \% \mathrm{Cl}$

I UFH versus placebo

Marchetti 1983

$0 / 16 \quad 0 / 13$

Not estimable

Subtotal (95\% CI)

16

13

Not estimable

Total events: 0 (Heparin), 0 (Control)

Heterogeneity: not applicable

Test for overall effect: not applicable

$2 \mathrm{UFH}$ versus no UFH

Gallus $1973 \quad 0 / 4 \quad 0 / 5$

Le Brigand 1981 13/1939 0/481

$0 / 481$

1943

486

$100.0 \%$

$100.0 \%$
Not estimable

$6.71[0.40,112.65]$

Subtotal $(\mathbf{9 5 \%}$ CI)

Total events: 13 (Heparin), 0 (Control)

Heterogeneity: not applicable

Test for overall effect: $Z=1.32(P=0.19)$ 


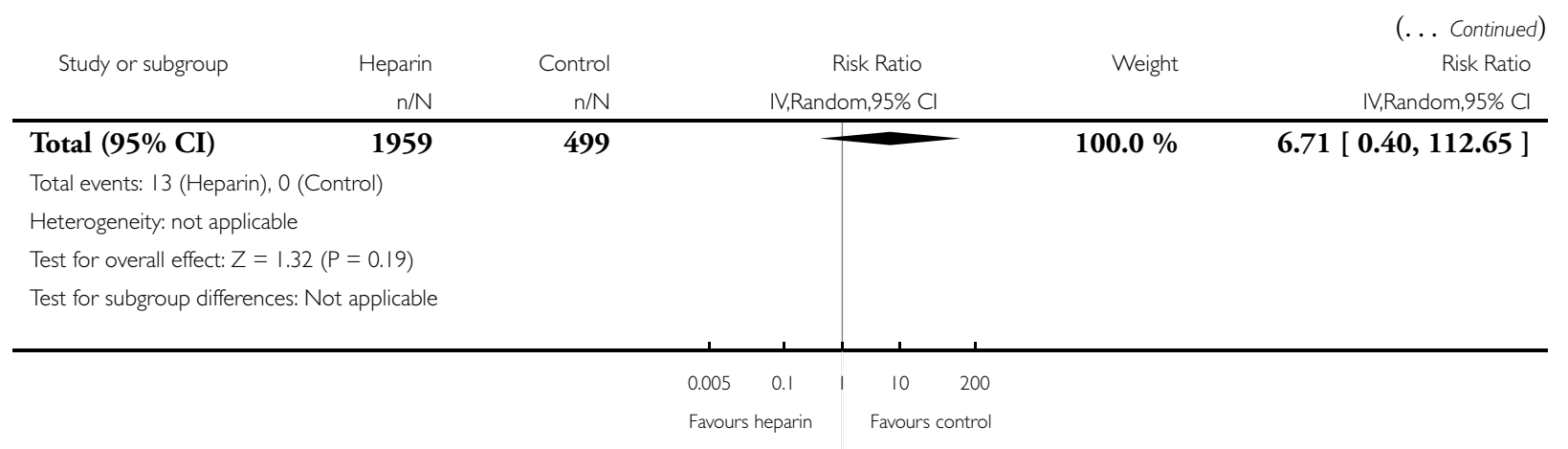

Analysis 2.2. Comparison 2 Thoracic surgery: symptomatic VTE, Outcome 2 UFH versus defibrotide.

Review: Primary prophylaxis for venous thromboembolism in patients undergoing cardiac or thoracic surgery

Comparison: 2 Thoracic surgery: symptomatic VTE

Outcome: 2 UFH versus defibrotide

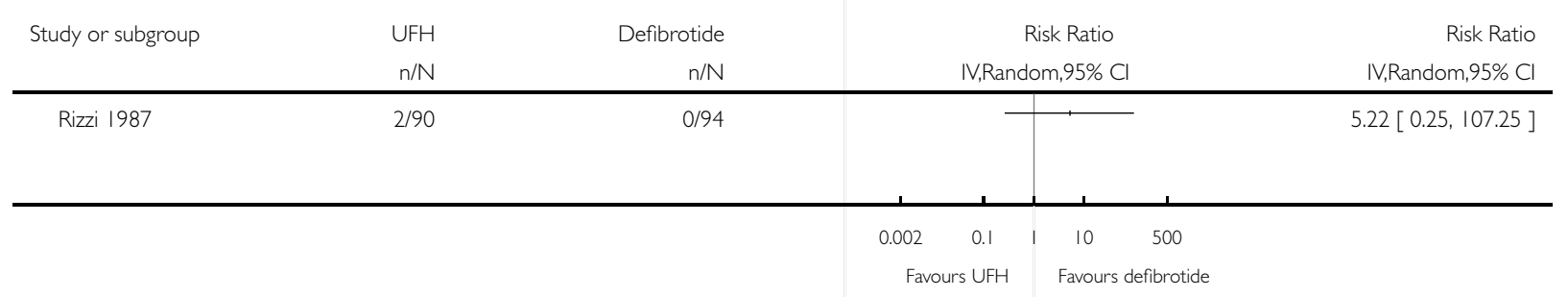




\section{Analysis 2.3. Comparison 2 Thoracic surgery: symptomatic VTE, Outcome 3 UFH versus LMWH.}

Review: Primary prophylaxis for venous thromboembolism in patients undergoing cardiac or thoracic surgery

Comparison: 2 Thoracic surgery: symptomatic VTE

Outcome: $3 \mathrm{UFH}$ versus LMWH

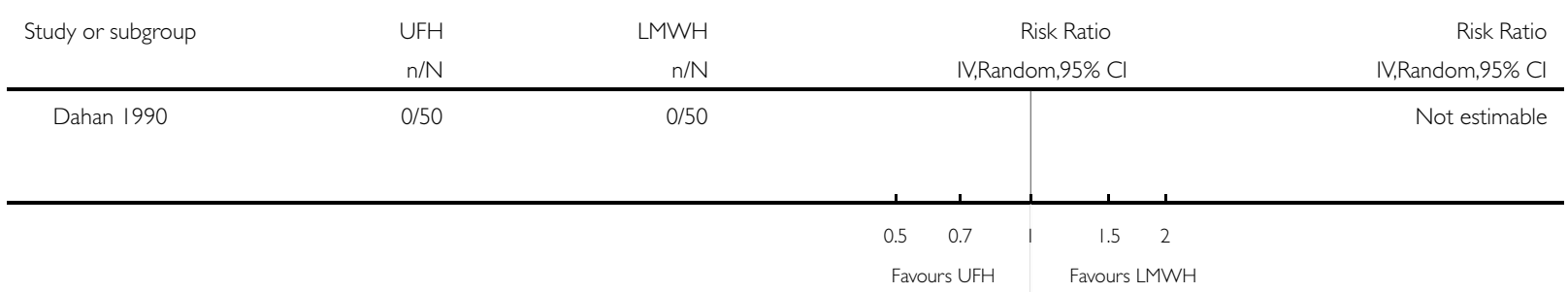

\section{Analysis 2.4. Comparison 2 Thoracic surgery: symptomatic VTE, Outcome 4 Fixed-dose LMWH versus} weight-adjusted dose LMWH.

Review: Primary prophylaxis for venous thromboembolism in patients undergoing cardiac or thoracic surgery

Comparison: 2 Thoracic surgery: symptomatic VTE

Outcome: 4 Fixed-dose LMWH versus weight-adjusted dose LMWH

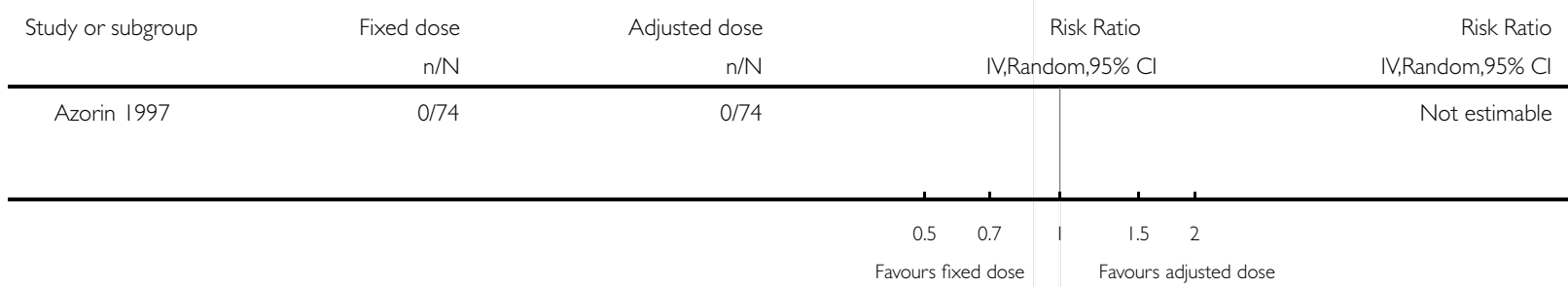


Analysis 3.I. Comparison 3 Cardiac surgery: major bleeding, Outcome I VKAs versus platelet inhibitor.

Review: Primary prophylaxis for venous thromboembolism in patients undergoing cardiac or thoracic surgery

Comparison: 3 Cardiac surgery: major bleeding

Outcome: I VKAs versus platelet inhibitor

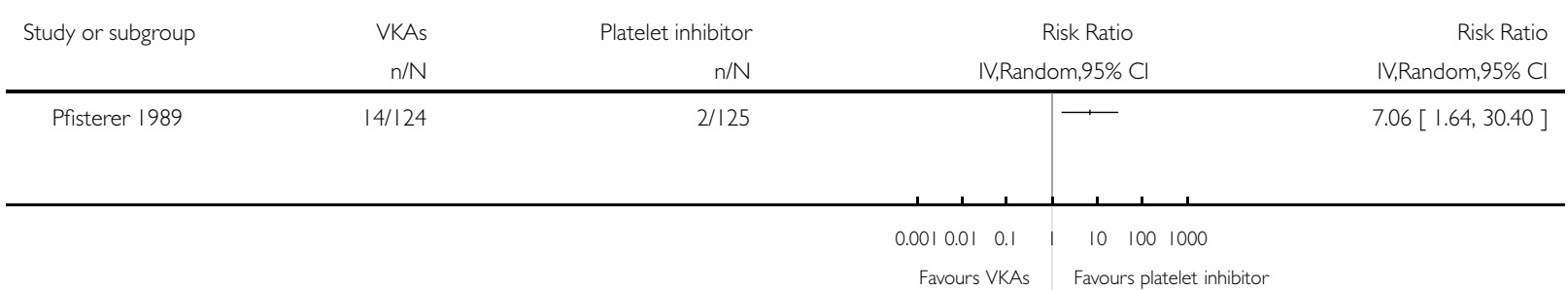

Analysis 3.2. Comparison 3 Cardiac surgery: major bleeding, Outcome 2 3-month VKAs versus 3-month platelet inhibitor.

Review: Primary prophylaxis for venous thromboembolism in patients undergoing cardiac or thoracic surgery

Comparison: 3 Cardiac surgery: major bleeding

Outcome: 2 3-month VKAs versus 3-month platelet inhibitor

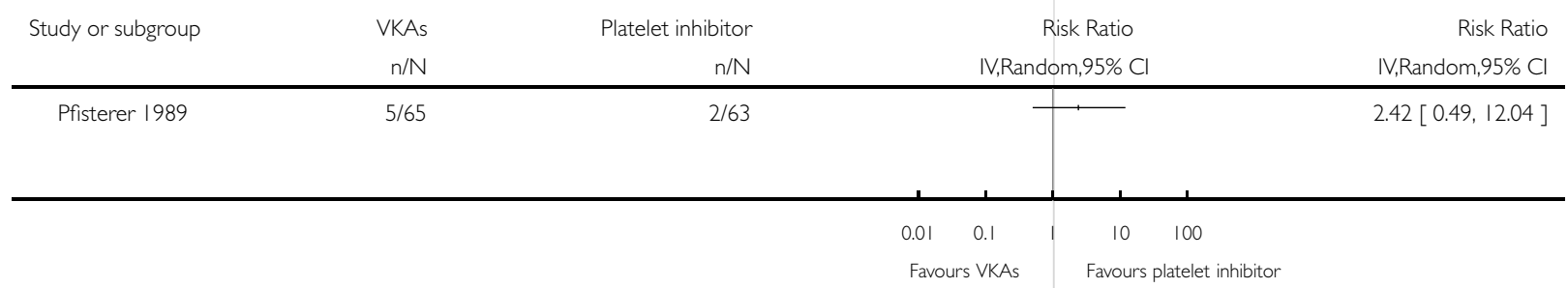




\section{Analysis 4.I. Comparison 4 Thoracic surgery: major bleeding, Outcome I UFH versus LMWH.}

Review: Primary prophylaxis for venous thromboembolism in patients undergoing cardiac or thoracic surgery

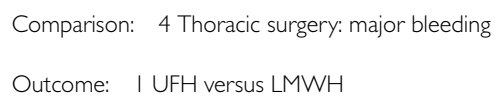

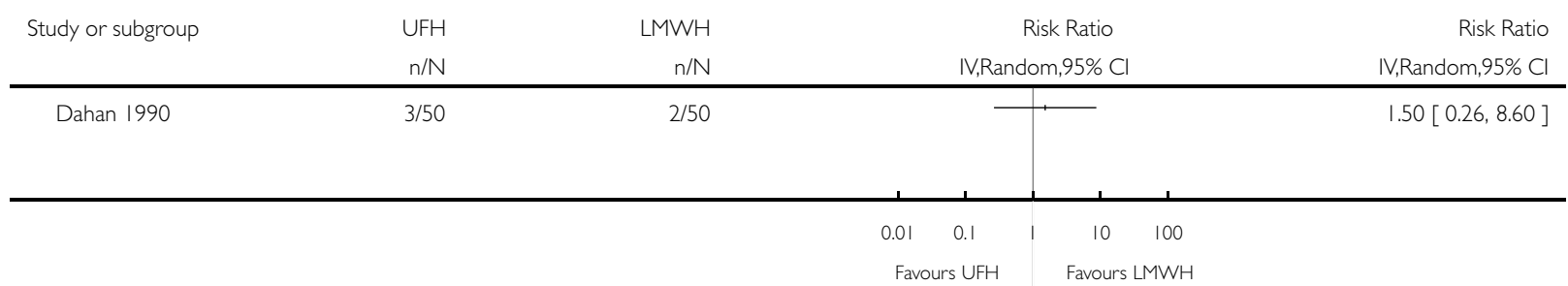

\section{Analysis 4.2. Comparison 4 Thoracic surgery: major bleeding, Outcome 2 Fixed-dose LMWH versus} weight-adjusted dose LMWH.

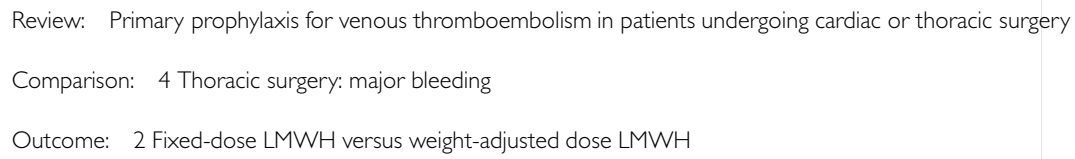

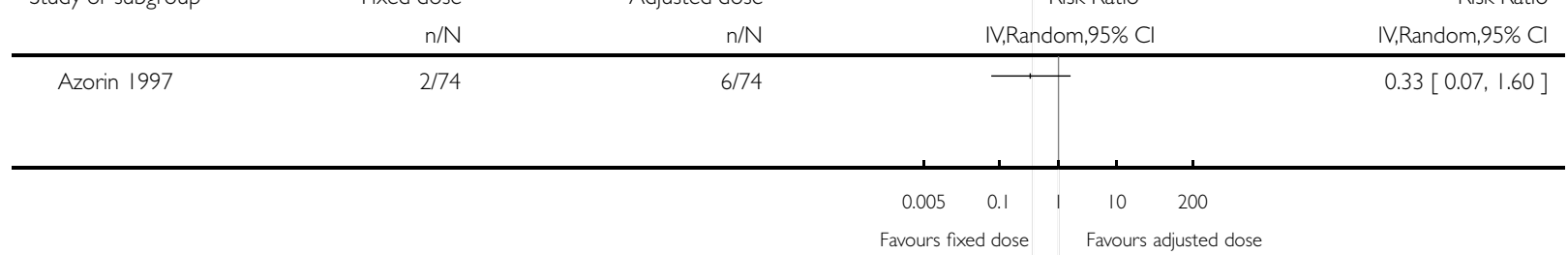




\section{Analysis 5.I. Comparison 5 Cardiac surgery: overall VTE, Outcome I UFH versus LMWH.}

Review: Primary prophylaxis for venous thromboembolism in patients undergoing cardiac or thoracic surgery

Comparison: 5 Cardiac surgery: overall VTE

Outcome: I UFH versus LMWH

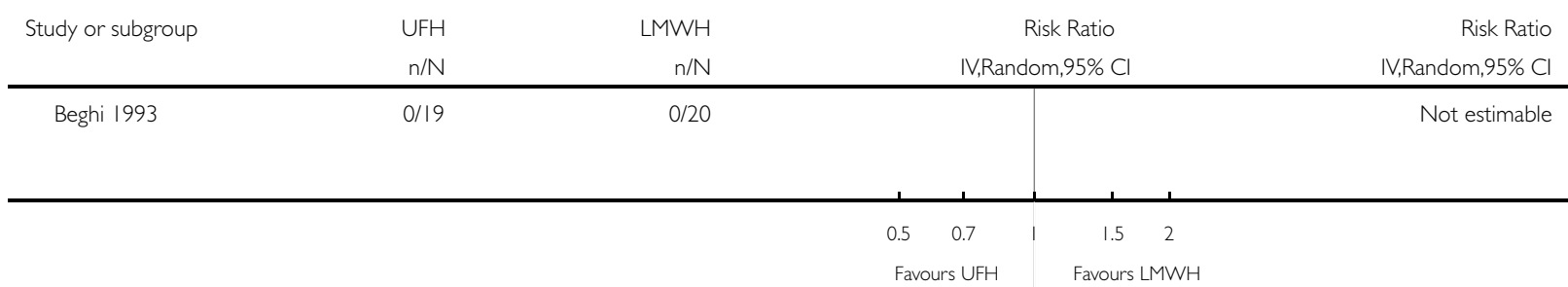

Analysis 5.2. Comparison 5 Cardiac surgery: overall VTE, Outcome 2 Intermittent pneumatic compression plus graded elastic compression stockings versus graded elastic compression stockings.

Review: Primary prophylaxis for venous thromboembolism in patients undergoing cardiac or thoracic surgery

Comparison: 5 Cardiac surgery: overall VTE

Outcome: 2 Intermittent pneumatic compression plus graded elastic compression stockings versus graded elastic compression stockings

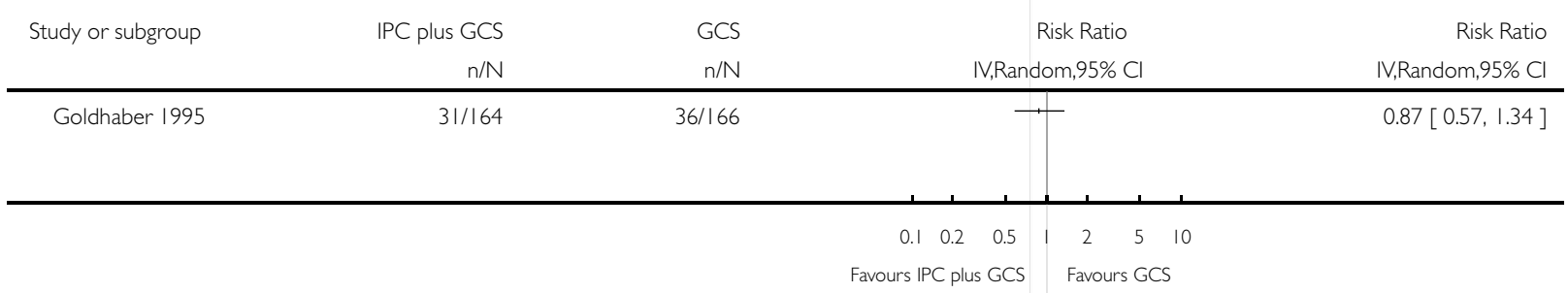




\section{Analysis 5.3. Comparison 5 Cardiac surgery: overall VTE, Outcome 3 VKAs versus platelet inhibitor.}

Review: Primary prophylaxis for venous thromboembolism in patients undergoing cardiac or thoracic surgery

Comparison: 5 Cardiac surgery: overall VTE

Outcome: 3 VKAs versus platelet inhibitor

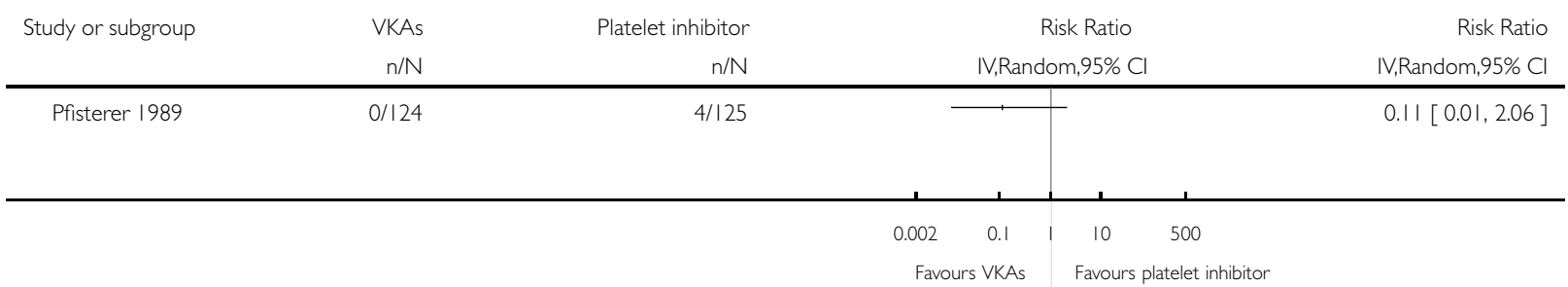

Analysis 5.4. Comparison 5 Cardiac surgery: overall VTE, Outcome 4 3-month VKAs versus 3-month platelet inhibitor.

Review: Primary prophylaxis for venous thromboembolism in patients undergoing cardiac or thoracic surgery

Comparison: 5 Cardiac surgery: overall VTE

Outcome: 4 3-month VKAs versus 3-month platelet inhibitor

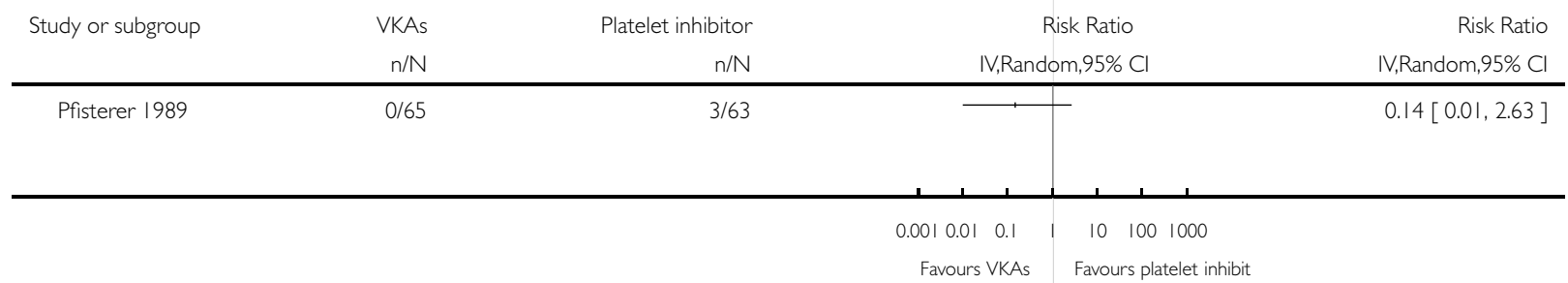


Analysis 5.5. Comparison 5 Cardiac surgery: overall VTE, Outcome 5 UFH plus aspirin versus UFH.

Review: Primary prophylaxis for venous thromboembolism in patients undergoing cardiac or thoracic surgery

Comparison: 5 Cardiac surgery: overall VTE

Outcome: $5 \mathrm{UFH}$ plus aspirin versus UFH

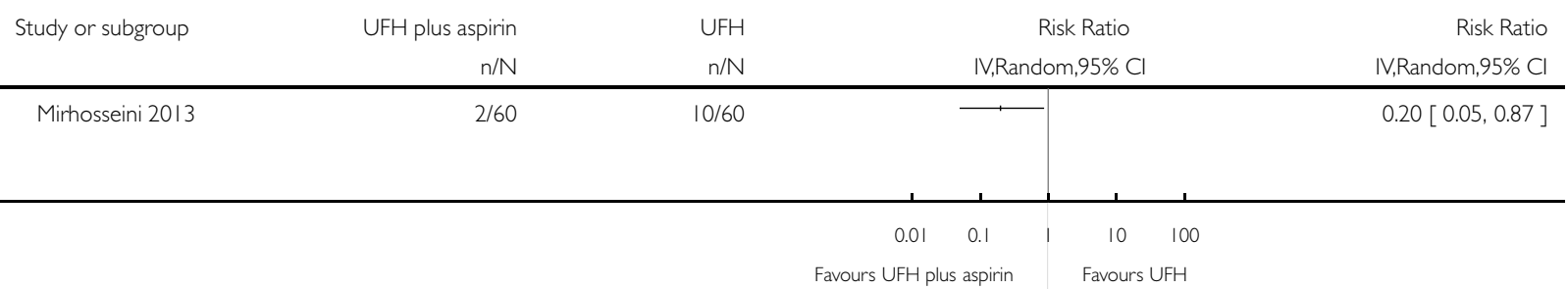

Analysis 6.I. Comparison 6 Thoracic surgery: overall VTE, Outcome I UFH versus inactive control.

Review: Primary prophylaxis for venous thromboembolism in patients undergoing cardiac or thoracic surgery

Comparison: 6 Thoracic surgery: overall VTE

Outcome: I UFH versus inactive control

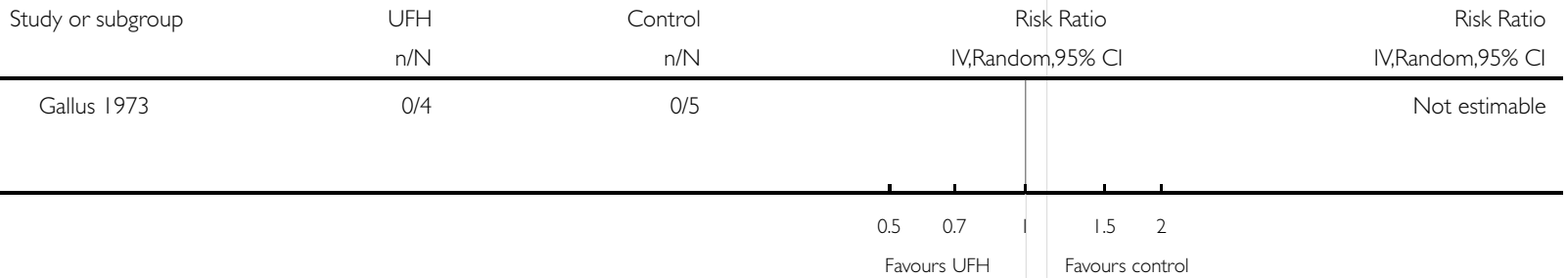




\section{Analysis 6.2. Comparison 6 Thoracic surgery: overall VTE, Outcome 2 UFH versus LMWH.}

Review: Primary prophylaxis for venous thromboembolism in patients undergoing cardiac or thoracic surgery

Comparison: 6 Thoracic surgery: overall VTE

Outcome: $2 \mathrm{UFH}$ versus LMWH

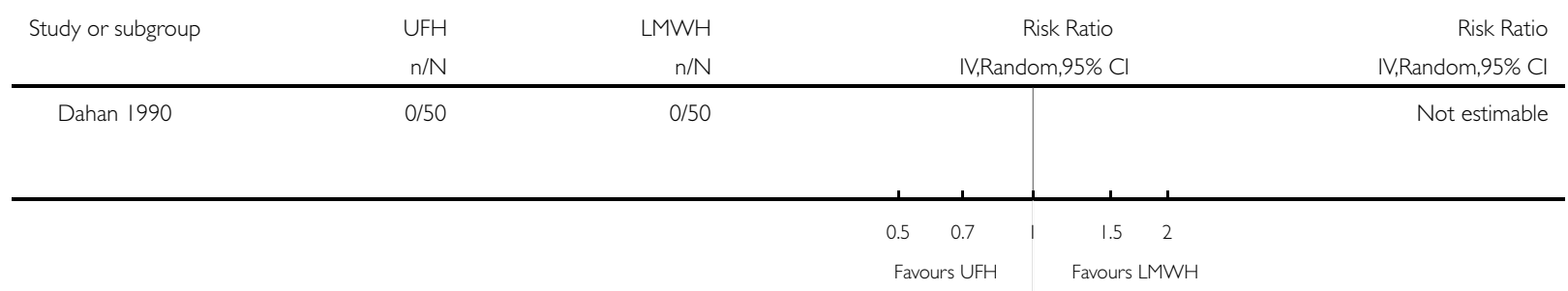

Analysis 6.3. Comparison 6 Thoracic surgery: overall VTE, Outcome 3 Fixed-dose LMWH versus weightadjusted dose LMWH.

Review: Primary prophylaxis for venous thromboembolism in patients undergoing cardiac or thoracic surgery

Comparison: 6 Thoracic surgery: overall VTE

Outcome: 3 Fixed-dose LMWH versus weight-adjusted dose LMWH

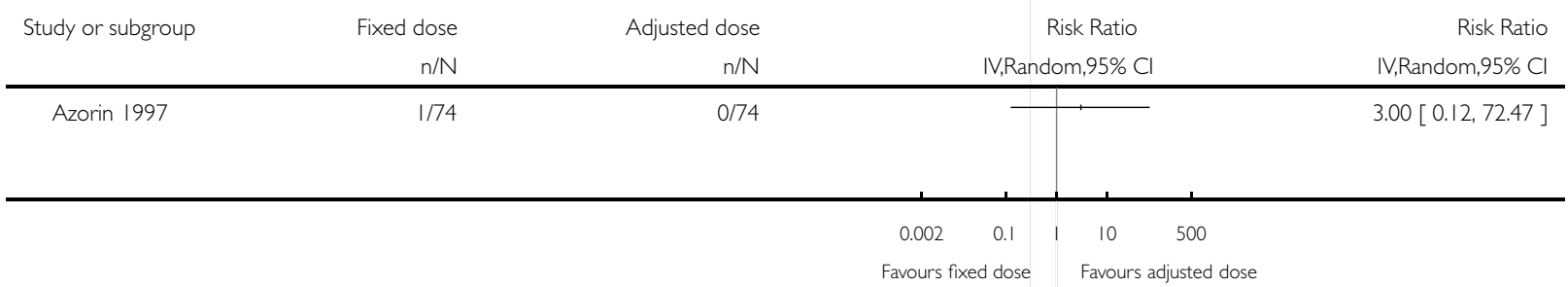




\section{Analysis 6.4. Comparison 6 Thoracic surgery: overall VTE, Outcome 4 UFH versus VKAs.}

Review: Primary prophylaxis for venous thromboembolism in patients undergoing cardiac or thoracic surgery

Comparison: 6 Thoracic surgery: overall VTE

Outcome: $4 \mathrm{UFH}$ versus VKAs

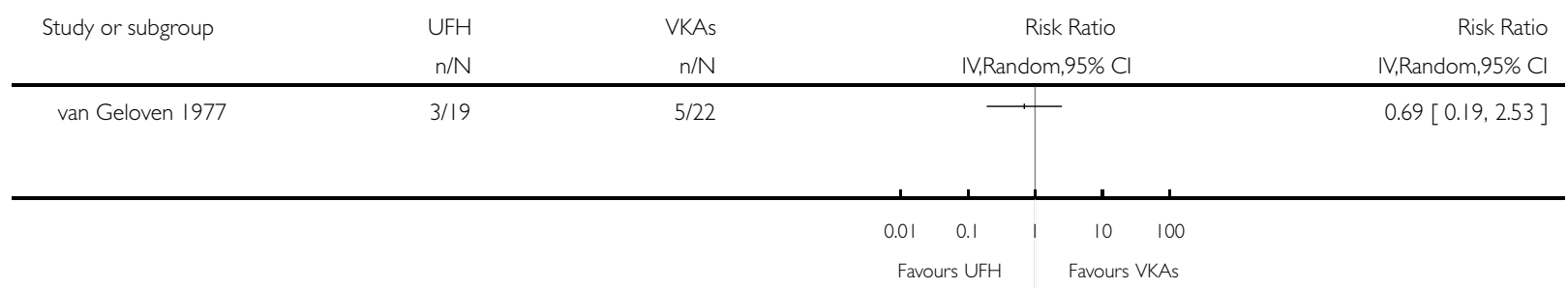

\section{Analysis 7.I. Comparison 7 Cardiac surgery: overall mortality, Outcome I VKAs versus platelet inhibitor.}

Review: Primary prophylaxis for venous thromboembolism in patients undergoing cardiac or thoracic surgery

Comparison: 7 Cardiac surgery: overall mortality

Outcome: I VKAs versus platelet inhibitor

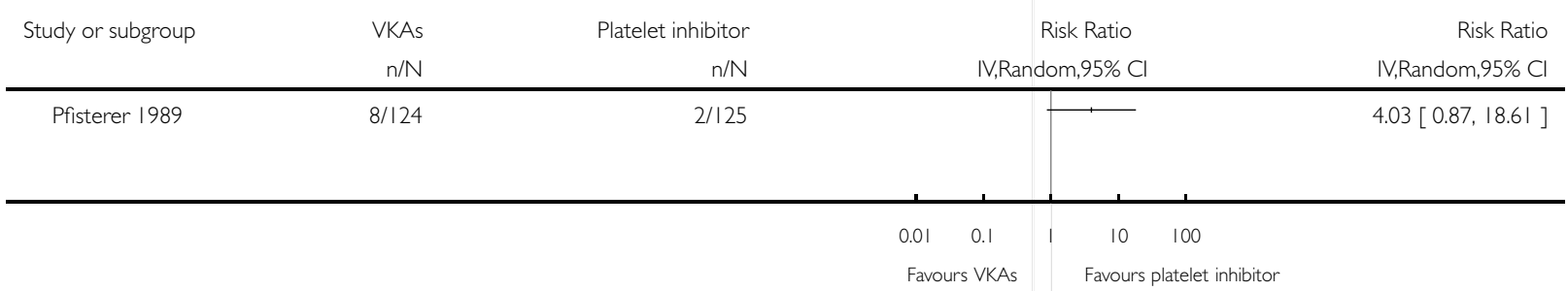




\section{Analysis 7.2. Comparison 7 Cardiac surgery: overall mortality, Outcome 2 3-month VKAs versus 3-month} platelet inhibitor.

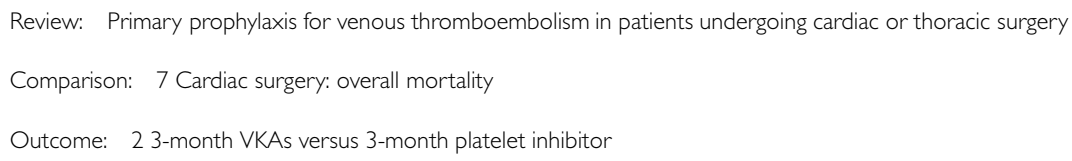

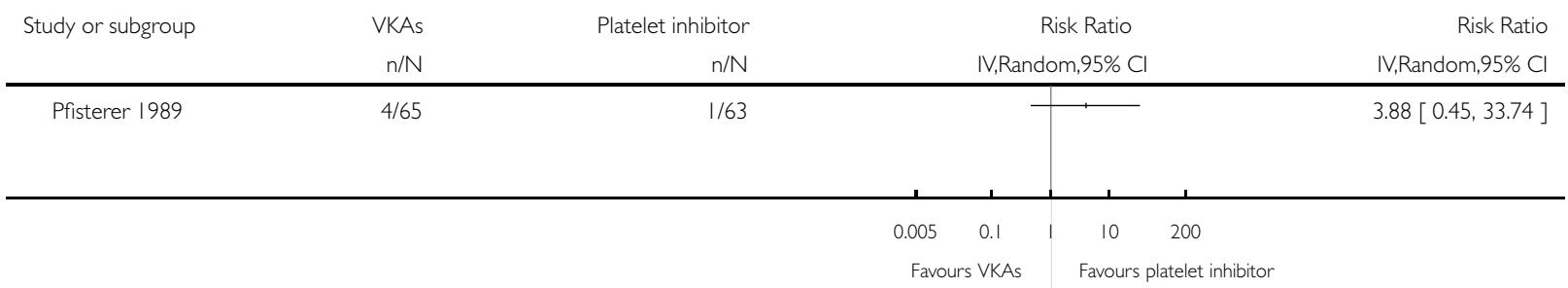

\section{Analysis 8.I. Comparison 8 Cardiac surgery: minor bleeding, Outcome I UFH versus LMWH.}

Review: Primary prophylaxis for venous thromboembolism in patients undergoing cardiac or thoracic surgery

Comparison: 8 Cardiac surgery: minor bleeding

Outcome: I UFH versus LMWH

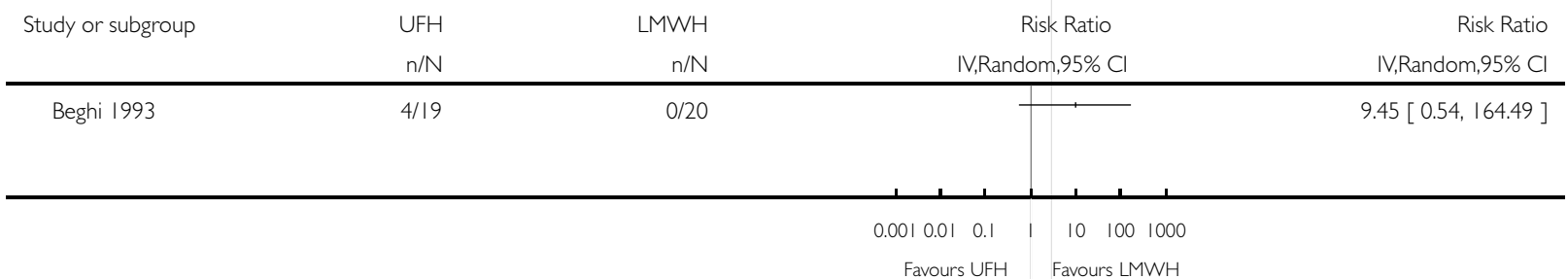


Analysis 8.2. Comparison 8 Cardiac surgery: minor bleeding, Outcome 2 VKAs versus platelet inhibitor.

Review: Primary prophylaxis for venous thromboembolism in patients undergoing cardiac or thoracic surgery

Comparison: 8 Cardiac surgery: minor bleeding

Outcome: 2 VKAs versus platelet inhibitor

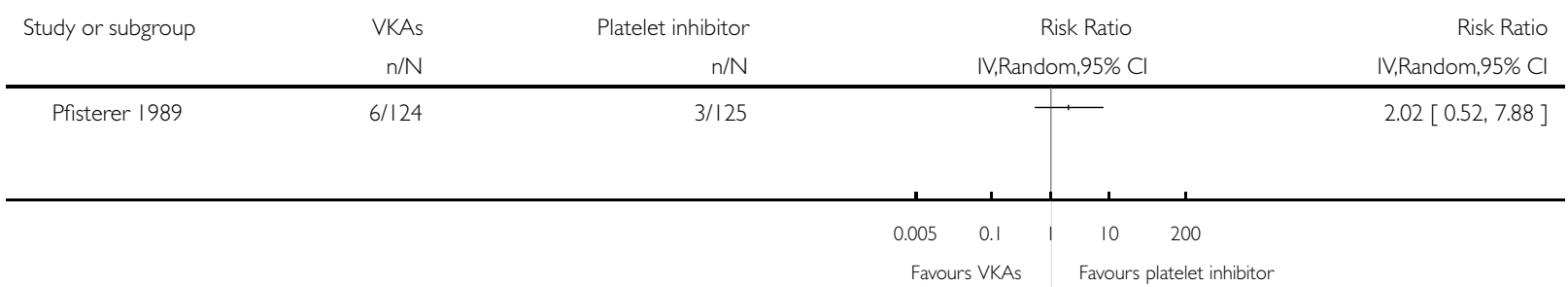

Analysis 8.3. Comparison 8 Cardiac surgery: minor bleeding, Outcome 3 3-month VKAs versus 3-month platelet inhibitor.

Review: Primary prophylaxis for venous thromboembolism in patients undergoing cardiac or thoracic surgery

Comparison: 8 Cardiac surgery: minor bleeding

Outcome: 3 3-month VKAs versus 3-month platelet inhibitor

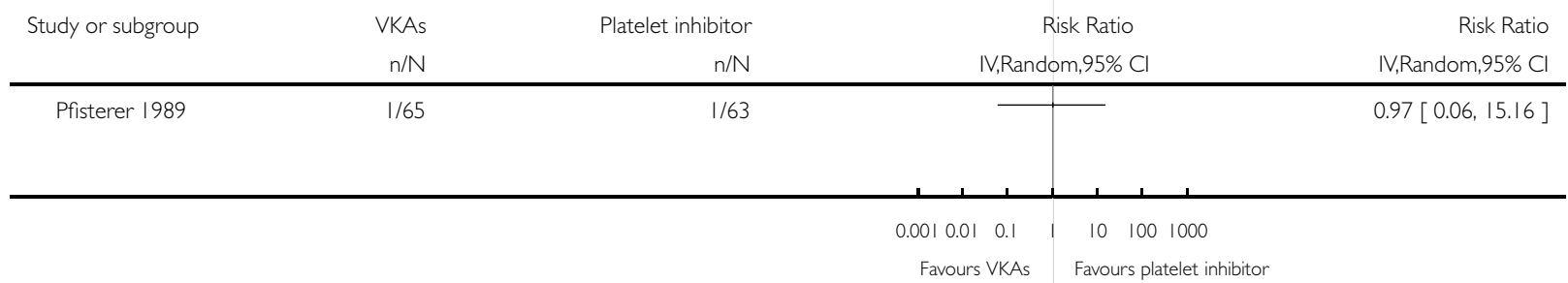


Analysis 8.4. Comparison 8 Cardiac surgery: minor bleeding, Outcome 4 UFH plus aspirin versus UFH.

Review: Primary prophylaxis for venous thromboembolism in patients undergoing cardiac or thoracic surgery

Comparison: 8 Cardiac surgery: minor bleeding

Outcome: 4 UFH plus aspirin versus UFH

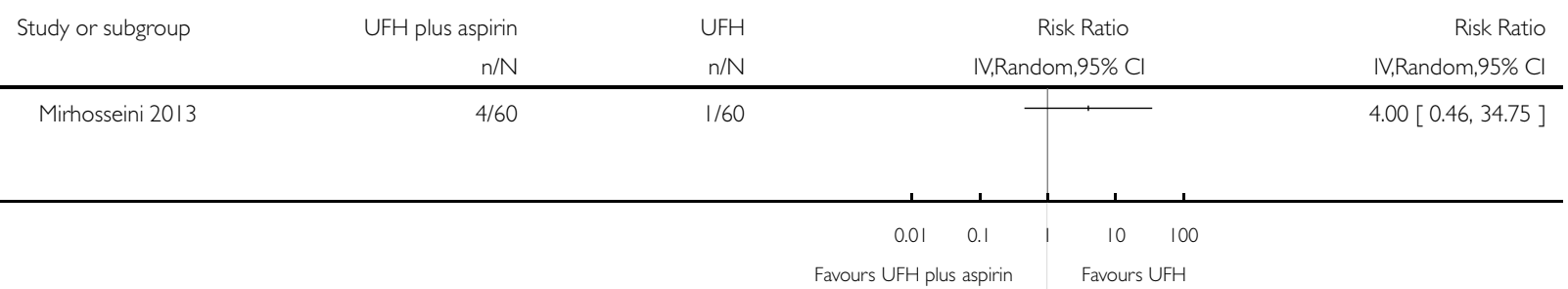

Analysis 9.1. Comparison 9 Thoracic surgery: minor bleeding, Outcome I UFH versus LMWH.

Review: Primary prophylaxis for venous thromboembolism in patients undergoing cardiac or thoracic surgery

Comparison: 9 Thoracic surgery: minor bleeding

Outcome: I UFH versus LMWH

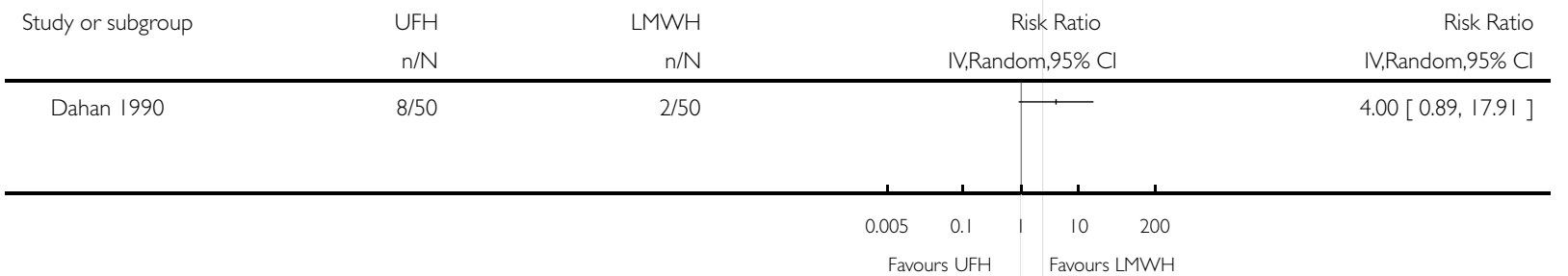


Analysis 9.2. Comparison 9 Thoracic surgery: minor bleeding, Outcome 2 Fixed-dose LMWH versus weight-adjusted dose LMWH.

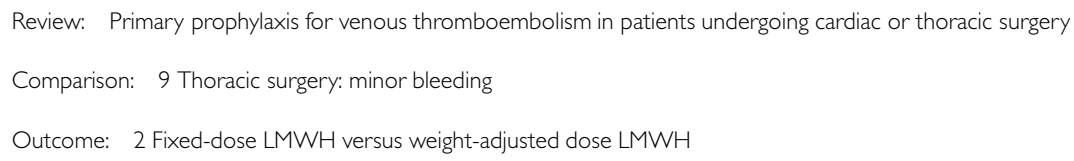

\begin{tabular}{llll|l} 
& $\mathrm{n} / \mathrm{N}$ & $\mathrm{n} / \mathrm{N}, \mathrm{Random}, 95 \% \mathrm{Cl}$ & $\mathrm{IV}, \mathrm{Random}, 95 \% \mathrm{Cl}$ \\
\hline Azorin 1997 & $\mathrm{I} / 74$ & $2 / 74$ & 1
\end{tabular}

$0.002 \quad 0.1 \quad 1 \quad 10 \quad 500$

Favours fixed dose Favours adjusted dose

\section{Analysis 10.I. Comparison I0 Thoracic surgery: serious adverse events, Outcome I Fixed-dose LMWH} versus weight-adjusted dose LMWH.

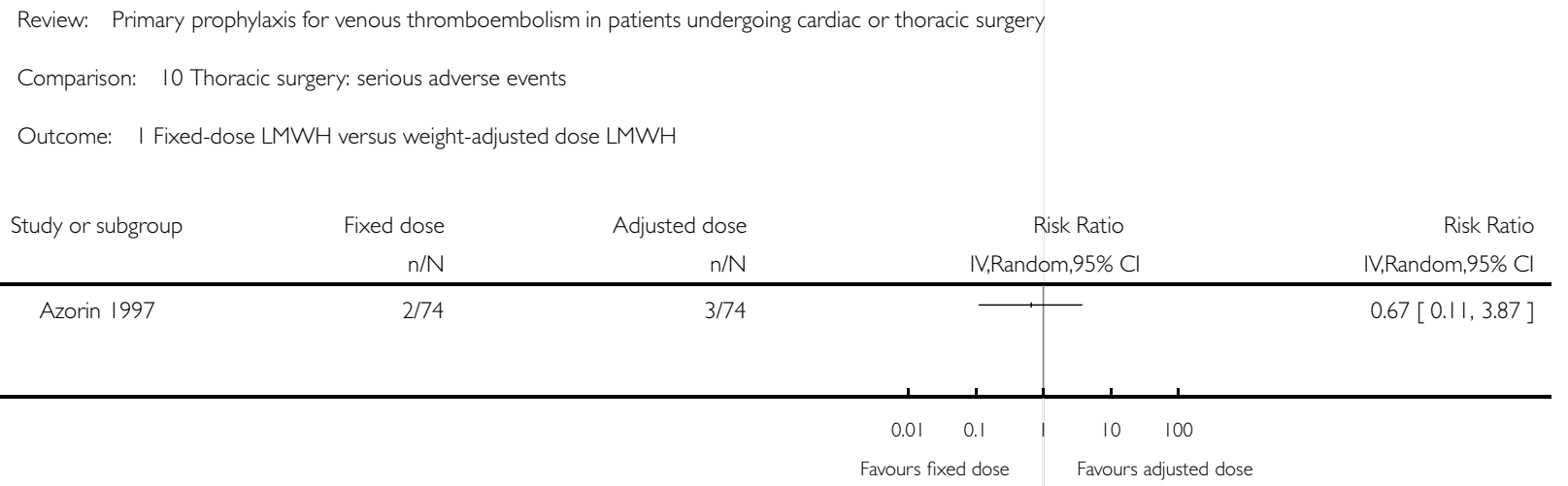




\section{Analysis I I.I. Comparison I I Cardiac surgery: adverse events, Outcome I VKAs versus platelet inhibitor.}

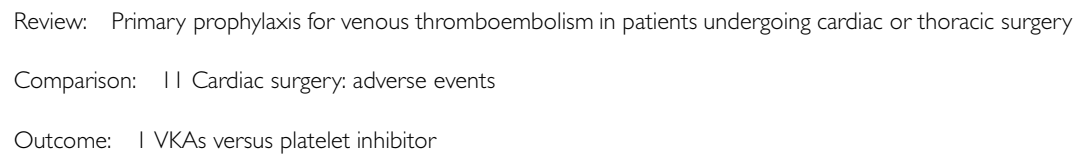

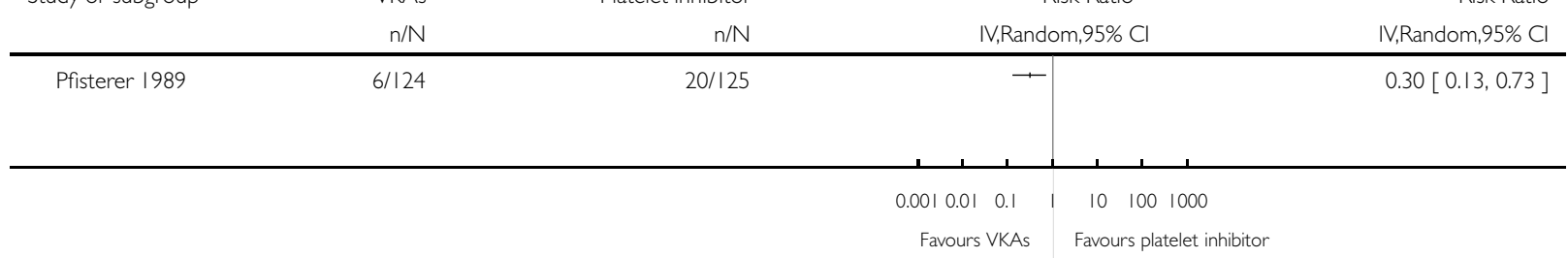

\section{Analysis II.2. Comparison I I Cardiac surgery: adverse events, Outcome 2 3-month VKAs versus 3-month} platelet inhibitor.

Review: Primary prophylaxis for venous thromboembolism in patients undergoing cardiac or thoracic surgery

Comparison: II Cardiac surgery: adverse events

Outcome: 23 -month VKAs versus 3-month platelet inhibitor

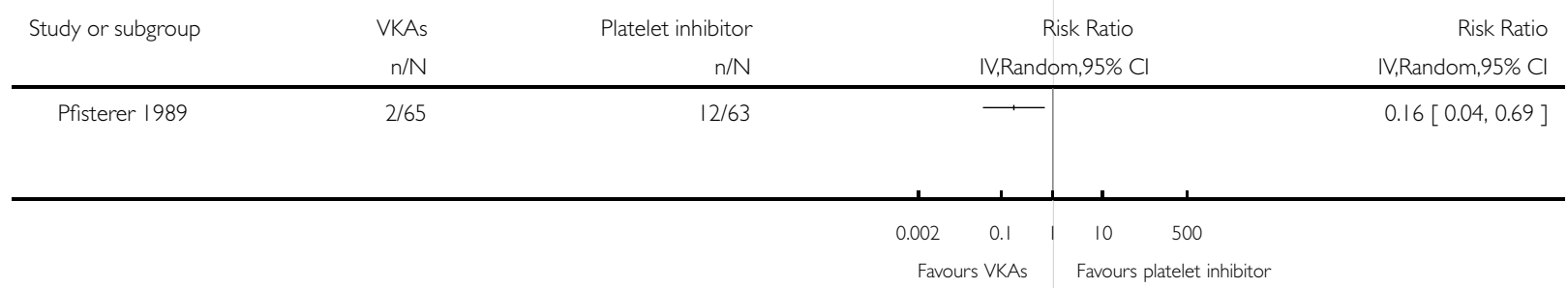


Analysis 12.I. Comparison I2 Thoracic surgery: adverse events, Outcome I Fixed-dose LMWH versus weight-adjusted LMWH.

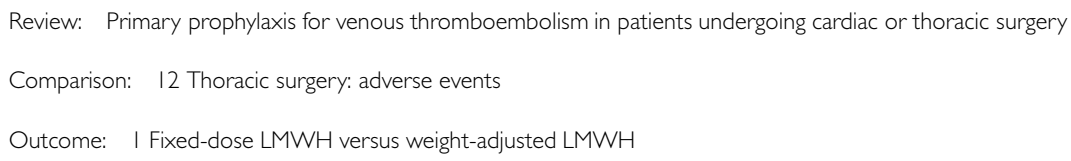

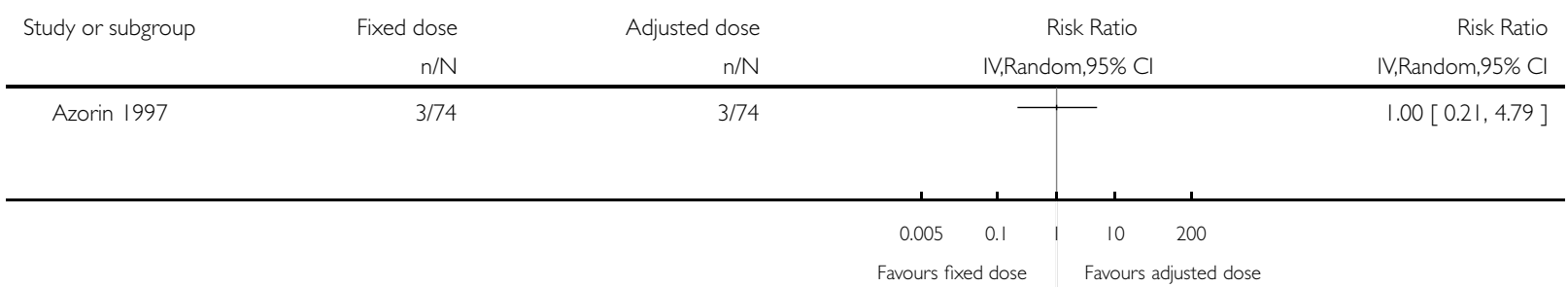

\section{A P P E N D I C ES}

\section{Appendix I. CENTRAL search strategy}

\begin{tabular}{|c|c|c|}
\hline \#1 & MESH DESCRIPTOR Thrombosis & 1126 \\
\hline$\# 2$ & MESH DESCRIPTOR Thromboembolism & 838 \\
\hline \#3 & MESH DESCRIPTOR Venous Thromboembolism & 155 \\
\hline \#4 & $\begin{array}{l}\text { MESH DESCRIPTOR Venous Thrombosis EXPLODE ALL } \\
\text { TREES }\end{array}$ & 1853 \\
\hline \#5 & $\begin{array}{l}\text { (thromboprophyla* or thrombus* or thrombotic* or throm- } \\
\text { bolic* or thromboemboli* or thrombos* } \text { or }^{*} \text { embol }^{*} \text { ):TI,AB, } \\
\text { KY }\end{array}$ & 12097 \\
\hline \#6 & $\begin{array}{l}\text { MESH DESCRIPTOR Pulmonary Embolism EXPLODE } \\
\text { ALL TREES }\end{array}$ & 674 \\
\hline \#7 & (PE or DVT or VTE):TI,AB,KY & 2635 \\
\hline$\# 8$ & $\left(\left(\left(\right.\right.\right.$ vein* $^{*}$ or ven*) near thromb*) $\left.{ }^{*}\right): \mathrm{TI}, \mathrm{AB}, \mathrm{KY}$ & 4579 \\
\hline \#9 & \#1 OR \#2 OR \#3 OR \#4 OR \#5 OR \#6 OR \#7 OR \#8 & 14035 \\
\hline
\end{tabular}


(Continued)

\#10 MESH DESCRIPTOR Cardiac Surgical Procedures EX- 10324 PLODE ALL TREES

\begin{tabular}{|c|c|c|}
\hline$\# 11$ & MESH DESCRIPTOR Thoracic Surgery & 139 \\
\hline \#12 & Sternotomy:TI,AB,KY & 415 \\
\hline \#13 & (thoracoplasty or thoracostomy):TI,AB, KY & 101 \\
\hline \#14 & Thoracoscopy:TI,AB,KY & 163 \\
\hline \#15 & (pneumonectomy or pneumectomy):TI,AB,KY & 433 \\
\hline \#16 & Thoracotomy:TI,AB,KY & 947 \\
\hline$\# 17$ & Thymectomy:TI,AB,KY & 48 \\
\hline$\# 18$ & Tracheostomy:TI,AB,KY & 268 \\
\hline \#19 & Tracheotomy:TI,AB,KY & 111 \\
\hline$\# 20$ & (cardiac near5 surg*):TI,AB,KY & 4210 \\
\hline \#21 & $\begin{array}{l}((\text { cardio* or coronary or heart) near } 5 \text { (surg* or bypass or stent* } \\
\text { or valve*)):TI,AB, KY }\end{array}$ & 13053 \\
\hline \#22 & ((thora* or lung or trachea*) near5 surgery):TI,AB,KY & 2127 \\
\hline \#23 & ((heart or lung) near5 transplant $\left.{ }^{*}\right): \mathrm{TI}, \mathrm{AB}, \mathrm{KY}$ & 1111 \\
\hline \#24 & (myocardial near5 surg*):TI,AB,KY & 906 \\
\hline \#25 & (pericardi* near5 surg*):TI,AB,KY & 56 \\
\hline \#26 & $\begin{array}{l}\text { MESH DESCRIPTOR Endocardium WITH QUALIFIERS } \\
\text { SU }\end{array}$ & 2 \\
\hline \#27 & $\begin{array}{l}\text { MESH DESCRIPTOR Fetal Heart EXPLODE ALL TREES } \\
\text { WITH QUALIFIERS SU }\end{array}$ & 1 \\
\hline \#28 & $\begin{array}{l}\text { MESH DESCRIPTOR Heart Atria EXPLODE ALL TREES } \\
\text { WITH QUALIFIERS SU }\end{array}$ & 84 \\
\hline
\end{tabular}

\#29 MESH DESCRIPTOR Heart Conduction System EX- 120 PLODE ALL TREES WITH QUALIFIERS SU 
(Continued)

\#30 MESH DESCRIPTOR Heart Septum EXPLODE ALL 24 TREES WITH QUALIFIERS SU

\#31 MESH DESCRIPTOR Heart Valves EXPLODE ALL TREES 445 WITH QUALIFIERS SU

\#32 MESH DESCRIPTOR Heart Ventricles EXPLODE ALL 71 TREES WITH QUALIFIERS SU

\#33 MESH DESCRIPTOR Papillary Muscles EXPLODE ALL 6 TREES WITH QUALIFIERS SU

\#34 MESH DESCRIPTOR Pericardium EXPLODE ALL TREES 19 WITH QUALIFIERS SU

\#35 MESH DESCRIPTOR Lung EXPLODE ALL TREES 110 WITH QUALIFIERS SU

\#36 MESH DESCRIPTOR Trachea EXPLODE ALL TREES 18 WITH QUALIFIERS SU

\#37 MESH DESCRIPTOR Esophagus EXPLODE ALL TREES 154 WITH QUALIFIERS SU

\#38 MESH DESCRIPTOR Diaphragm EXPLODE ALL TREES 0 WITH QUALIFIERS SU

\#39 MESH DESCRIPTOR Thoracic Cavity EXPLODE ALL 13 TREES WITH QUALIFIERS SU

\#40 MESH DESCRIPTOR Thoracic Wall WITH QUALIFIERS 2 SU

\#41 MESH DESCRIPTOR Ribs EXPLODE ALL TREES WITH 9 QUALIFIERS SU

\#42 MESH DESCRIPTOR Sternum EXPLODE ALL TREES 135 WITH QUALIFIERS SU

\#43 \#10 OR \#11 OR \#12 OR \#13 OR \#14 OR \#15 OR \#16 OR 20952 \#17 OR \#18 OR \#19 OR \#20 OR \#21 OR \#22 OR \#23 OR \#24 OR \#25 OR \#26 OR \#27 OR \#28 OR \#29 OR\#30 OR \#31 OR \#32 OR \#33 OR \#34 OR \#35 OR \#36 OR\#37 OR \#38 OR \#39 OR \#40 OR \#41 OR \#42 


\section{CONTRIBUTIONSOFAUTHORS}

Study conception: Di Nisio.

Protocol development: Di Nisio, Rutjes, Porreca.

Acquisition of data: Di Nisio, Rutjes, Peinemann.

Analysis and interpretation of data: Di Nisio, Rutjes, Peinemann, Porreca.

Drafting of the manuscript: Di Nisio, Rutjes.

Critical revision of the manuscript for important intellectual content: Di Nisio, Rutjes, Peinemann, Porreca.

Statistical analysis: Di Nisio, Rutjes.

Obtaining funding: not applicable, no funding available.

Supervision: Rutjes.

\section{DECLARATIONSOF INTEREST}

MdN: Di Nisio declares consultancy fees from Bayer Health Care and Grifols.

FP: none known.

EP: none known.

AR: none known.

\section{SOURCES OF SUPPORT}

\section{Internal sources}

- No sources of support supplied

\section{External sources}

- Chief Scientist Office, Scottish Government Health Directorates, The Scottish Government, UK.

The PVD Group editorial base is supported by the Chief Scientist Office

\section{DIFFERENCES BETWEEN PROTOCOL AND REVIEW}

In the protocol we planned to estimate the between-trial heterogeneity of the results with the $\mathrm{I}^{2}$ statistic (Higgins 2003; Rücker 2008). However, the paucity of data precluded the evaluation of heterogeneity either with the $\mathrm{I}^{2}$ statistic, or with the Tau ${ }^{2}$, as currently advised by the Cochrane Handbook for Systematic Reviews of Interventions (Higgins 2011). Similarly, the low number of studies identified precluded any exploration of the effects of trial characteristics such as the type of lesion operated (malignant versus benign in noncardiac thoracic surgery trials), type of cardiac surgery (coronary artery bypass grafting versus valve surgery), urgent versus elective procedure, and quality items on symptomatic VTE or major bleeding. Similarly, the effect of sub-optimal design choices and biases related to small study size could not be evaluated. We aimed to use GRADE to describe the quality of the overall body of evidence (Guyatt 2008; Higgins 2011). As we could not statistically pool any outcome data across trials, we omitted the 'Summary of findings' table with GRADE assessment. The exclusion criterion "video assisted thoracic surgery", which was specified in the protocol, was subsequently removed at the review stage since it was in conflict with the inclusion criterion "thoracoscopic lung surgery". Although the search did not exclude studies on video assisted thoracic surgery nor thoracoscopic lung surgery, we retrieved no such studies.

Primary prophylaxis for venous thromboembolism in patients undergoing cardiac or thoracic surgery (Review) 